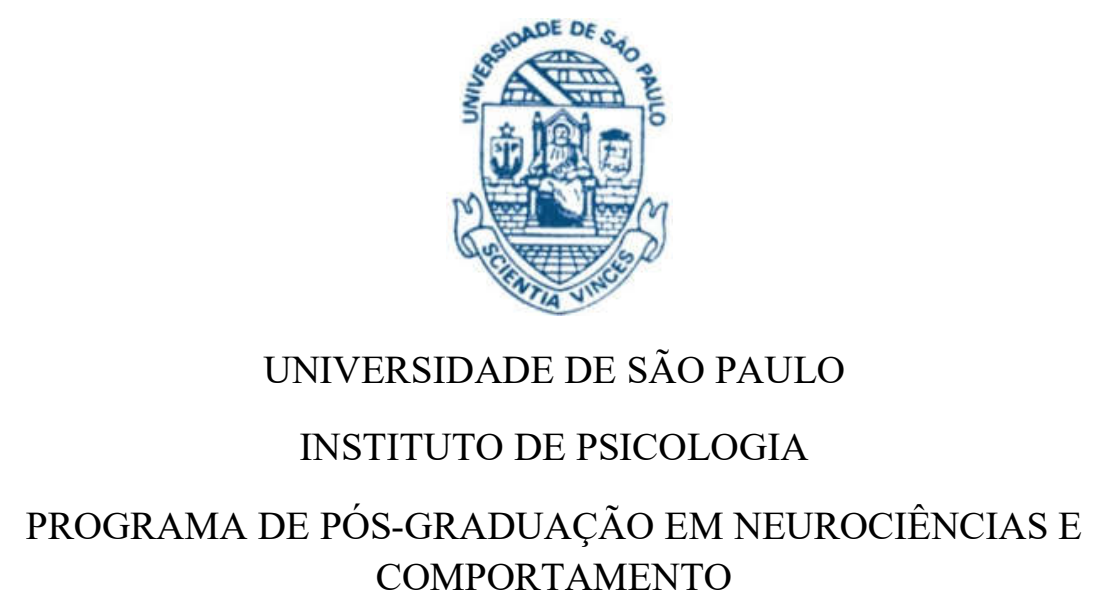

WILLIAM EDUARDO PATARROYO SERNA

ADMINISTRAÇÃO DE MORFINA E COCAÍNA EM CONTINGÊNCIAS OPERANTES E PAVLOVIANAS: DIFERENÇAS GÊNICAS E COMPORTAMENTAIS EM RATOS

(Versão Corrigida)

São Paulo 
WILLIAM EDUARDO PATARROYO SERNA

\section{ADMINISTRAÇÃO DE MORFINA E COCAÍNA EM CONTINGÊNCIAS OPERANTES E PAVLOVIANAS: DIFERENÇAS GENICAS E COMPORTAMENTAIS EM RATOS}

Tese de doutorado apresentada ao
Departamento de Neurociências e
Comportamento (NEC) da Universidade de
São Paulo (USP) como requisito para a
obtenção do título de Doutor

Área de concentração: Neurociências e Comportamento

Orientadora: Profa. Dra. Miriam García Mijares

Coorientador: Prof. Dr. Luciano Freitas Felício

São Paulo 


\section{AUTORIZO A REPRODUÇÃO E DIVULGAÇÃO TOTAL OU PARCIAL DESTE TRABALHO, POR QUALQUER MEIO CONVENCIONAL OU ELETRÔNICO, PARA FINS DE ESTUDO E PESQUISA, DESDE QUE CITADA A FONTE.}

Catalogação na publicação Biblioteca Dante Moreira Leite Instituto de Psicologia da Universidade de São Paulo Dados fornecidos pelo(a) autor(a)

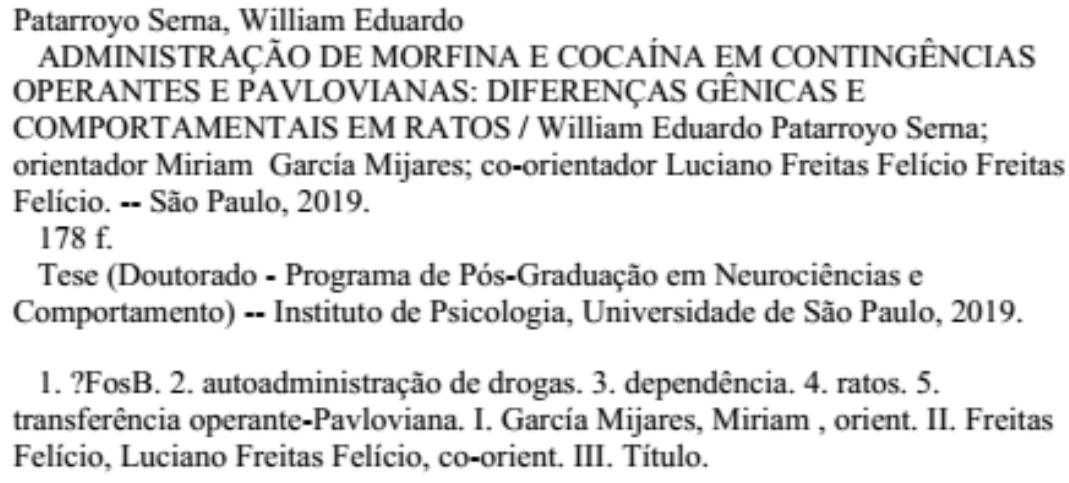

1. ?FosB. 2. autoadministração de drogas. 3. dependência. 4. ratos. 5. transferência operante-Pavloviana. I. García Mijares, Miriam, orient. II. Freitas Felício, Luciano Freitas Felício, co-orient. III. Título. 
O presente trabalho foi financiado pela Coordenação de Aperfeiçoamento de Pessoal de Nível Superior (CAPES), processo 1453426, e pela Fundação de Amparo à Pesquisa do Estado de São Paulo (FAPESP), processos 2014/25020-7 e 2016/222210-5. 


\section{WILLIAM EDUARDO PATARROYO SERNA}

\section{Administração de Morfina e Cocaína em Contingências Operantes e Pavlovianas: Diferenças Gênicas e Comportamentais em Ratos}

Tese de doutorado apresentado apresentada ao Departamento de Psicologia Experimental da Universidade de São Paulo como requisito para a obtenção do título de Doutor.

Área de concentração: Psicologia Experimental.

Apresentado e aprovado em:

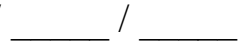

\section{Presidente da Banca}

Prof. Dr.

Instituição: Assinatura:

\section{Banca Examinadora}

Prof. Dr.

Instituição: Assinatura:

Prof. Dr.

Instituição:

Assinatura:

Prof. Dr.

Instituição: Assinatura:

Prof. Dr.

Instituição: Assinatura:

Prof. Dr.

Instituição: Assinatura: 
À minha mãe, pelo seu amor e apoio incondicionais. 
A good walker leaves no tracks. A good speech has no flaws to censure. A good reckoner uses no tallies.

A good door needs no lock, Yet no one can open it. Good binding requires no knots, Yet no one can loosen it.

The Wise Man is always good at helping people, so that none are cast out; he is always good at saving things, so that none are thrown away. This is called applied intelligence.

Surely the good man is the bad man's teacher; and the bad man is the good man's business. If the one docs not respect his teacher, or the other doesn't love his business, his error is very great.

This is indeed an important secret. (Lao Tzu: Tao Té Ching-Chapter 27) 


\section{Agradecimentos}

A mi familia, em especial a mi madre, por creer em mí y apoyar mis desiciones, por educarme y nunca rendirse. Por estar siempre ahí a pesar de la distancia. Por la preocupación y los Buenos deseos. A mis hermanos, por querer que sea una mejor persona y un mejor ejemplo cada día. A mi papá Mário, por estar siempre pendiente de mí, de lo que necesito y de cómo me siento. A Armando, por su especial cariño, por abrirme sus brazos y su corazón. A todos los que me han brindado su amor y cariño durante mi vida, mostrando su verdadero interés día tras día, creyendo en mi y apoyando mis sueños, ¡muchísimas gracias!

A minha orientadora, Dra. Miriam Miriam García-Mijares, pela sua guia e orientação durante o doutorado. Pelas reuniões e discussões que ajudaram à realização desta dissertação. Por me mostrar novos caminhos, e especialmente, pelo jeito carinhoso em que me acolheu desde que cheguei ao Brasil.

A Luciano Freitas Felício, meu co-orientador pela sua colaboração na realização deste estudo e pela confiança que teve comigo desde o começo. Pelas reuniões e pela atenção sempre disponível.

A Newton Canteras, pela disposição e aconselhamento. Por apoiar e acreditar em mim e neste estudo de pesquisa. Por permitir a realização de procedimentos experimentais no seu laboratório no ICB-USP.

A Emilio Ambrósio, mi amigo y orientador en Madrid. Muchas gracias por la confianza y el cariño, por el tiempo dedicado y en especial por todo lo que me enseñaste, para la academia y para la vida.

A Marisol Lamprea, por su apoyo todos estos años, sus enseñanzas, sus consejos y su amistad, que atesoro en lo más profundo de mi pecho

A meus amigos Andeson, Alceu e Rodrigo, pelas incontáveis discussões, pelo interesse e disposição, pela ajuda constante ante qualquer adversidade, por ser um ombro para me apoiar e um ouvido para me escutar.

A Raquel e às famílias Reis e Paiva, pelo apoio, carinho e amizade. Por terem sido um pilar na minha vida. 
Aos meus colegas do Laboratório de Psicofarmacologia, em especial Aline (LU3K), Yulla e Gabriela pela assistência durante os procedimentos cirúrgicos.

Aos meus colegas do Laboratório de Neuroanatomia Funcional, em especial a Amanda pela ajuda e disposição com os procedimentos experimentais.

A mis colegas del Laboratorio de Psicobiología de las Adicciones, en Madrid, por las reuniones y discusiones, por abrirme sus puertas y por su amistad. Alberto, Alejandro, David, Roberto, Mónica y Javier, muchas gracias!

A Rafael, Nicolás y Federico, pela grande amizade e pelo apoio constante e incondicional, per estar sempre aí para mim e tornar a minha vida mais leve e feliz.

Gracias a Sandrita, Lina y a Nacho, por animarme y ayudarme a levantar en incontables caídas. Por ayudarme a encontrar mi norte cuando me sentí perdido, por su amistad.

To Alexia, thank you for bringing light to my path and smiles to my face. Thank you for your sweetness and understanding.

Aos seguranças, pessoal de manutenção e limpeza, bioteristas e todos aqueles que com o seu trabalho diário contribuíram e ajudaram direta ou indiretamente à realização deste trabalho.

Um agradecimento muito, muito especial aos "péssimos exemplos", por me mostrarem o que não devo fazer e em quem devo evitar me converter. 


\section{SUMÁRIO}



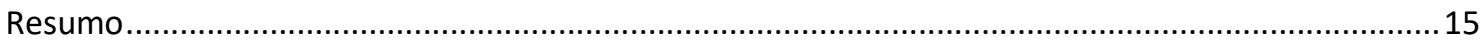



Administração de Morfina e Cocaína em Contingências Operantes e Pavlovianas: Diferenças Gênicas

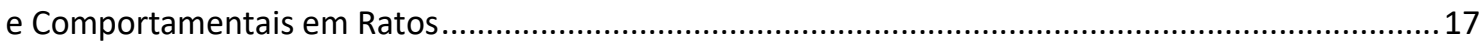

Modelos de Estudo de Administração de Drogas ...................................................................................26

Controle de Estímulos da procura, consumo e recaída .........................................................................30

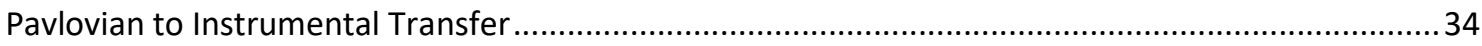

Morfina e Cocaína como Drogas de Abuso em Estudos de Dependência ............................................ 44

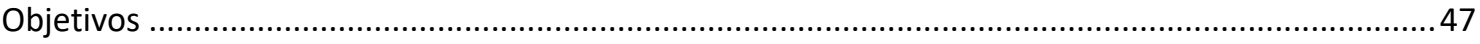

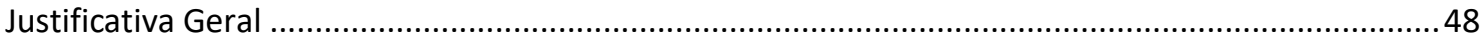

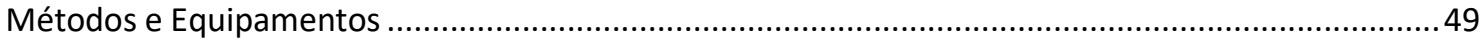

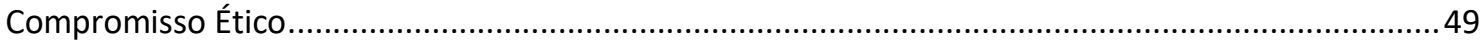

Animais

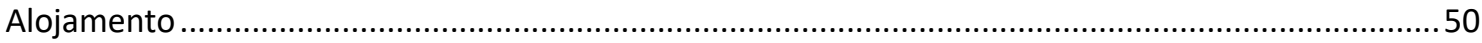

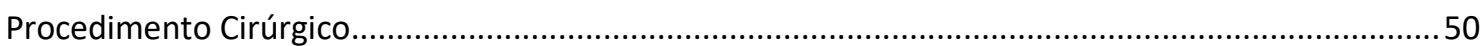

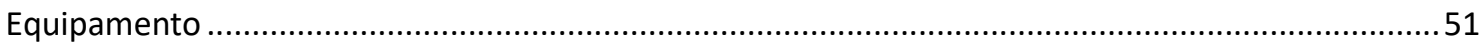





Experimento 1. Expressão do IEG $\Delta$ FosB na Administração de Morfina em Contingências Operante e

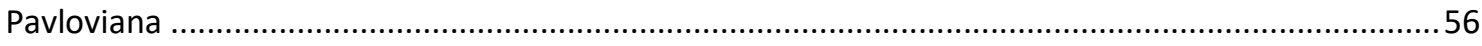

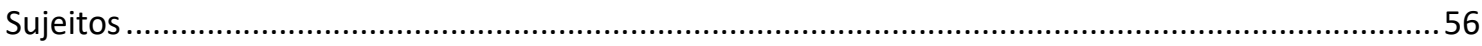



Fase 1. Administração de Morfina em Esquema Acoplado................................................................56

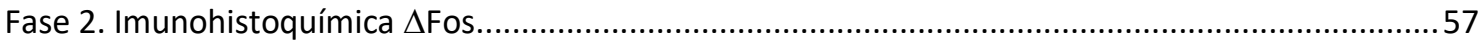


Análise de dados

Resultados

Discussão

Experimento 2. Procedimento de Respostas de Busca e Administração de Morfina nas Associações por Contingências Pavloviana e Operante ....................................................................................... 76

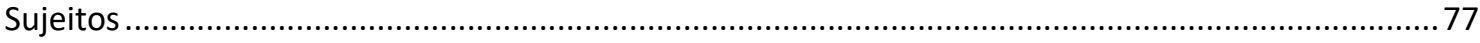



Fase 1. Treino Associativo de Morfina e S1 em Esquema Acoplado ....................................................78

Fase 2. Treino Discriminativo em Contingência Operante ou Pavloviana de Morfina ..........................79

Fase 3. Treino de Encadeamento das Respostas de Busca e Autoadministração de Morfina............... 80

Fase 4. Teste de Transferência Sob o Controle de S1 nas Respostas de Busca e Autoadministração de

Morfina

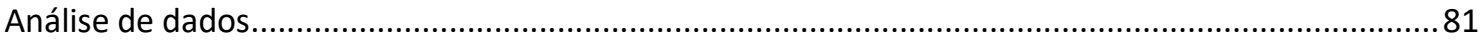



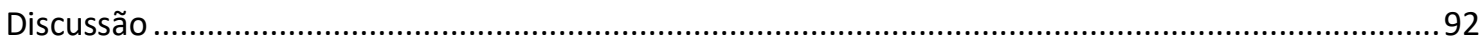

Experimento 3. Associações por Contingências Pavloviana e Operante nas Respostas de Busca e



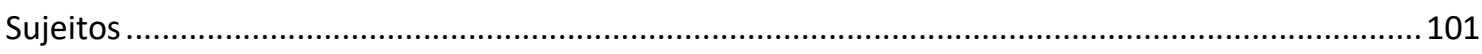

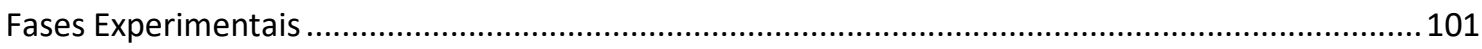

Fase 1. Treino Associativo de COC e S1 em Esquema Acoplado ......................................................... 101

Fase 2. Treino Discriminativo em contingência operante ou Pavloviana de COC...............................102

Fase 3. Treino de Encadeamento das Respostas de Busca e Autoadministração de COC...................103

Fase 4. Teste de Transferência Sob Controle de S1 nas Respostas de Busca e Autoadministração de

COC 


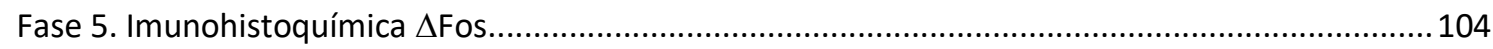



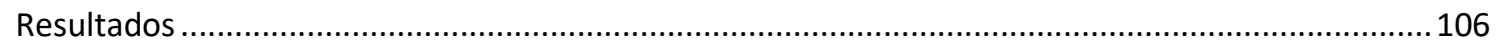

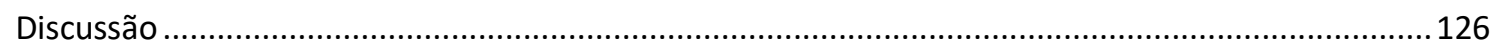

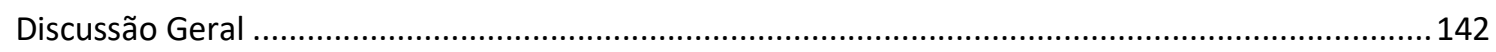



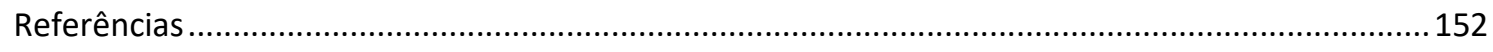




\section{ÍNDICE DE FIGURAS}

Figura 1 - Esquema da caixa operante 52

Figura 2 - Esquema da disposição das luzes estímulo, buzzer e dos operandos nas caixas operantes dos experimentos. 53

Figura 3 - Média de infusões durante a Fase 1 do Experimento 1 ..................................... 59

Figura 4 - Marcação de células imunorreativas a $\triangle$ FosB no mPFC. ............................... 60

Figura 5 - Marcação de células imunorreativas a $\Delta$ FosB no NAc.

Figura 6 - Imagem microscópica da marcação de células imunorreativas a $\Delta$ FosB no NAc. 61

Figura 7 - Marcação de células imunorreativas a $\triangle \mathrm{FosB}$ no Caudado Putamen $(\mathrm{CPu})$......... 62

Figura 8 - Marcação de células imunorreativas a $\Delta$ FosB no Hipocampo. ........................... 63

Figura 9 - Marcação de células imunorreativas a $\Delta$ FosB na Amígdala. ............................. 64

Figura 10 - Índice discriminativo durante a Fase 2 do Experimento 2. ........................... 82

Figura 11 - Média de infusões durante a Fase 3 do Experimento $2 \ldots \ldots \ldots \ldots \ldots \ldots \ldots \ldots \ldots \ldots \ldots \ldots . . . . . . \ldots 3$

Figura 12 - Frequência de respostas de busca e autoadministração na presença de S1. ........ 84

Figura 13 - Frequência total de respostas de busca e autoadministração. ............................ 85

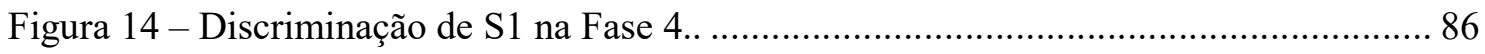

Figura 15 - Índice discriminativo por sujeito nas barras de busca e administração............... 87

Figura 16 - Preferência por B na presença dos estímulos discriminativos......................... 88

Figura 17 - Porcentagem de respostas de busca e administração em S1 e S2.................... 89

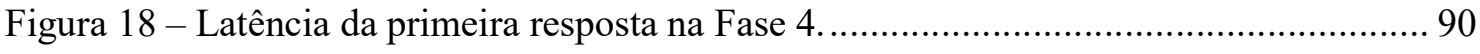

Figura 19 - Índice discriminativo durante a Fase 2 do Experimento 3. ........................... 108

Figura 20 - Média de infusões durante a Fase 3 do Experimento $3 \ldots \ldots \ldots \ldots \ldots \ldots \ldots \ldots \ldots \ldots \ldots \ldots . . . \ldots 109$

Figura 21 - Frequência de respostas de busca e autoadministração na presença de S1...... 110

Figura 22 - Frequência total de respostas de busca e autoadministração. ......................... 111

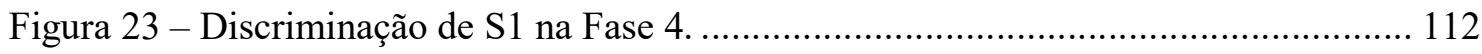


Figura 24 - Índice discriminativo por sujeito nas barras de busca e administração............. 113

Figura 25 - Preferência por B na presença dos estímulos discriminativos......................... 114

Figura 26 - Porcentagem de respostas de busca e administração em S1 e S2 .................... 115

Figura 27 - Latência da primeira resposta na Fase 4 ................................................... 116

Figura 28 - Células imunorreativas a $\Delta$ FosB No Córtex Pré-frontal Nas fases 2 e 4 do



Figura 29 - Marcação de células imunorreativas a $\Delta$ FosB no Córtex Pre-Frontal Medial



Figura 30 - Marcação de células imunorreativas a $\Delta$ FosB no Núcleo Acumbente (NAc) no

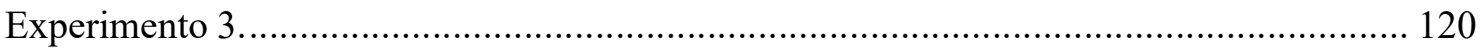

Figura 31 - Marcação de células imunorreativas a $\triangle \mathrm{FosB}$ no Caudado Putamen $(\mathrm{CPu})$ no

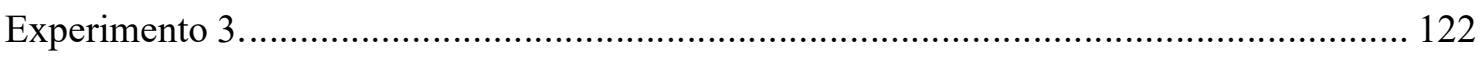

Figura 32 - Marcação de células imunorreativas a $\Delta$ FosB no Hipocampo no Experimento 3.

Figura 33 - Marcação de células imunorreativas a $\Delta$ FosB na Amígdala no Experimento 3.125 
PATARROYO SERNA, William Eduardo. Administração de Morfina e Cocaína em Contingências Operantes e Pavlovianas: Diferenças Gênicas e Comportamentais em Ratos. Tese de Doutorado. São Paulo, 2019. Universidade de São Paulo, Instituto de Psicologia.

\section{Resumo}

Estudos reportando que a autoadministração repetida de drogas de abuso causa mudanças comportamentais, e na expressão de $\Delta \mathrm{FosB}$, diferentes às causadas pela administração passiva repetida da mesma droga, em conjunto com estudos de discriminação de estímulos, têm sido chaves para compreender a dependência às drogas. Neste estudo se apresentam resultados de 3 experimentos que avaliaram diferenças gênicas e comportamentais entre a autoadministração de morfina e cocaína sob uma contingência operante, e a administração passiva destas drogas sob uma contingência Pavloviana, usando um modelo de administração de drogas acoplado e um protocolo de transferência operante-Pavloviana (PIT) seletiva em ratos. Os sujeitos foram distribuídos em três grupos: Administração por Contingência Operante (CO), Administração por Contingência Pavloviana (CP) e Controle (Ctr). No Experimento 1, cada sujeito do grupo $\mathrm{CO}$ foi exposto a sessões de autoadministração endovenosa de morfina. Depois, a expressão do gene $\Delta$ FosB foi medida utilizando uma técnica imuno-histoquímicas em diferentes áreas do cérebro. No Experimento 2 os ratos foram expostos a um protocolo de PIT, treinando de forma inicial as contingências operante e Pavloviana separadamente, em associação a S1, utilizando infusões de morfina como reforçador. Em seguida foi treinado um encadeado de respostas (busca e administração) e finalmente, os sujeitos foram testados para avaliar o controle de estímulos que S1 adquiriu sobre as respostas de busca e administração. O Experimento 3 foi realizado utilizando os métodos dos primeiros dois experimentos, utilizando cocaína como reforçador. Em conjunto, os dados imunohistoquímicos e comportamentais sugerem que a maior expressão de $\Delta \mathrm{FosB}$ em subáreas envolvidas na dependência às drogas, em comparação entre os grupos $\mathrm{CO}$ e $\mathrm{CP}$, está relacionada ao controle de estímulos estabelecido por $\mathrm{S} 1$ pelas diferentes contingências de aprendizagem. Ainda, os resultados apontam que estas áreas em que se encontrou uma expressão de $\Delta$ FosB diferencial por diferentes contingências de administração de drogas coincidem com algumas das reportadas como envolvidas na PIT. Os resultados estão em concordância com estudos que reportam que a administração repetida de uma droga em contingências operantes ou pavlovianas alteram diferencialmente estruturas cerebrais envolvidas nos processos da dependência às drogas e apoiam a literatura que reporta que o estabelecimento de controle de estímulos que caracteriza a dependência se pode estabelecer por processos de aprendizagem na contingência operante e Pavloviana.

Palavras chave: $\Delta \mathrm{FosB}$, autoadministração de drogas, cocaína, dependência, morfina, ratos, transferência operante-Pavloviana. 
PATARROYO SERNA, William Eduardo. Morphine and Cocaine Administration Under Operant and Pavlovian Trainings: Genetic and Behavioral Differences in Rats. Doctoral Thesis. Sao Paulo, 2019. University of Sao Paulo, Psychology Institute.

\begin{abstract}
Studies reporting that repeated drug self-administration produces behavioral changes, and in $\Delta$ FosB expression, different from those produced by repeated passive administration of the same drug have been very important, together with stimulus control studies, have been the key to understand mechanisms underlying drug abuse. This study presents results from 3 experiments evaluating gene and behavioral differences between self-administration of morphine and cocaine under an operant contingency, and passive administration of these drugs under a Pavlovian contingency, using a yoked drug administration model and a selective Pavlovian to instrumental transfer (PIT) protocol in rats. Subjects were divided into three groups: Operant Contingency Administration (CO), Pavlovian Contingency Administration (CP) and Control (Ctr). In Experiment 1, each subject in the $\mathrm{CO}$ group was exposed to intravenous morphine self-administration sessions. Then, expression of $\Delta \mathrm{FosB}$ gene was measured using an immunohistochemical technique in different areas of the brain. In Experiment 2 rats were exposed to a PIT protocol, initially training the operant and Pavlovian contingencies separately in association with $\mathrm{S} 1$, using morphine infusions as a reinforcer. Then a chain of responses (seeking and taking) was trained and finally, subjects were tested to evaluate S1 stimulus control over search and administration responses. Experiment 3 was performed using the methods from the first two experiments, using cocaine as a reinforcer. Together, immunohistochemical and behavioral data interact and suggest that a higher expression on $\triangle \mathrm{Fos} B$ expression in subareas involved in drug dependence, in comparison between $\mathrm{CO}$ and $\mathrm{CP}$ groups, is related to stimuli control established by $\mathrm{S} 1$ through the different learning contingencies. Moreover, results point out these same areas in which different $\Delta \mathrm{FosB}$ expression was found by different drug administration contingencies match some of those reported as being involved in PIT. Results are in agreement with studies reporting that repeated administration of a drug in operant or pavlovian contingencies differentially alter brain structures involved in drug dependence processes and support literature reporting the establishment of stimulus control characterizing addiction can be establish by learning processes in the operant and Pavlovian contingencies.
\end{abstract}

Keywords: $\triangle$ FosB, drug self-administration, cocaine, dependence, morphine, Pavlovian to instrumental transfer, rats. 


\section{Administração de Morfina e Cocaína em Contingências Operantes e Pavlovianas: Diferenças Gênicas e Comportamentais em Ratos}

Quando uma droga, como cocaína (COC), morfina, anfetaminas (ANF), ou álcool, ingressa repetidamente em um organismo, pode causar mudanças relativamente permanentes no Sistema Nervoso Central (SNC) e no comportamento, que podem variar de acordo com as contingências envolvidas na sua administração (Choi et al., 2011; Jacobs, Smit, de Vries, \& Schoffelmeer, 2003, 2005; Lüscher \& Malenka, 2011). Por exemplo, a administração de uma droga pode ser consequência de um comportamento emitido pelo próprio organismo, ou pode ser produto de ação de agentes externos sobre o organismo (e.g., uma injeção administrada por outra pessoa ou uma máquina). O primeiro caso, é comumente chamado de “autoadministração" ou "administração ativa" e é considerado uma instância de comportamento operante. O segundo caso, é denominado de "heteroadministração" ou "administração passiva".

A administração passiva envolve geralmente o Condicionamento Pavloviano de respostas aos estímulos ambientais que precedem e acompanham o efeito da droga. Dado que a relação entres esses estímulos e o efeito da droga é independente das respostas do organismo, a administração passiva, na sua forma mais básica, pode ser considerada como um exemplo de Contingência Pavloviana (CP).

Em termos gerais, a contingência Pavloviana consiste em uma relação de contingência estímulo-estímulo (S-S). Um estímulo incondicional (US) pode evocar uma resposta incondicional, como no exemplo clássico da salivação de um cão na presença de comida (Pavlov, 1927). Quando se desenvolve uma relação CS-US entre um estímulo condicional (CS) e um US, se observa uma resposta condicional (CR), se entende que uma contingência 
Pavloviana foi estabelecida (Skinner 1937), por exemplo, a salivação do cão na presença do experimentador encarregado de disponibilizar a comida.

Por outro lado, a autoadministração envolve o condicionamento de respostas do organismo aos efeitos da droga. Por exemplo, é verificado que o organismo se injeta morfina quando sua consequência é a diminuição de dor. Dado que o efeito da droga depende da resposta do organismo, a autoadministração é considerada uma instancia de Contingência Operante $^{1}(\mathrm{CO})$.

$\mathrm{Na}$ sua forma mais básica, a contingência operante é denotada como $\mathrm{R} \rightarrow \mathrm{S}^{\mathrm{R}}$ (Skinner 1937), que indica a relação de dependência entre o estímulo reforçador $\left(\mathrm{S}^{\mathrm{R}}\right)$, por exemplo, diminuição da dor, e a classe de respostas $(\mathrm{R})$ que o produz, por exemplo, se injetar morfina (Siegel, 1976). Porém é amplamente reconhecido que as relações entre respostas e suas consequências dependem do ambiente em que acontecem, isto é, estímulos do ambiente estabelecem as condições em que uma classe de respostas determinada terá determinada consequência. Por exemplo, injetar-se diminuirá a dor apenas se o líquido da seringa for morfina, mas não se for alguma substância inócua, como salina; portanto, estímulos que sinalizem que o líquido da seringa é morfina, mas não os que sinalizem que é salina, controlarão a resposta de se injetar. Essa relação de dependência a estímulos que antecedem a relação reposta-consequência é denotada como $S d-R \rightarrow S^{R}$ (Skinner, 1937; 1938). Assim, na relação de $\mathrm{CO}$, o $\mathrm{S}^{\mathrm{R}}$ mantém relações condicionais tanto com a $\mathrm{R}$, quanto com o $\mathrm{Sd}$ (SR apenas acontece se R é produzido na presença de $\mathrm{Sd}$ ).

\footnotetext{
${ }^{1}$ Os termos mais frequentemente achados na literatura em inglês são self-administration (autoadministração) para a contingência operante e passive administration (administração passiva) para a contingência Pavloviana.
} 
Em resumo, na contingência operante existe uma relação de dependência entre o ambiente, o comportamento do sujeito e o efeito da droga, enquanto na contingência Pavloviana existe relação de dependência entre o ambiente e o efeito da droga. Em qualquer dos casos, a relação dos eventos antecedentes (CS ou $\mathrm{Sd}$ ) com as respostas produzidas na sua presença é denominada de controle de estímulos.

Existe um longo debate nas Ciências do Comportamento sobre os processos comportamentais que envolvem cada tipo de contingência. Alguns autores argumentam que a contingência operante e contingência Pavloviana são estratégias de treino diferente que produzem controle de estímulo por processos comportamentais semelhantes (Bindra, 1972; Delgado \& Hayes, 2014; Donahoe, Burgos, \& Palmer, 1993; Rehfeldt \& Hayes, 1998). Outros, no entanto, defendem que tanto o procedimento de treino, quanto os comportamentos por eles estabelecidos são diferentes (Miller \& Konorski, 1928; Pear \& Eldridge, 1984; Rescorla \& Solomon, 1967; Skinner 1937). Essa discussão foge do escopo do presente trabalho, mas trabalhos como os de Burgos (2018), Domjam (2016) e Troisi II e Mauro (2017) evidenciam que essa questão continua ainda em debate.

Nas neurociências, a diferenciação entre administração passiva e autoadministração de drogas é abordada pelo estudo dos mecanismos neurais que participam ou são alterados por cada uma. A literatura a respeito sugere que as mudanças de longo prazo no SNC ocasionadas pela administração passiva repetida de drogas (não contingente à emissão de uma resposta) é diferente da autoadministração, (contingente à emissão de uma resposta), e que as mudanças produzidas pela segunda estão relacionadas a padrões compulsivos de uso de drogas.

Sabe-se que a administração repetida de drogas de abuso como morfina, COC, ANF, e álcool, entre outras, causam mudanças relativamente permanentes no Sistema Nervoso Central (SNC), e que parte dessa neuroplasticidade está diretamente associada ao 
desenvolvimento de dependência (Jacobs et al, 2003). Estudos experimentais na área de dependência às drogas têm demonstrado que administração repetida de uma droga sob contingência operante produz mudanças gênicas (no SNC) diferentes às causadas pela administração repetida sob contingência Pavloviana da mesma droga (Choi et al., 2011; Jacobs et al., 2003, Lüscher et al, 2011, Miguéns et al.,2008).

Os fatores de transcrição mais estudados pela literatura da área são os genes de resposta imediata ou IEGs (pela sua sigla em inglês, immediate-early genes). Quando estes genes são transcritos, ativam proteínas quinases que produzem a fosforilação de várias proteínas celulares (Nestler, 2014). Famílias de IEGs como Jun e Fos são rapidamente ativadas pela ação de fármacos como $\mathrm{COC}, \mathrm{ANF}$, opióides, nicotina, entre outros; motivo pelo qual se acredita que a expressão desses genes possa estar implicada direta ou indiretamente na aquisição, manutenção e recaída da autoadministração e da dependência às drogas (Nestler, 2012, 2014; Perrotti et al., 2008; Winstanley et al., 2007).

Um membro da família Fos, o $\Delta$ FosB, tem sido diretamente ligado a estes comportamentos relacionados às drogas de abuso, pois com administrações repetidas de droga, os níveis de $\Delta \mathrm{FosB}$ acumulam-se gradualmente, sugerindo que tem funções de longo prazo na regulação da expressão gênica da célula (Nestler, 2012, 2014). Devido a estas características várias pesquisas têm procurado desvendar o papel do $\Delta \mathrm{FosB}$ no comportamento de autoadministração de drogas. Por exemplo, aumentos significativos na expressão de $\Delta$ FosB no núcleo accumbens (NAc) (e outras partes do estriado), e outras áreas do SNC (associadas ao consumo e dependência de drogas) são causados pela autoadministração aguda de drogas de abuso como COC, morfina, anfetamina e álcool, persistindo semanas após a administração da droga ter sido suspensa (Perrotti et al., 2008). 
Para comparar as mudanças produzidas pelos dois tipos de administração $(\mathrm{CO}$ e $\mathrm{CP})$ é frequentemente utilizado o procedimento de administração acoplada ou operante acoplado. Esse procedimento permite o estudo simultâneo da administração de uma mesma droga sob contingência operante (autoadministração) e sob contingência Pavloviana (administração passiva), separando as histórias de administração sem alterar a dosagem de droga administrada. O procedimento consiste em conectar ambientes experimentais de treino, de forma que o desempenho de um sujeito determina a apresentação de estímulos e/ou esquemas para si mesmo e outro(s) sujeito(s) acoplado(s) a este (Catania, 1999). No caso específico da administração de drogas, o procedimento padrão com animais se caracteriza pelo acoplamento de pelos menos três ambientes: contingente, acoplado e controle (ou veículo). Em cada ambiente é alocado um animal. No ambiente contingente, a emissão de uma resposta operante (como pressão à barra ou focinhar) tem como consequência a infusão da droga, ou seja, existe uma relação de contingência entre a resposta e o efeito da droga (i.e., condição CO). No ambiente acoplado, a administração da droga é independente da resposta do sujeito alocado nele, mas contingente à resposta do animal alocado no ambiente contingente, portanto, o animal acoplado recebe a mesma dose de droga simultaneamente ao sujeito no ambiente contingente; note-se que no ambiente acoplado não é manipulada a relação de contingência entre a resposta do animal e o efeito da droga e apenas o contexto pode ser relacionado ao efeito da droga (i.e., condição CP). No ambiente controle, o animal é submetido a um procedimento similar ao do ambiente acoplado, mas no lugar de uma droga, uma infusão de veículo é administrada.

Usando um procedimento de administração acoplada como o descrito acima, diferentes estudos têm reportado diferenças de expressão gênica em áreas cerebrais de sujeitos que receberam uma droga sob contingência operante ou Pavloviana. Por exemplo, Kuzmin e Johanson (1999) observaram que em animais que receberam COC sob 
contingência operante houve aumento do mRNA do c-Fos na amígdala lateral (LA) e basolateral (BLA), enquanto os animais que receberam COC sob contingência Pavloviana mostraram uma diminuição no mRNA de c-Fos nas mesmas áreas. Tendo em conta que a BLA possui conexões eferentes dirigidas ao NAc Core e Shell que ajudam a mediar a motivação e se acredita esteja implicada na aprendizagem relacionada a estímulos ambientais/contextuais (Martinez, Carvalho-Netto, Ribeiro-Barbosa, Baldo, \& Canteras, 2011; Setlow, Holland \& Gallagher, 2002), é uma subárea de grande interesse para o presente estudo.

Winstanley et al. (2007) reportam a expressão de $\Delta \mathrm{FosB}$ unicamente em animais que receberam $\mathrm{COC}$ sob CO, mas não sob CP, no Córtex Orbito-frontal (OFC), o qual está relacionado a comportamentos de meta dirigida (goal-directed, em inglês) e também de impulsividade, características da procura por drogas na dependência (Barbey, Krueger \& Grafman, 2009). Outro exemplo é reportado por Choi et al. (2011), em um estudo que mostra que mudanças neurais como a hiper-regulação da expressão de receptores AMPA na Área Tegmental Ventral (VTA), a qual está implicada na "motivação" da administração de COC, após administração da droga sob $\mathrm{CO}$, mas não sob CP.

Dois estudos de especial interesse para este trabalho, Perrotti et al. (2008) e Winstanley et al. (2007), observaram a expressão do fator de transcrição de $\Delta$ FosB no NAc (core e shell) e no Córtex Orbitofrontal (OFC), após a administração de COC sob contingência operante e Pavloviana em ratos. No estudo de Winstanley et al. (2007), ratos foram expostos durante três semanas em administração crônica de COC $(0,5 \mathrm{mg} / \mathrm{kg}$ por infusão) sob o procedimento de administração acoplada. A expressão de $\Delta$ FosB no OFC de todos os animais foi medida por imunohistoquímica, sendo que este IEG foi expresso apenas pelos sujeitos sob a contingência operante e não sob a Pavloviana. Segundo os autores, esta é 
uma região-chave não só regulação de comportamentos de meta dirigida, mas também de impulsividade, características da procura por drogas na dependência.

No estudo de Perrotti et al. (2008) foram realizados dois experimentos. No primeiro, ratos foram expostos durante duas semanas em administração crônica de COC $(0,5 \mathrm{mg} / \mathrm{kg}$ por infusão) sob o procedimento de administração acoplada. A expressão de $\Delta$ FosB foi medida no NAc Core e Shell, e Caudado-Putamen $(\mathrm{CPu})$ por imunohistoquímica. Não foram encontradas diferenças significativas na expressão de $\Delta \mathrm{FosB}$ entre os grupos sob a contingência operante e sob a Pavloviana, sendo que ambos expressaram amplamente este IEG. No segundo experimento, ratos receberam por duas semanas injeções intraperitoneais diárias de uma de quatro substâncias, COC, morfina, etanol e tetraidrocanabinol, isto é, as drogas foram administradas sob CP. Posteriormente, foram realizadas medidas de $\Delta$ FosB por técnica imunohistoquímica em diferentes áreas do SNC (PFC, estriado dorsal, NAc, septum lateral e medial, hipocampo, amígdala, substância cinzenta, área tegmental ventral e substância nigra, entre outros), encontrando que as quatro drogas induziram a expressão deste IEG em quantidades que variaram em relação à droga e a região, mas tendo todas as quatro drogas em comum uma forte expressão de $\Delta$ FosB no NAc.

Juntos, os resultados dos estudos de Perrotti et al. (2008) e Winstanley et al. (2007), indicam que: a) a indução por $\mathrm{COC}$ de $\triangle \mathrm{FosB}$ em regiões estriatais (NAc e $\mathrm{CPu}$ ) se pode dar emCO ou CP; b) a indução por COC da expressão de $\triangle \mathrm{FosB}$ no OFC depende do tipo de contingência de administração, sendo apenas expresso após a autoadministração da droga (CO). Portanto, os dados sugerem que ainda que ambas as formas de interação do organismo com a COC produzam alterações em regiões chave na dependência às drogas, associadas com a integração de informação emocional e cortical (Goto \& Grace, 2008), implicação em atribuir significado motivacional a estímulos pavlovianos (Ambroggi, Ghazizadeh, Nicola, \& Fields, 2011; Everitt, 2001), aquisição de informação de estímulos ambientais que podem 
modular o comportamento (Saddoris, Stamatakis, \& Carelli, 2011), motivação e centro do prazer responsável pelo processamento da sensação de gosto no reforço positivo (West \& Carelli, 2016), e mediação de funções como aprendizagem de sequências e seleção de estratégias (Devan, McDonald, \& White, 1999); apenas a administração da droga sob contingência operante causou algumas das mudanças neurais necessárias para desenvolver dependência.

Ainda que os estudos de Perrotti et al. (2008) e Winstanley et al. (2007) pareçam direcionar a questão sobre a relação entre autoadministração e administração passiva de drogas, os procedimentos comportamentais utilizados e os resultados derivados deles podem não ser úteis para entender as diferencias produzidas na expressão de IEGs pela administração de droga sob contingências operantes e pavlovianas. Isso porque em nenhum desses experimentos são manipulados os estímulos que antecedem a emissão da resposta operante (grupo contingente) ou que apenas antecedem a infusão da droga (grupo acoplado). Ao não manipular essa variável, a infusão que recebe o grupo acoplado pode não estar acontecendo sob um CP, pois os efeitos da droga não são contingentes aos estímulos presentes na câmara experimental desse grupo (i.e. na sua presença e na sua ausência a droga é infundida). Ainda que pode ser argumentado que, em teoria, alguns estímulos que aparecem apenas no momento da infusão (e.g. som da bomba de infusão) devem adquirir função de CS do efeito da droga.

O controle dos estímulos associados aos efeitos da droga é atualmente considerado chave para se entender a passagem do uso recreativo de drogas ao seu abuso. Entretanto, não existe consenso entre os processos de controle de estímulos que seriam críticos. Parte dos estudos da área de dependência propõe que os comportamentos de busca e autoadministração de drogas de sujeitos dependentes de drogas, são controladas por CSs estabelecidos durante a administração das drogas (Bachteler, Economidou, Danysz, Ciccocioppo, \& Spanagel, 2005; 
Robinson \& Berridge, 1993, 2003, 2008). Em contrapartida, outros autores alegam que os comportamentos de busca e autoadministração de drogas observados na dependência de drogas são produto de relações operantes (Chen et al., 2008; Melzack, 1990; Stefanski, Ladenheim, Lee, Cadet, \& Goldberg, 1999), sendo a contingência operante considerada um processo chave para compreender o comportamento de consumo abusivo e a busca por drogas (Chen et al., 2008; Heyman, 2010; Herrnstein \& Prelec, 1992; Jacobs et al., 2003; Kuzmin \& Johansson, 1999; Melzack, 1990; Stefanski et al., 1999).

Como será evidente posteriormente, a controvérsia entre as propostas acima mencionadas parece estar associada a alguns equívocos conceituais, como por exemplo, a distinção entre controle de estímulos operante ou pavloviano estar fundamentada na controlabilidade ou não que o sujeito tem sobre o próprio comportamento: respostas operantes seriam controladas pelo próprio sujeito e CRs seriam incontroláveis e involuntárias. Adicionalmente, será explicado em uma seção posterior como seria possível que um CS tivesse controle sobre respostas de busca e autoadministração de uma droga, por um processo comportamental chamado Transferência Pavloviana-operante (PIT). Porém antes de entrarmos nessa questão, primeiro definiremos os comportamentos alvo do estudo da área de Dependência de Drogas: procura, consumo e recaída.

No estudo experimental sobre o controle de estímulos de respostas mantidas por drogas, são frequentemente usados modelos animais que pretendem simular respostas de procura e autoadministração por drogas, e também recaída a estas. A procura por drogas é definida pelos comportamentos de busca, aquisição e forrageio da droga (Sanchis-Segura \& Spanagel, 2006); conseguir o dinheiro para comprar a droga, comprar esta e frequentar os locais onde a droga está disponível são exemplos destes comportamentos. A autoadministração de drogas pode ser definida como o comportamento que imediatamente precede a ingestão da droga (por exemplo, se injetar, cheirar, ingerir ou fumar uma droga são considerados comportamentos de 
autoadministração). Por último, a recaída é um termo usado para descrever a retomada da autoadministração de drogas, após algum período de abstinência (Epstein, Preston, Stewart, \& Shaham, 2006). O controle de estímulos da procura, consumo e recaída às drogas são de particular interesse para este trabalho, pois os dois primeiros os comportamentos que caracterizam a dependência, e a recaída seria o processo de restabelecimento destes comportamentos posteriormente à sua extinção. Por esse motivo serão melhor detalhados a seguir.

\section{Modelos de Estudo de Administração de Drogas}

Para o estudo experimental do controle de estímulos da resposta mantida por drogas, são frequentemente usados modelos animais que pretendem simular os comportamentos de autoadministração, procura por drogas e recaída. Para este estudo são de particular interesse os modelos denominados por Sanchis-Segura \& Spanagel (2006), de procura e autoadministração de drogas. No modelo de autoadministração operante (i.e., CO) é comumente utilizada uma caixa operante (ou caixa de Skinner) a qual está equipada com operandi ou manipulandi que transmitem uma resposta operante a um (ou mais) dispositivo que se encarrega de entregar um reforçador. Estas caixas são geralmente adaptadas a depender das necessidades experimentais: para transmitir a(s) resposta(s) operante(s), com alavancas, rodas, receptores infravermelhos, entre outros; para entregar um reforçador, como sistema de entrega de comida ou soluções líquidas, dispositivos de injeção para diferentes rotas (e.g. endovenosa, intragástrica, oral, intracraniana), e adicionalmente, estas caixas podem ser adaptadas com módulos de luzes, tons, e outros para seres utilizados como estímulos discriminativos ou reforçadores condicionados. O procedimento básico de autoadministração consiste em equipar a caixa com um primer operandum ligado a entrega de um reforçador e um segundo ligado a entrega de um veículo ou sem consequências programadas. Infinidade de variações podem existir nos procedimentos de autoadministração, dependendo do operandi, dispositivos de entrega e estímulos 
discriminativos que possa ter uma pesquisa particular, mas para ser considerado um procedimento de autoadministração, deve existir minimamente a possibilidade de uma resposta operante ter como consequência a administração de uma substância. Este modelo oferece maior flexibilidade de delineamento experimental comparado com modelos não operantes. Enquanto aos procedimentos de autoadministração de drogas, este tem se mostrado confiável e válido como modelo de consumo de drogas em humanos (Sanchis-Segura et al., 2006).

No modelo de procura por drogas e recaída, comumente é realizado um treino como o descrito anteriormente em primeira instância, e posterior ao de autoadministração operante, os sujeitos são expostos a uma fase de extinção, na qual as suas respostas no operandi não têm consequências programadas. Finalmente é realizada a fase de teste, em que as respostas operantes produzem a mesma consequência que no treino inicial (i.e., administração da mesma dose da substância). Segundo Sanchis-Segura et al. (2006), existe um erro de definição neste modelo de recaída, pois estritamente falando, prévia à recaída, a autoadministração de drogas não se passa por uma etapa de extinção, mas sim de privação. Por este motivo, principalmente, talvez seja adequado definir este como um modelo de recaída, porém continua sendo um valioso modelo de procura por drogas. O comportamento de procura por drogas se interpreta como a busca, forrageio e aquisição de uma droga quando esta não está disponível, fenômeno comumente referido por alguns autores como craving (Sanchis-Segura et al., 2006). Dado isto, existem algumas opções procedimentais a depender do estudo para a fase final (teste), comumente chamada de reinstalação. Uma destas é o priming $^{2}$, o qual consiste em administrar uma dose não operante nos sujeitos antes do teste,

$2 \mathrm{O}$ principal inconveniente metodológico com o priming como estímulo para desencadear (trigger) comportamentos de busca e de autoadministração é a possível interferência produzida pelos efeitos psicoativos da droga, a qual pode incrementar ou diminuir a locomoção, resultando em incrementos/decrementos espúrios. 
interpretando a reinstalação do responder previamente extinto como busca por drogas e recaída desencadeada por ação farmacológica. Outro possível procedimento no teste é a apresentação de estímulos previamente condicionados à administração da droga (ou em alguns casos, condicionados a estímulos estressantes), interpretando a reinstalação do responder previamente extinto na presença destes estímulos, e não de outros não relacionados, como busca por drogas e recaída desencadeada por estímulos ambientais (externas). Uma terceira opção procedimental é expor os sujeitos a algum protocolo de estresse antes da fase de teste, interpretando a reinstalação do responder previamente extinto como busca por drogas e recaída desencadeada por estresse.

Comumente, os modelos utilizados para estudar a procura por drogas incluem o treino prévio da resposta de autoadministração de uma droga na presença de estímulos ambientais, isto acontece tanto no modelo de autoadministração quanto no modelo de procura e autoadministração. Em outras palavras, todos os sujeitos aprendem uma associação estímuloresposta-consequência. Isto representa um inconveniente procedimental para um estudo que pretenda interpretar as respostas separadamente, dado que dificulta/impossibilita a interpretação da CP e da CO por separado (Sanchis-Segura et al., 2006).

No modelo de autoadministração de drogas é geralmente assumido que a contingência em vigor é de caráter exclusivamente operante, dada a relação resposta-consequência implícita. Mesmo assim, não se pode descartar que o mesmo ambiente onde é realizado o ambiente possui (e é em si mesmo) estímulos condicionados à droga, o que implica uma relações S-S. Em outras palavras, também existe um condicionamento Pavloviano no condicionamento operante (Donahoe et al., 1994, Colwill \& Rescorla, 1988; Rescorla, 1991, 1994). Da mesma forma, no modelo de procura por drogas, no qual a contingência treinada é operante discriminativa, criam-se relações S-S. A despeito de ambos modelos manipularem contingências operantes, é assumido por boa parte da literatura que os modelos de procura 
por droga medem comportamentos condicionados por contingências Pavloviana e que os modelos de autoadministração informam sobre comportamentos condicionados por contingências operantes (e.g., Berridge, Robinson \& Aldridge; 2009; Robinson \& Berridge, 2008; Colwill \& Rescorla, 1985). Assim, frequentemente os modelos de procura são utilizados para pesquisar mudanças neurais relativas a processos em $\mathrm{CP}$ e os modelos de autoadministração são utilizados para pesquisar mudanças neurais relativas a processos em ACO. Entretanto, por ambos procedimentos envolverem contingências operantes e possivelmente Pavlovianas, não são os mais adequados para se pesquisar mudanças neurais e comportamentais produzidas pela $\mathrm{CP}$ ou pela $\mathrm{CO}$.

Um modelo pouco usado pela área de dependência às drogas, mas que permite observar a comparação direta entre CP e ACO, é o modelo de autoadministração acoplada ou operante acoplado. Este permite o estudo simultâneo da administração de uma droga sob contingências operantes (autoadministração) e administração da mesma droga sob contingências Pavlovianas (administração passiva), separando as histórias de administração sem alterar a dosagem de droga administrada. O modelo operante acoplado consiste na conexão de ambientes experimentais, de forma que o desempenho de um sujeito determina a apresentação de estímulos e/ou esquemas para si mesmo e outro(s) sujeito(s) acoplado(s) a este (Catania, 1999). No caso específico da administração de drogas, o procedimento padrão com animais se caracteriza pelo acoplamento de pelos menos três ambientes: contingente, acoplado e controle (ou veículo). Em cada ambiente é alocado um animal. No ambiente contingente, a emissão de uma resposta operante tem como consequência a infusão da droga, ou seja, existe uma relação de contingência entre a resposta e o efeito da droga (ACO). No ambiente acoplado, a administração da droga é independente da resposta do sujeito alocado nele, mas contingente à resposta do animal alocado no ambiente contingente, portanto, o animal acoplado recebe a mesma dose de droga simultaneamente ao sujeito no ambiente 
contingente; note-se que no ambiente acoplado não é manipulada a relação de contingência entre a resposta do animal e o efeito da droga e apenas o contexto pode ser relacionado ao efeito da droga (ACP). No ambiente controle, o animal é submetido a um procedimento similar ao do ambiente acoplado, mas no lugar de uma droga, uma infusão de veículo é administrada.

O modelo operante acoplado é de grande relevância para o estudo da dependência às drogas dado que permite distinguir entre os dois tipos de efeitos que causam neuroplasticidade quando uma droga ingressa em um organismo, um resultante do efeito farmacológico ${ }^{3}$ de uma substância de ação central no SNC, como na CP, e outro resultante dos processos comportamentais associados à autoadministração da droga, como na $\mathrm{CO}$ (Dacher \& Nugent, 2011; Lüscher \& Malenka, 2011). Por permitir diferenciar entre mudanças comportamentais produzidas por processos operantes e Pavlovianos na administração de drogas, além de permitir a análise independente dos dois tipos de mudanças no SNC produzidas pela autoadministração e a administração passiva, este modelo é uma valiosa ferramenta para o desenvolvimento deste estudo.

\section{Controle de Estímulos da procura, consumo e recaída}

Estímulos ambientais podem adquirir controle sobre comportamentos reforçados por drogas se foram associados de forma prévia ao efeito da droga. Esse fenômeno é verificado em animais humanos (e.g. Childress, McLellan, Ehrman, \& O'Brien, 1988; O'Brien, Ehrman, \& Ternes, 1986) e em animais não humanos (e.g. Goldberg, Spealman, \& Kelleher, 1979; Woods \& Schuster, 1968; Weiss, Kearns, Cohn, Schindler, \& Panlilio, 2003). Desde os anos 60,

\footnotetext{
${ }^{3}$ Tendo em conta que não existe um efeito puramente farmacológico em um organismo vivo consciente, pois este está sempre em contato com estímulos ambientais, portanto os efeitos da droga estão sujeitos aos estímulos ambientais presentes no momento da ação central, existindo a probabilidade de aprendizagem, mesmo que não associativa.
} 
autores como Thompson e Ostlund (1965) mostraram que é possível que estímulos ambientais ocasionem que um sujeito retome padrões comportamentais que previamente tiveram a função de aliviar sintomas de abstinência, e desde então também se tem reportado que sintomas de abstinência podem ser condicionados a um estímulo especifico e posteriormente ser evocados por este, como na contingência Pavloviana (Goldberg \& Schuster, 1967; Wikler \& Pescor, 1967), produzindo padrões comportamentais de uso de drogas de abuso caracterizados como dependência (McDonald \& Siegel, 2004; Siegel, 2005; Siegel \& Ramos, 2002) e recaída do uso após períodos de abstinência prolongada (O’Brien, Childress, Ehrman, \& Robbins, 1998; Robinson \& Berridge, 2008).

Fundamentados nessas pesquisas, vários autores da literatura especializada no estudo da dependência de drogas tem proposto que os padrões de procura autoadministração e recaída observadas em sujeitos dependentes são função do controle de estímulos ambientais associados aos efeitos da droga (e.g. Everitt \& Robbins, 2005; Kalivas \& O'Brien, 2008; Kalivas, Peters, \& Knackstedt, 2006; Robinson \& Berrigde 2003; Siegel, 2005; Siegel \& Ramos, 2002).

Diferentes autores têm exposto as suas propostas para explicar como um estímulo ambiental adquire controle sobre respostas de busca e autoadministração de drogas. A teoria da saliência do Incentivo de Robinson \& Berridge (1993, 2003, 2008) é uma das mais citadas na literatura das neurociências, liderando várias das pesquisas realizadas na área e é usada como fundamento para distinguir entre os processos pavlovianos e operantes da procura e recaída (Everitt \& Robbins, 2005; Berridge, Robinson \& Aldridge, 2009). Por esse motivo, descrevemos a seguir as propostas principais da teoria.

De acordo com a Teoria da Sensibilização do Incentivo, na sensibilização da saliência do incentivo, o estímulo produzido pelo uso repetido de drogas em contextos específicos seria o processo chave que leva à dependência. A sensibilização do incentivo aconteceria porque 
os sistemas neurais responsáveis pela saliência do incentivo dos estímulos são sensibilizados pela administração repetida da droga, causando que o indivíduo sensibilizado, quando exposto à droga ou a estímulos associados a ela, quisesse a droga mesmo não gostando dela (Robinson \& Berridge, 1993, 2003, 2008; Berridge \& Robinson, 2016).

A teoria distingue dois processos no desenvolvimento da dependência, "gostar" da droga e "querer" a droga" (Robinson \& Berridge, 2003, 2008; Berridge e Robinson, 2016). O gostar" "é usado por estes autores para se referir abreviadamente ao impacto prazeroso de um $\mathrm{S}^{\mathrm{R}}$ sobre um organismo, mediado por sistemas neurais não dependentes de dopamina, que envolvem a saliência do incentivo de um estímulo. Por outro lado, o "querer" 5 seria uma forma de motivação a qual é mediada por sistemas dopaminérgicos mesolímbicos, um processo "não racional" que pode instigar e orientar um comportamento em um sujeito, sem necessariamente ter emoção consciente, desejo ou um objetivo específico, i.e. sem "gostar" necessariamente. Os autores definem o "querer" como a ativação de processos que envolvem a saliência do incentivo de um estímulo. Em outras palavras, o querer está associado com CSs que sinalizam um $\mathrm{S}^{\mathrm{R}}$, que fariam esses CSs mais salientes, ou seja, mais chamativos e atrativos para o organismo (Hickey \& Peelen, 2015).

Na autoadministração de drogas não patológica estaria envolvida circuitaria neural do gostar da droga, i.e., sistema opioide (Smith \& Berridge, 2007), porém na dependência de drogas seria a circuitaria do querer a que estaria envolvida, i.e., sistema dopaminérgico (Koob, 1992; Pavuluri, Volpe \& Yuen, 2017). A passagem do uso recreacional ao uso compulsivo seria explicado pela sensibilização da circuitaria do querer aos estímulos do ambiente associados com a droga, o que aconteceria após sua administração repetida. O que

\footnotetext{
${ }^{4}$ Do inglês "liking".

${ }^{5}$ Do inglês "wanting".
} 
se observa em termos comportamentais é que na presença desses estímulos respostas fisiológicas que são interpretadas como querer ou fissura pela droga são produzidas e a autoadministração da droga é incontrolável, pois a resposta do sistema neural está aumentada.

Berridge, Robinson e Aldridge (2009) reformularam a Teoria da Sensibilização do Incentivo em termos da evidência empírica que sustenta a proposta dos diferentes mecanismos neurofisiológicos de "querer" e "gostar", mas descartam a correspondência desses mecanismos com a diferenciação entre processos comportamentais operantes e Pavlovianos. De acordo com os autores, "Estudos das neurociências dos efeitos de 'gostar', 'querer', e dos componentes de aprendizagem de recompensas, revelaram que estes processos psicológicos são mapeados em distintos sistemas cerebrais de recompensa, neuroquímicos e neurofisiológicos, em um grau determinado" (p. 71) ${ }^{6}$. Portanto, na teoria mais recente da sensibilização do incentivo, o “querer" e o "gostar” envolvem mecanismos neuronais de recompensa diferentes e não necessariamente correspondem exclusivamente a processos operantes ou Pavlovianos, como afirmado na teoria original. Porém, segundo estes autores, a ênfase na eliciação produzida por um estímulo condicionado em contingência Pavloviana seria o mecanismo fundamental na dependência as drogas.

Garcia-Mijares e Silva (2006) apontam que existem vários problemas ao tentar explicar a dependência em termos de "querer e gostar", pois não fica claro se "querer" é um comportamento/resposta ou um estímulo, comprometendo o uso do termo como variável causal, ao ser definida pelos autores como um estímulo que ativa processos neurais associados à saliência do estímulo (Robinson \& Berridge, 2003). Portanto o processo psicológico que explicaria a autoadministração de uma droga não está claro. Contudo, para os

\footnotetext{
${ }^{6}$ Original em inglês: 'Affective neuroscience studies of 'liking', 'wanting', and learning components of rewards have revealed that these psychological processes map onto distinct neuroanatomical and neurochemical brain reward systems to a marked degree".
} 
objetivos do presente trabalho, a teoria é relevante por enfatizar que a contingência entre a apresentação de dois estímulos (um estímulo ambiental e o efeito da droga), assim como a sensibilização dos sistemas neuronais envolvidos, são os processos básicos da dependência.

Estudos reportam que circuitos dopaminérgicos de animais expostos intermitentemente a comida ou drogas respondem exageradamente a infusões autoadministradas de anfetamina, i.e., a resposta desse sistema ao efeito da anfetamina é sensibilizada (Everitt \& Robbins, 2005; Everitt et al., 2008; Robinson \& Berridge,1993; Volkow, Wang, Fowler, \& Telang, 2008; Wyvell \& Berridge 2001). Estes animais, quando expostos a estímulos associados a esses reforçadores (CSs) produzem respostas de físsura, ou seja, iniciam uma cadeia de respostas que se inicia pela sua busca e finaliza com a autoadministração da droga (em consumo compulsivo). Esses estudos sugerem que tal como proposto pela teoria do incentivo, a sensibilização é um mecanismo importante na dependência de drogas.

Em resumo, é essencial à Teoria da Sensibilização do Incentivo a ideia que estímulos ambientais são condicionados de forma pavloviana aos efeitos da droga, e que na presença deles se produzem respostas no sistema nervoso central que instigam o sujeito a procurar e consumir a droga. Portanto, segundo esta lógica, a procura e consumo de droga do dependente seriam respostas operantes induzidas ou alterados pela presença de estímulos eliciadores, ou seja, são comportamentos determinados por processos de transferência de controle Pavloviano-operante, que serão explicados com maior detalhe a seguir.

\section{Pavlovian to Instrumental Transfer}

A Transferência Pavloviana-Operante, ou PIT pela sua sigla em inglês (Pavlovian to instrumental transfer), se encontra comumente na literatura, tanto para descrever um 
processo comportamental, quanto para fazer referência ao procedimento experimental desenvolvido para poder observar este processo ou fenômeno.

O procedimento de PIT possui diversas variações, mas todas envolvem, em geral, três fases: treino Pavloviano (Fase 1), treino operante (Fase 2) e teste de transferência (Fase 3). Os treinos Pavloviano e operante podem aparecer primeiro em qualquer ordem (ou na Fase 1 ou na Fase 2), a depender do objetivo do estudo, e em seguida um teste é realizado para se observar o efeito do CS sobre o responder operante. No treino Pavloviano é realizado um pareamento CS-US, e.g., uma luz pode se tornar um CS ao ser pareada com droga (i.e., US). No treino operante, o animal recebe droga como consequência de emitir alguma resposta (por exemplo, pressionar a barra). Uma vez realizados esses procedimentos independentes, o teste de transferência é realizado em extinção (i.e., sem consequência programada para o responder), no qual a resposta operante é avaliada na presença do CS e na sua ausência. O objetivo do teste é verificar se o CS do treino Pavloviano adquire controle sobre a resposta operante, sem nunca ter sido associado a ela. Em geral, o resultado indica uma maior ocorrência de respostas operantes na presença do CS do que na sua ausência.

Os primeiros estudos relacionados à PIT datam da década dos 40s. Estes reportaram que um estímulo associado com comida podia aumentar a frequência de uma resposta operante que tinha também comida como consequência (Estes \& Skinner, 1941; Estes, 1943). Estes primeiros estudos não propunham os processos comportamentais que estariam envolvidos na PIT. Posteriormente, foi proposta a Teoria dos Dois Processos (em inglês, Two-process Learning Theory) sendo estudada inicialmente por Rescorla e Solomon (1967), postulando que os condicionamentos decorrentes de CPs e a COs poderiam implicar diferentes processos de aprendizagem. Nesse contexto, a PIT era considerada como a alteração de um tipo de comportamento (i.e. operante) por manipulações no treino de outro (i.e., pavloviano). 
Rescorla e Solomon (1967) consideravam que as respostas emocionais aversivas ou apetitivas ficavam sob controle pavloviano de dicas ambientais, que quando eliciadas, interferiam ou facilitavam a ocorrência de uma resposta operante. Por esse motivo, o procedimento foi muito utilizado para o estudo da influência das respostas emocionais condicionadas sobre operantes em curso.

Algumas décadas depois, a explicação da PIT foi refinada. Estudos como os de Dickinson e Dawson (1987) e Balleine (1994) ajudaram a entender a transferência como um processo caracterizado pela motivação no lugar da emoção. Ainda, neste momento, o fator 'escolha', que caracteriza principalmente a PIT, não estava sendo explicado. Com o desenvolvimento de novas tecnologias no começo do século, as neurociências se uniram ao estudo da transferência. Dois grandes contribuições foram obtidas: o processo comportamental foi dividido de acordo em transferência seletiva, não seletiva e generalizada, caracterizadas por diferentes substratos neurais (Corbit \& Balleine, 2005; 2011). No procedimento de transferência seletiva o mesmo US1 (e.g droga) é usado para treinar um CS1 e uma resposta operante R1. O procedimento de transferência não-seletiva é uma variação do anterior, que avalia se a transferência depende de se usar o US como $\mathrm{S}^{\mathrm{R}}$, e se ela ocorre de forma seletiva em relação à resposta operante. Por último, o procedimento de transferência generalizada permite avaliar a ocorrência de PIT para estímulos que foram associados a reforçadores diferentes dos treinados na Fase 1.

Estudos com procedimentos de PIT, seletiva ou não-seletiva, têm mostrado que quando o reforçador em um treino operante é o mesmo US, comumente resulta na maior frequência de resposta na presença do CS do que na sua ausência (Allman, DeLeon, Cataldo, Holland, \& Johnson, 2010; Holland, 2004). Por outro lado, quando o US é aversivo e o reforçador apetitivo, é comum observar a diminuição da taxa de resposta na presença do CS (Holland, 2004; Colwill \& Rescorla, 1985). Tanto o procedimento, quanto o fenômeno são 
comumente denominados de desvalorização (e.g., Holland, 2004; Rescorla, 1985). Ainda, o efeito da PIT (transferência ou desvalorização) possa variar em razão de parâmetros como a apetitividade ou adversidade de US, a PIT também pode variar em função de diferentes fatores experimentais como a magnitude do US (van den Bos et al., 2004), a duração e sincronicidade com que o CS é apresentado na CP (Crombag et al., 2008), a quantidade de treino e o uso de múltiplos reforçadores (Holland, 2004), a similaridade entre as respostas no treino operante e no teste de transferência (Baxter \& Zamble, 1982), o tempo de exposição do CS treinado na associação por contingência Pavloviana (Holmes, Marchand \& R Coutureau, 2010), entre outros.

Três experimentos foram realizados por Galarce, Crombag e Holland (2007) utilizando os procedimentos PIT e desvalorização para avaliar o efeito da especificidade do reforço na transferência Pavloviana-operante, mostrando que, depois do CO, o valor de um CS (apetitivo ou aversivo) associado a um US, pode alterar a frequência do responder operante emitido na presença deste CS. No primeiro experimento, inicialmente, os animais foram expostos ao treino sob contingência Pavloviana com dois tons de diferente intensidade (CS1 e CS2), sendo CS1 associado à sacarose e CS2 à maltodextrina disponibilizadas em receptáculos de comida diferentes. Posterirormente, os animais passaram por um treino de contingência operante (uma barra para receber sacarose próxima a um receptáculo e uma segunda barra para receber maltodextrina próxima a um segundo receptáculo). Quando os CSs foram introduzidos em situação de extinção durante o teste de transferência, os animais apresentaram PIT respondendo significativamente mais na barra que foi associada com cada CS quando estes estavam presentes durante o treino.

O segundo experimento de Galarce, Crombag e Holland (2007) foi realizado expondo os mesmos animais do primeiro experimento ao retreino de contingência Pavloviana e contingência operante prévios. Depois os animais foram alimentados ad-libitum e foram 
medidos os consumos de sacarose e maltodextrina na presença de CS1 e CS2, sendo registrado maior consumo de sacarose na presença de CS1 e de maltodextrina na presença de CS2, o que sugere que a PIT se pode apresentar diretamente na resposta consumatória, incrementando a administração de uma substância associada previamente a um CS. No terceiro experimento os animais dos experimentos anteriores foram ainda expostos a um procedimento de desvalorização. A contingência Pavloviana consistiu na apresentação de CS1 ou CS2, disponibilizando sacarose ou maltodextrina junto com uma injeção de cloreto de lítio (LiCl) para produzir aversão ao sabor. Depois de dez dias o teste de desvalorização foi apresentado. Comportamentos apetitivos (aproximação e entrada ao receptáculo da comida) e consumatório (consumir a comida) foram examinados na presença de CS1 e CS2, mostrando a redução de ambos os comportamentos no receptáculo correspondente na presença de CS1 e CS2. O que sugere que a desvalorização é um processo que pode ter efeito após uma tarefa ser amplamente treinada e ainda se mostrar específico para uma CR quando várias relações CS-US foram aprendidas. Juntos, estes três experimentos são um claro exemplo de como se apresenta a PIT generalizada depois de adquiridas relações CS-US em um condicionamento Pavloviano, tanto na PIT quanto na desvalorização.

Um exemplo de PIT seletiva são os dois experimentos de Holland (2004) que tinham como objetivo avaliar a quantidade de treino sobre a PIT. No primeiro experimento, ratos privados de comida foram treinados sob uma contingência Pavloviana com os tons CS1 e CS2; um foi pareado com pellets de comida (US1) e outro não (US2), respectivamente. Em seguida, estes receberam um treino sob contingência operante de pressão à barra para obter o US1 comida por duas, cinco ou vinte sessões. Depois, foi realizada uma única sessão de transferência, em que tentativas discretas de CS1 e CS2 foram apresentadas em condições de extinção. Logo, foi realizada mais uma sessão de treino Pavloviano e uma de treino operante. Posteriormente, quatro sessões de desvalorização foram efetuadas, disponibilizando US1 
seguido de uma injeção de LiCl. Foi então realizada mais uma sessão de transferência, idêntica à primeira, e finalmente foi testada a aversão à comida nas caixas viveiro sem usar LiCl. No segundo experimento de Holland (2004), outros sujeitos foram condicionados sob um procedimento similar ao do primeiro experimento. Foram realizados pareamentos com apresentações contrabalançadas de comida (US1) ou uma solução de sacarose (US2). As apresentações de US1 e US2 foram randomizadas de modo que fossem iguais os pareamentos de CS1-comida, CS1-sacarose, CS2-comida e CS2-sacarose. Depois, os ratos foram distribuídos entre dois grupos e deu-se início ao treino operante das respostas de pressão à barra (R1) e de pular uma corrente situada no teto da caixa operante (R2). Um dos grupos foi treinado para responder em R1 e R2 para receber US1 ou US2, respectivamente, o outro grupo foi treinado para responder em R1 para receber US1 e em R2 e R3 (apertar um painel) para receber US2. Os sujeitos passaram por mais uma sessão de treino Pavloviano e posteriormente por duas sessões de transferência nas mesmas condições que no experimento 1 (tentativas discretas de CS1 e CS2 foram apresentadas em condições de extinção), sendo que uma destas sessões foi realizada disponibilizando unicamente R1 e a outra unicamente com R2 (responder em R3 não foi registrado). Igual ao primeiro experimento, os animais receberam mais uma sessão de treino Pavloviano e uma de treino operante (idênticas às anteriores para cada grupo). Os grupos foram divididos em duas metades e foi realizado um procedimento de desvalorização apresentando o $\mathrm{US} 1+\mathrm{LiCl}$ ou o US2+LiCl durante quatro dias. Duas sessões de transferência idênticas às anteriores foram realizadas. Por último, o US1 foi apresentado nas caixas viveiro.

Estes resultados mostram que a quantidade de treino em contingência operante com um único reforçador tem efeitos diretamente proporcionais na taxa de frequência do operante associado na presença do CS quando é de caráter apetitivo, e efeitos opostamente proporcionais nesta frequência quando o CS e de caráter aversivo, durante a transferência 
(PIT). Quando múltiplos reforçadores foram usados (Experimento 2), os processos de PIT e desvalorização foram menos influenciados pela quantidade de treino.

Crombag, Galarce e Holland (2008) mostraram como diferentes relações CS-US estabelecidas em uma contingência Pavloviana podem influenciar as respostas de busca (apetitivas e consumatórias), quando o CS é apresentado depois de um treino em CO. Dois grupos de camundongos foram treinados sob CP. O primeiro grupo foi treinado com um tom duração de 10s (CS), seguido de leite (US); o outro grupo passou por um treino semelhante, mas o CS teve uma duração de 2 min. Depois, a resposta de pressão à barra foi treinada usando o US como reforçador. Finalmente, durante o teste, o CS foi apresentado em extinção e as respostas na barra registradas. O grupo de animais na condição de treino em contingência Pavloviana de 2 min mostrou PIT e apresentou significativamente mais respostas em relação ao grupo na condição de treino Pavloviano de 10s, mostrando que o tempo de exposição entre a apresentação de CS e US utilizado em uma contingência Pavloviana é um parâmetro que pode influenciar a aparição de PIT generalizada.

Considerados em conjunto, os experimentos descritos indicam que o fenômeno da PIT é modulada por diversos parâmetros como o tempo de exposição apresentado entre CS e US em um condicionamento sob CP, quantidade de treino no treino em contingência Pavloviana e a quantidade de respostas treinadas no treino de CP. Sugerem, portanto, que o efeito do estímulo condicionado sobre o responder operante não é um fenômeno de "tudo ou nada" e que diferentes graus e tipos de transferência podem ser obtidos por manipulação do treino CS-US. Usando um procedimento semelhante, diferentes autores tem a aparição de PIT com resultados similares, como Stebbins e Smith (1964) com macacos, Rescorla e Lolordo (1965) com cães, Morse e Skinner (1958) com pombos e Lansade et al., (2013) com cavalos. A observação de PIT em diferentes espécies sugere que a PIT é um processo básico do comportamento. 
Contudo, a pesquisa de PIT tem focado principalmente nesta transferência como processo comportamental, medindo variáveis como índice discriminativo frequência de respostas, e interpretando a interação entre contingência operante e Pavloviana (Holmes, Marchard \& Couterau, 2010), mas não discute o fenômeno comportamental da transferência em termos de motivação. Como apontado previamente, a autoadministração de drogas é uma questão de escolha (Balleine, 1994; Dickinson \& Dawson;1987) e não unicamente uma resposta emocional, sem controle, evocada por controle de estímulos em organismos. Ainda, o estudo dos substratos neurais tem permitido caracterizar a PIT de acordo aos seus substratos neurais (Corbit \& Balleine, 2005; 2011), os quais são diferentes na transferência seletiva e na transferência generalizada como explicado em seguida.

Diversos estudos apontam o Núcleo Accumbens (Goto \& Grace, 2008), a Área Tegmental Ventral (e.g. Corbit \& Janak, 2007), a Amígdala (e.g. Corbit and Balleine, 2005), e o Córtex Prefrontal (e.g. Ostlund \& Balleine, 2007) como as principais áreas que participam dos processos de PIT seletivo e generalizado.

Estudos do início do século pareciam ser contraditórios em relação às estruturas neurais que estariam implicadas na PIT. Inicialmente, Hall et. al (2001) e Holland e Gallagher (2003) reportam que lesões no NAc core, mas não shell, impedem a PIT, e seu estudo sugere que a Amígdala Central (CeA) e o NAc core, mas não a Amígdala Basolateral (BLA) nem o NAc shell, estão implicados nos processos de PIT. Entretanto, Blundell et al. (2001) e Corbit e Balleine (2001) reportaram que lesões o NAc shell, mas não o core, afeta a PIT, sugerindo de forma contraditória aos outros estudos (Hall et. al, 2001; Holland \& Gallagher, 2003) que o NAc shell cumpre sim um papel dentro dos processos de PIT. Estudos posteriores realizados por Corbit e Balleine $(2005,2011)$ identificaram o paradigma fazendo distinções entre PIT específica e PIT generalizada esclarecem que a primeira é impedida por lesões de BLA e NAc shell e a segunda é impedida por lesões de CeA e NAc core. 
O NAc tem conexões diretas com o Córtex Pré-frontal (PFC). Se esperaria o envolvimento do PFC no PIT dado que regula funções executivas relacionadas com diferentes aspectos de comportamentos de meta dirigida, como uma sequência de respostas que levam a obter um reforçador (Barbey, Krueger \& Grafman, 2009), além de estar associado à memória de trabalho e mediação de associações resposta-consequência (Corbit \& Balleine, 2003a) e à aprendizagem operante CS-CR (Tran-Tu-Yen, Marchand, Pape, Scala, \& Coutureau, 2009). Por este motivo, alguns estudos têm sido realizados para observar as possíveis relações. Ostlund e Balleine (2007) reportam que lesões no Córtex Orbital Frontal (OFC) do PFC impediu PIT seletiva, porém unicamente quando estas lesões foram realizadas post-treino e não quando foram feitas prévio ao treino. O que indicaria, segundo os autores, a função do OFC ventral na PIT seletiva está implicada na aquisição da relação CS-US, mas não a da R-SR . Adicionalmente, lesões completas de OFC ventral e lateral ocasionaram déficits na aparição de PIT específica, o que sugere que na PIT específica as subáreas ventral e lateral do OFC são necessárias para a aquisição do CP. Keistler, Baker e Taylor (2015) reportam que lesões bilaterais do PFC Pré-limbico (PL) impediram a aparição de PIT específico e adicionalmente, ao fazer a desconexão entre o Córtex Infralímbico (IL) e Shell, puderam confirmar que esta via faz parte específica dos circuitos de PIT específico, o que indica a necessidade desta via e das subáreas implicadas para a aprendizagem a aquisição de relações CS-US.

Estudos no Estriado Dorsomedial (DMS) e no Dorsolateral (DLS) mostram que a inativação de estes tem efeitos diferentes na PIT. O estudo de Corbit e Janak (2007) encontrou que a inativação de DSL impediu a apresentação de transferência seletiva, enquanto a inativação de DMS impediu a apresentação de transferência generalizada. Adicionalmente, em um estudo posterior destes autores, a DLS, a DMS anterior ou posterior foram desativadas durante o $\mathrm{CP}$, encontrando que, durante o teste de transferência, a 
inativação de DLS junto com a de DMS posterior podem afetar a aquisição da relação CSUS, enquanto que a inativação de DMS anterior e posterior afetaram a aquisição de associações R-S ${ }^{\mathrm{R}}$ (Corbit \& Janak 2010). Juntos, estes estudos que utilizam lesões para pesquisar as funções e relevância das conexões na PIT, têm aportado importantes dados sobre as áreas e conexões implicadas na aquisição de associações CS-US e R-S , para ajudar a compreensão destes processos de aprendizagem e a sua função na PIT.

Existem vários estudos que indicam que a dopamina (DA) é um neurotransmissores crítico do processo de PIT, pois (1) lesões na substância nigra (SN), que impedem a liberação de dopamina no NAc, reduzem a PIT generalizada (El-Amamy \& Holland, 2007); (2) lesões na VTA, que impedem a liberação de DA no NAc, ocasionam redução tanto de PIT seletiva quanto generalizada (Corbit et al., 2007); (3) a PIT generalizada é potencializado por agonistas de DA (Pecina et al., 2006), é enfraquecida por antagonistas desse neurotransmissor (Dickinson et al., 2000).

Leung e Balleine (2015) e Corbit et al. (2007) relataram que ao interromper a via do Ventral Palladium medial (VP-m) para o VTA se reduze a taxa de respostas da PIT específica. Os últimos autores argumentam que seus resultados sugerem que o VTA medeia o “componente motivacional” (taxa global de respostas) da PIT e que o Tálamo Mediodorsal (MD) media o "componente cognitivo" (o efeito da aprendizagem preditiva na escolha).

Em resumo, os resultados destes estudos reportam estruturas implicadas no processo de PIT, as quais ao serem lesionadas podem alterar ou impedir o surgimento da transferência, dada a sua função na aprendizagem operante e/ou pavloviana. Adicionalmente, como apresentado na seção anterior, a autoadministração (na contingência operante) e a administração passiva (na contingência Pavloviana) de uma droga podem induzir de forma diferencial a expressão gênica de $\Delta \mathrm{FosB}$, o qual tem sido reportado por ser um importante 
mecanismo biomolecular nos estudos de dependência às drogas, reportado pela a relação direta que tem a sua expressão em áreas como o NAc e o aumento na resposta de autoadministração de uma droga (Olsen, 2011; Robinson \& Nestler, 2011; Ruffle, 2014). Ainda, existe uma importante discussão sobre o controle que os estímulos associados às drogas por contingência operante e contingência Pavloviana adquirem durante a aprendizagem, originando a incógnita se realmente é um destes tipos de contingência seria a chave para que um organismo desenvolva dependência às drogas.

Existe uma lacuna na literatura que permita tentar responder esta pergunta, pois além dos estudos aqui mencionados, existem poucos estudos que estudem o controle de estímulos que considerem fatores comportamentais e bioquímicos diretamente relacionados na dependência às drogas, como o treino ou associação de drogas em contingência operante e Pavloviana utilizando um esquema acoplado, e a medição da expressão génica de IEGs usando procedimentos de administração passiva e autoadministração. Ainda, a maioria destes usam apenas COC como droga de estudo, impossibilitando a comparação com outras drogas de abuso para determinar aspectos gerais na dependência às drogas.

No presente estudo, propõe-se a morfina e a COC como as drogas a serem estudadas na administração em contingência operante e Pavloviana, dadas as características que são mencionadas a seguir.

\section{Morfina e Cocaína como Drogas de Abuso em Estudos de Dependência}

A morfina é um agonista dos receptores opióides e faz parte da família dos opióides ${ }^{7}$, os analgésicos mais utilizados e eficazes para o tratamento da dor e transtornos afins (Dacher et al., 2011), sendo amplamente utilizada no âmbito hospitalar. Contudo, também possui

\footnotetext{
${ }^{7}$ Opióides são substâncias de origem endógena ou sintética, referindo-se de forma ampla a todos os compostos relacionados ao ópio.
} 
grande potencial para produzir dependência (Christie, 2008; De Vries \& Shippenberg, 2002), caracterizada pelo seu uso indiscriminado, recaída e busca compulsiva ou fissura (Everitt \& Robbins, 2005; Robinson \& Berridge,1993). Junto a outros opióides, como o ópio e a heroína, a morfina é autoadministrada por humanos (Comer et al., 2012) e animais não humanos, como ratos (Alexander, Coambs, \& Hadaway, 1978; Cicero, Aylward, \& Meyer 2003; Silva \& Heyman, 2001), camundongos (Criswell \& Ridings, 1983) e primatas não humanos (Sanchez-Ramos \& Schuster, 1977).

Diferentes efeitos comportamentais podem ser observados quando a morfina é usada como reforçador, dependendo tanto da dose administrada como do tipo de condicionamento. Koob (1992) relatou uma função hiperbólica (parabólica), na relação dose-resposta gerada por esquemas de FR (fixed ratio) baixos, indicando que pouco se pode observar do efeito da morfina sobre o comportamento quando altas doses são usadas, dado seu efeito sedativo. Por outro lado, Goldberg e Tang (1977) reportaram uma função linear na relação dose-resposta quando o esquema utilizado foi de segunda ordem ${ }^{8}$.

Existe uma extensa literatura que demonstra que os efeitos incondicionados da morfina são facilmente condicionados a estímulos presentes no ambiente (e.g., McDonald, \& Siegel, 2004; Siegel, 1988, 2001). Por exemplo, o efeito analgésico da morfina pode ser induzido pela presença de um estímulo condicionado (CS) quando associada previamente a este em um procedimento Pavloviano (Siegel, 1976; Siegel, Hinson, \& Krank, 1978), mesmo depois de um período de abstinência (Hinson, Poulos, Thomas, \& Cappell, 1986). Tolerância condicionada a diferentes efeitos produzidos pela morfina são adquiridos após alguns dias de

\footnotetext{
${ }^{8}$ Um esquema de segunda ordem consiste basicamente em um esquema composto. Neste, uma sequência de respostas é requerida em um primeiro esquema para apresentar um estímulo condicionado (de um pareamento prévio entre este e um reforçador). Após completar este primeiro esquema múltiplas vezes, como segundo esquema, a consequência é a apresentação do reforçador.
} 
administração. Esta tolerância condicionada está ligada aos estímulos ambientais e é observada de várias formas, como overdose em ratos ao receber uma dose alta, a qual foi administrada por vários dias, em um ambiente diferente ao usual, ou como hiperalgesia em ratos que são administrados com um placebo no mesmo ambiente no qual foram administrados com morfina repetidas vezes (Siegel et al, 1978; Siegel, 1976, 1988, 2001, 2005). Quando a morfina é administrada repetidamente em um ambiente determinado, observa-se sensibilização condicionada ao efeito ativador psicomotor (Badiani, Oates, \& Robinson, 2000) e preferência condicionada de lugar (PCL) marcada (Reid, Marglin, Mattie, \& Hubbell, 1989).

A cocaína (COC) é um forte estimulante que atua como inibidor da recaptação de serotonina, norepinefrina e dopamina, motivo pelo qual é utilizada principalmente com fins recreativos (Pomara et al. 2012). Entre seus efeitos psicoativos se tem reportado a perda do contato com a realidade, intenso sentimento de felicidade, euforia e agitação (Zimmerman, 2012). A COC também possui algumas aplicações médicas, para produzir adormecimento e reduzir o sangramento durante cirurgias de condutos lacrimais e nasais (Harper \& Jones, 2006), porem sendo pouco utilizada com estas finalidades ao ser facilmente substituível por anestésicos de uso local que não causam os efeitos secundários que esta produz, como toxicidade cardiovascular e glaucoma (Dwyer, Sowerby, Rotenberg, 2016).

Esta droga tem sido reportada como reforçadora, sendo autoadministrada por humanos (Childress, McLellan, Ehrman, \& O’Brien, 1987, 1988; Ehrman, Robbins, Childress, \& O’Brien, 1992) e por animais de laboratório (Goldberg \& Gardner 1981; Goldberg, Spealman, \& Kelleher, 1979; Koob 1992; Mierzejewski, Koroś, Goldberg, Kostowski, \& Stefański, 2003). Esta autoadministração é caracterizada por ser mantida por altas taxas de resposta e por depender de apresentações de CSs associados à COC em contingência operante ou Pavloviana (Goldberg et al. 1979; Katz 1979; Weissenborn, 
Robbins \& Everitt, 1997). Existe um grande número de estudos na literatura que reporta que estímulos ambientais podem adquirir controle sobre comportamentos reforçados por COC quando associados previamente a esta (e.g. Childress et al., 1988; Ehrman, et al, 1992; Goldberg, Spealman, \& Kelleher, 1979; Weiss, et. al., 2003; Kruzich, Congelton, \& See, 2001).

As propriedades que a COC possui como reforçador são atribuídas a seus efeitos nos sistemas dopaminérgicos mesolímbicos, ao qual é atribuído o “centro do prazer”, ou em outras palavras, o sistema do reforço (Pomara et al. 2012; Wise, 1996). Seus efeitos reforçadores são caracterizados a nível neural pela capacidade que a COC tem para se unir a transportadores de dopamina (Ritz et al., 1988; Rocha et al., 1998), serotonina (Uhl et al., 2002), e também pelo seu envolvimento no sistema glutamatérgico (Kalivas, 2004).

Em resumo, os efeitos da morfina e da COC sobre o comportamento estão bem caracterizados pela literatura e os seus atributos como reforçador estão bem estabelecidos e documentados, portanto, reproduzíveis. Estas características fazem da morfina e da COC drogas de abuso ideais para estudar o abuso e dependência de drogas, sendo de grande relevância. O uso hospitalar de morfina e outros opioides representam o grande desafio científico de manter as suas potentes propriedades analgésicas, limitando o desenvolvimento de tolerância e dependência a estas. Adicionalmente, o abuso de opioides, assim como de COC e seus derivados, traz uma grande preocupação na área da saúde.

\section{Objetivos}

O presente trabalho tem como objetivos verificar: i) o efeito da contingência operante e Pavloviana de morfina e COC sobre a expressão gênica de $\Delta \mathrm{FosB}$; e ii) o efeito da contingência operante e Pavloviana de morfina e COC sobre as respostas de busca e autoadministração destas drogas. Para atingir os objetivos mencionados foram realizados três 
experimentos comparando a contingência operante e a Pavloviana de morfina ou COC, utilizando o modelo de administração acoplado. O primeiro experimento pretendendo observar e medir a expressão de $\Delta \mathrm{FosB}$ (o qual se acredita estar associado ao aumento do valor reforçador de drogas de abuso e, com isso, ao processo que conduz à dependência) induzida pela contingência Pavloviana e a contingência operante de morfina em diferentes áreas do cérebro implicadas na dependência às drogas. O segundo experimento pretendeu observar e avaliar o controle de estímulos nas respostas de busca e autoadministração de morfina na presença de um estímulo associado à droga por meio de contingência operante ou Pavloviana. O Experimento 3 pretendeu avaliar tanto a expressão de $\Delta$ FosB induzida pela contingência Pavloviana e a contingência operante de COC em diferentes áreas do cérebro implicadas na dependência às drogas, quanto o controle de estímulos nas respostas de busca e autoadministração de COC na presença de um estímulo associado à droga por meio de contingência operante ou Pavloviana.

\section{Justificativa Geral}

Os experimentos propostos no presente estudo têm como finalidade tentar resolver a incógnita referente à dependência que pode causar ou não a administração repetida de uma droga sob contingência operante ou Pavloviana, pois como exposto anteriormente, as contingências envolvidas nestes dois tipos de administração poderiam ser a chave para compreender os mecanismos relacionados à dependência às drogas. Adicionalmente, a literatura anteriormente descrita mostra que sujeitos que autoadministram ativamente uma droga de ação central (em CO) apresentaram diferenças gênicas e comportamentais (relacionadas à dependência às drogas), comparados com sujeitos que receberam a mesma droga passivamente (em CP). Foram encontradas na literatura unicamente publicações usando drogas como COC, ANF e álcool para estudar diferenças gênicas e comportamentais 
entre contingência operante e Pavloviana, mas nenhuma reportando o uso de morfina, sendo os dados produzidos pelo presente estudo totalmente inovadores no estudo da dependência do medicamento anestésico de maior uso hospitalar no mundo.

O presente estudo ainda consolida uma linha nova de pesquisa no Laboratório de Psicofarmacologia da Universidade de São Paulo e forma parcerias entre três laboratórios de pesquisa das áreas de Neurociências e Análise do Comportamento. Os experimentos 1 e 2 foram realizados com a coorientação do Prof. Luciano F. Felício (Faculdade de Medicina Veterinária e Zootecnia da USP) e a colaboração do Prof. Newton Canteras (Instituto de Ciências Biomédicas da USP). O experimento 3 foi realizado sob a supervisão e tutoria do professor Emilio Ambrósio, no Laboratório de Psicobiologia da Dependência da Universidad Nacional de Educación a Distáncia (UNED), em Madri, Espanha.

\section{Método Geral e Equipamentos}

\section{Compromisso Ético}

O presente estudo foi desenvolvido na sua totalidade com a prévia aprovação de comités de ética. Os experimentos 1 e 2, executados na USP, Institutos de Psicologia e Ciências Biomédicas do campus de São Paulo, foram aprovados pelo Comitê de Pesquisa em Uso de Animais (CEUA, protocolo 2014/014). Os experimentos 3 e 4, executados na UNED, Faculdade de Psicobiologia de Madri, foram aprovados pelo Comitê Europeio de ética e pesquisa em animais (86/609/EEC Directive).

\section{Animais}

Foram utilizados na totalidade 120 ratos machos da cepa Wistar, provenientes do Biotério de Produção de Ratos do Instituto de Ciências Biomédicas da USP, para os experimentos 1 e 2 realizados na USP; e 72 ratos machos da cepa Lewis, provenientes de Charles River Laboratories, França, para o experimento 3, realizado na UNED. Os 
procedimentos experimentais foram iniciados após um período mínimo de adaptação de duas semanas ao laboratório e após de ter atingido 280-300gr de peso.

\section{Alojamento}

Todos os sujeitos foram alojados e manipulados de acordo com as normas dos comités de ética que aprovaram os estudos. Os sujeitos foram alojados em gaiolas-viveiro individuais de policarbonato transparente (Euroestandard tipo II, 267 x 207 x $140 \mathrm{~mm}$ ) com grade superior para a alimentação. Estas gaiolas-viveiro foram alocadas em estante ventilada (Alesco) especial para manutenção de animais de laboratórios, isolada acusticamente, com controle interno de temperatura, ciclo de $12 \mathrm{~h}$ claro e $12 \mathrm{~h}$ escuro (luzes ligadas às 07:00 h) e com acesso ad libitum à água e comida durante todas as fases.

\section{Procedimento Cirúrgico}

Antes do início dos procedimentos comportamentais, os sujeitos dos experimentos $1 \mathrm{e}$ 2 foram anestesiados com uma injeção intraperitoneal de mescla de cetamina SYNTEC ${ }^{\circledR}$ (75 $\mathrm{mg} / \mathrm{kg}$ ) e xilazina SYNTEC ${ }^{\circledR}(9 \mathrm{mg} / \mathrm{kg})$. Os sujeitos dos Experimentos 3 e 4 foram anestesiados por meio de um sistema de vaporização de descarte de gás passivo (Harvard Apparatus $\left.^{\circledR}\right)$, utilizando isoflurano $(0,8 \mathrm{lpm})$ e oxigênio. Um cateter esterilizado de Dow Corning SILASTIC ${ }^{\circledR}$ (I.D. 0.020 x O.D. 0.037 in., wall 0.010 in.) foi introduzido na veia jugular direita de cada animal. A parte distal do cateter foi passada sob a pele da região cervical anterior até a região cervical posterior, e exteriorizada utilizando um botão de acesso bascular Instech Labs ${ }^{\mathrm{TM}}$ (VAB95BS). Na finalização do procedimento, os animais receberam uma dose única de pentabiótico Pequeno Porte ${ }^{\circledR}$ (benzilpenicilina benzatina, benzilpenicilina procaína, benzilpenicilina potássica, sulfato de diidroestreptomicina e sulfato de estreptomicina base, Fort Dodge, Brasil, em dose $1 \mathrm{ml} / \mathrm{kg}$ ) por via intramuscular, e uma dose de Banamine $^{\circledR}$ (Flunixina meglumina, Schering-Plough, em dose de $2,5 \mathrm{mg} / \mathrm{kg}$ ) por via subcutânea. 
Todos os locais de incisão foram desinfetados com uma solução de iodo antes e após o procedimento cirúrgico. Vinte e quatro horas após a cirurgia, e diariamente durante o transcurso do experimento (antes de depois de cada sessão experimental), os cateteres foram lavados com uma mistura de $0,1 \mathrm{ml}$ de solução de heparina $\mathrm{Hemofol}^{\circledR}$ (500 UI) e salina bacteriostática a $0,9 \%$, posteriormente com $0,1 \mathrm{ml}$ salina bacteriostática a $0,9 \%$, e finalmente preenchidos com $0,1 \mathrm{ml}$ de solução de sulfato de gentamicina Gentomicin Syntec ${ }^{\circledR}$ (120 $\mu \mathrm{g} / \mathrm{ml})$.

\section{Equipamento}

Foram usadas caixas de condicionamento operante de fabricação Med Associates ${ }^{\circledR}$, de dimensões $32 \times 25 \times 21 \mathrm{~cm}$, isoladas acusticamente. As caixas dispunham de um orifício circular de $2 \mathrm{~cm}$ de diâmetro no centro do teto para permitir a passagem da cânula que transporta a droga através deste. Todas as caixas foram inseridas em cubículos individuais e fechados, com ventilação interna e ruído branco para melhor isolamento de sons externos (Fig. 1). A infusão de droga foi realizada através de um sistema de injeção instalado na parte externa de cada caixa experimental. Esse sistema consistiu em um suporte giratório conectado por um extremo a uma bomba de infusão (modelo Med Associates PHM-100-3.33 para os Experimentos 1 e 2 e modelo Harvard 22 para o Experimento 3), e por outro, conectado ao cateter colocado cirurgicamente no animal. 


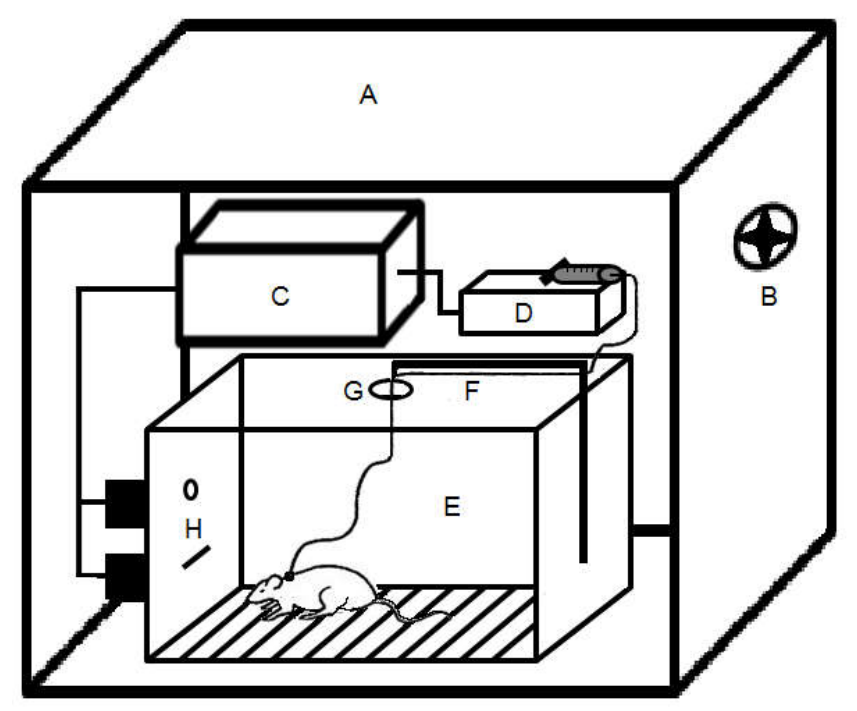

Figura 1 - Esquema da caixa operante. A figura mostra uma esquematização da distribuição do sistema de infusão integrado com a caixa operante e os seus componentes. A. Caixa de isolamento acústico. B. Exaustor. C. Caixa controladora. D. Bomba de infusão. E. Caixa operante. F. Suporte giratório. G. Teto de acrílico com orifício central. H. Parede com operandos e estímulos luminosos e sonoros.

No experimento 1 as caixas equipadas com uma barra retrátil (ENV-112CM MED's

Response Devices) situada no centro da parede direita (a $4 \mathrm{~cm}$ de altura da grade) e uma

lâmpada branca de $1 \mathrm{~W}$ (colocado $7 \mathrm{~cm}$ acima da barra). Para as fases 1 e 2 do Experimento

2, cada caixa foi equipada com uma roda operante (ENV-113M MED's Response Devices), situado no centro da parede direita (a $4 \mathrm{~cm}$ da grade. As caixas também tiveram duas lâmpadas de 1 W (uma verde e uma branca) colocadas nos cantos superiores (ENV-221M MED's Stimulus), esquerdo e direito respetivamente, $7 \mathrm{~cm}$ acima do sensor infravermelho. Adicionalmente foi utilizado um tom de 1,5 kHz (aproximadamente $76 \mathrm{~dB}$ ). Para as fases restantes, a roda operante foi removida e duas barras retráteis foram colocadas embaixo de cada lâmpada ( $4 \mathrm{~cm}$ acima da grade e $7 \mathrm{~cm}$ embaixo das lâmpadas), uma em cada canto inferior (Fig. 2). O funcionamento das caixas, da bomba de infusão e o registro das respostas foram feitos através de um computador $I B M-P C$, com programas e interface da $M e d$ Associates. 




Figura 2 - Esquema da disposição das luzes estímulo, buzzer e dos operandos nas caixas operantes dos experimentos. A figura mostra uma visão frontal esquemática da parede interior direita das caixas operantes. No Experimento 1, o estímulo luminoso S1 (luz branca) foi colocado em cima da barra retrátil, ambos na parte central da parede direita da caixa operante.

No experimento 2, em todas as fases, os estímulos luminosos S1 (luz verde) e S2 (luz branca) foram colocados nos cantos superiores esquerdo e direito (respeitivamente) da parede direita da caixa operante. Nas Fases 1 e 2, a roda operante foi localizada na parte central da caixa, e durante as Fases 3 e 4, esta foi substituído por duas barras retráteis situadas embaixo das luzes branca e verde. No Experimento 3 o S1 foi um clicker (ENV-135M MED's Stimulus) localizado na parte central exterior da parede dos operandos e o S2 foi o som produzido por um buzzer $(2,5 \mathrm{kHz})$, situado na mesma localização.

\section{Drogas}

Para os Experimentos 1 e 2, foi utilizado sulfato de morfina (Laboratório Cristália ${ }^{\mathrm{TM}}$, São Paulo, Brasil) foi dissolvida em veículo salina $(0,9 \% \mathrm{NaCl})$ para ser administrado por via i.v. em volume de $3,33 \mathrm{mg} / \mathrm{ml}$ na dose de $0,75 \mathrm{mg} / \mathrm{kg}$. A velocidade de infusão foi de $0,1 \mathrm{ml}$ de solução a cada 3s. Para o experimento 3 foi utilizado cloridrato de cocaína (Agencia Española de Medicamentos y Productos Sanitarios, AEMPS) dissolvida em veículo salina 
$(0,9 \% \mathrm{NaCl})$ para ser administrado por via i.v. em volume de $3,33 \mathrm{mg} / \mathrm{ml}$ na dose de 0,75 $\mathrm{mg} / \mathrm{kg}$. A velocidade de infusão foi aproximadamente de $0,1 \mathrm{ml}$ de solução a cada s, sendo ajustada para cada sujeito individualmente em função do seu peso.

\section{Protocolo Imuno-histoquímico para $\Delta \mathrm{Fos}$}

Uma hora após o término da última sessão de administração da droga, os ratos foram anestesiados com uma injeção intraperitoneal de hidrato de cloral $0,2 \%$ na proporção 0,4 $\mathrm{ml} / 100 \mathrm{~g}$ de peso corpóreo. Em seguida, através de uma bomba peristáltica (Cole Parmer ${ }^{\circledR}$ ) foram perfundidos por via transaórtica inicialmente com $150 \mathrm{ml}$ de uma solução salina $0,9 \%$, seguida de $500 \mathrm{ml}$ de uma solução fixadora de paraformaldeído a 4\% diluído em tampão fosfato de sódio $0,1 \mathrm{M}(\mathrm{pH} 7,4)$. Os cérebros permaneceram na caixa craniana por $3 \mathrm{~h}$ antes de serem removidos e transferidos para uma solução contendo sacarose $20 \%$ em tampão fosfato de potássio, onde permaneceram por aproximadamente $12 \mathrm{~h}$. Em seguida, cortes frontais seriados $(30 \mu \mathrm{m})$ foram obtidos utilizando-se um micrótomo de congelamento. Os cortes foram colhidos sequencialmente em 5 compartimentos, de forma que a distância entre os cortes num mesmo compartimento seja $200 \mu \mathrm{m}$. Um compartimento foi usado para deteç̧ão imuno-histoquímica de $\Delta$ FosB. Os cortes foram incubados inicialmente em uma solução de tampão fosfato de potássio $0,02 \mathrm{M}$ contendo triton $\mathrm{X}-100$ a $0,3 \%$, soro normal de cabra a $2 \%$ e anticorpo policlonal $\Delta$ FosB, $\left(102\right.$, SC-48/Sta Cruz Biothecnology $\left.{ }^{\circledR}\right)$ numa diluição de 1:20.000.

O complexo antígeno anticorpo foi localizado utilizando-se uma variação do sistema formado pelo complexo avidinabiotina (ABC) (Hsu \& Raine, 1981). Após a incubação com o anticorpo primário, os cortes foram incubados em uma solução contendo anticorpo biotinilado anti-IgG de coelho, feito em cabra (Ctrector Laboratories $\left.{ }^{\circledR}\right)$, numa diluição de 1:200, em temperatura ambiente, por 1 hora e 30 minutos e em seguida, colocados em uma 
solução contendo o composto avidina-biotina-HRP (ABC Elite Kit, Vector Laboratories $\left.{ }^{\circledR}\right)$ numa diluição de 1:200, por 1 hora e 30 minutos, para ligar a peroxidase ao complexo antígeno-anticorpo. Na reação da imunoperoxidase, para a revelação do complexo antígenoanticorpo foi utilizado o protocolo de Itoh, Konishi, Nomura, Mizuno, Nakamura, e Suguimoto (1979). Resumidamente, os cortes foram incubados em uma solução contendo 50mg de tetrahidrocloreto de 3-3' diaminobenzidina-DAB, 0,6mg de glicose oxidase (Sigma), $2 \mathrm{ml}$ de uma solução aquosa de sulfato de níquel a 10\% e 40mg de cloreto de amônia em $100 \mathrm{ml}$ de tampão fosfato de sódio $0,1 \mathrm{M}$, por 5 minutos. Em seguida, foi adicionado $\beta$-Dglicose (Sigma), e a reação foi interrompida após 15 min aproximadamente. Os cortes foram então montados em lâminas recobertas com gelatina, desidratados e recobertos com DPX (Aldrich Chemical Co. ${ }^{\circledR}$ ). 


\section{Experimento 1. Expressão do IEG $\Delta$ FosB na Administração de Morfina em Contingências Operante e Pavloviana}

O objetivo do Experimento 1 foi verificar o efeito da $\mathrm{CO}$ e $\mathrm{CP}$ de morfina sobre a expressão gênica de $\Delta \mathrm{FosB}$ em diferentes áreas do cérebro implicadas na dependência às drogas, destacando o efeito diferencial entre as duas formas de administração.

\section{Sujeitos}

Foram usados 19 ratos albinos machos da cepa Wistar, experimentalmente ingênuos. As cirurgias foram realizadas quando os sujeitos atingiram $280 \mathrm{~g}-300 \mathrm{~g}$ de peso. Sete dias após a recuperação da cirurgia, os animais foram distribuídos aleatoriamente em três grupos: Administração por Contingência Operante $(\mathrm{ACO}, \mathrm{n}=7)$, Administração por Contingência Pavloviana (ACP, $n=7)$ e Controle $(\mathrm{Ctrl}, \mathrm{n}=5)$, formando trios com um sujeito de cada grupo.

\section{Fases Experimentais}

\section{Fase 1. Administração de Morfina em Esquema Acoplado}

Os sujeitos do grupo CO foram expostos a uma contingência operante em esquema CRF (continous reinforcement) de pressão à barra para obter uma infusão i.v. de morfina. Cada vez que um sujeito do grupo $\mathrm{CO}$ recebeu uma dose de morfina, o sujeito do grupo $\mathrm{CP}$ e o do grupo Ctrl a ele acoplados receberam sob contingência Pavloviana uma injeção i.v da droga na mesma dose ou de veículo $(1,0 \mathrm{ml} / \mathrm{kg})$, respectivamente. Cada infusão foi sinalizada pela apresentação simultânea de uma luz estímulo branca $(1 \mathrm{~W})$ por 10s nas caixas correspondentes ao trio, sendo sequenciada por um time out (TO) de 1 min, no qual a barra retrátil não esteve disponível. Sessões diárias consecutivas foram realizadas durante três semanas. Cada sessão teve duração máxima de $2 \mathrm{~h}$ programadas, mas podia terminar antecipadamente para um trio se o membro do grupo $\mathrm{CO}$ atingisse 20 infusões naquela sessão. 


\section{Fase 2. Imunohistoquímica $\Delta$ Fos}

O procedimento é explicado com detalhe na secção de Métodos e Equipamentos do presente trabalho. Em resumo, uma hora após o término da última sessão de administração da droga, os sujeitos foram perfundidos para fixar os tecidos. Os cérebros foran removidos e posteriormente processados para obter cortes frontais seriados, com $30 \mu \mathrm{m}$ de espessura usando um micrótomo de congelação. Os cortes foram incubados inicialmente em uma solução de tampão fosfato de potássio $0,02 \mathrm{M}$ contendo triton $\mathrm{X}-100$ a $0,3 \%$, soro normal de cabra a $2 \%$ e anticorpo policlonal $\Delta$ FosB, $\left(102\right.$, SC-48/Sta Cruz Biothecnology $\left.{ }^{\circledR}\right)$. O complexo antígeno-anticorpo foi localizado utilizando-se uma variação do sistema formado pelo complexo avidina-biotina, e após a incubação com o anticorpo primário, os cortes foram incubados em uma solução contendo anticorpo biotinilado anti-IgG de coelho, feito em cabra, e em seguida, colocados em uma solução contendo o composto avidina-biotina-HRP, para ligar a peroxidase ao complexo antígeno-anticorpo. Posteriormente se realizou a revelação do complexo antígeno-anticorpo incubando os cortes em uma solução contendo 50mg de tetrahidrocloreto de 3-3' diaminobenzidina-DAB, 0,6mg de glicose oxidase (Sigma), $2 \mathrm{ml}$ de uma solução aquosa de sulfato de níquel a 10\% e 40mg de cloreto de amônia em 100ml de tampão fosfato de sódio $0,1 \mathrm{M}$, e em seguida, foi adicionado $\beta$-D-glicose, interrompendo a reacão após 10 min aproximadamente. Os cortes foram então montados em lâminas recobertas com gelatina para poder obter as imagens de microscopia que foram analizadas.

Para analisar o material, foi realizada inicialmente uma avaliação semiquantitativa da expressão das proteínas $\Delta \mathrm{FosB}$ no NAc (core e shell), regiões do sistema nervoso central nas quais estas proteínas se expressaram de forma diferencial para $\mathrm{CO}$ e $\mathrm{CP}$ em um estudo piloto prévio. Posteriormente foi realizada a contagem de células imunorreativas à proteína $\Delta$ FosB

para as áreas neurais de maior interesse (ver Tabela 1) utilizando o software Image Pro Plus ${ }^{\circledR}$. 
Tabela 1. Áreas Neurais Estudadas no Experimento 1

\begin{tabular}{llll}
\hline \multicolumn{1}{c}{ ÁREA } & \multicolumn{2}{c}{ SUBÁREA } \\
\hline Córtex Pre-Frontal Medial (mPFC) & Córtex Cingulado (Cg1) & Córtex Prelímbico (PrL) & Córtex Infralímbico (IL) \\
Nucleo Acumbente $(\mathrm{NAc})$ & Core & Shell & \\
Caudado Putamen $(\mathrm{CPu})$ & Lateral & Basolateral & \\
Hippocampo & Giro Dentado (DG) & Corno de Amon 1 (CA1) & Corno de Amon 3 (CA3) \\
Amígdala & Basolateral & Central & Medial \\
\hline
\end{tabular}

\section{Análise de dados}

A diferença de expressão de $\Delta \mathrm{FosB}$ das diferentes subáreas entre grupos foi calculada realizando testes não paramétricos para amostras independentes. O teste de Kruskall-Wallis foi realizado para detectar diferenças estatísticas, e quando achadas estas $(p<0,05)$, o teste $\mathrm{U}$ de Mann-Whitney com fator de correção Bonferroni foi utilizado como post hoc. Todas as análises estatísticas foram executadas fazendo uso do software aplicativo IBM SPSS ${ }^{\circledR}$.

\section{Resultados}

Durante a única fase do Experimento 1, a Fase 1 (Administração de Morfina em Esquema Acoplado), os sujeitos dos três grupos foram expostos a um arranjo experimental no qual cada vez que um sujeito do grupo CO tinha como consequência do seu responder uma dose de morfina, o sujeito do grupo $\mathrm{CP}$ e o do grupo Ctr a ele acoplados receberam sob contingência Pavloviana uma injeção i.v da droga na mesma dose ou de veículo (1,0 ml/kg), respectivamente. A média de infusões $(M=5,617, S D=1,093)$ esteve dentro do esperado segundo o que se reporta para estudos de autoadministração de morfina (Mierzejewski et al, 2003; Suto, Wise, \& Vezina, 2011). 




Figura 3 - Média de infusões durante a Fase 1 do Experimento 1. O gráfico mostra a frequência da média de infusões de morfina dos sujeitos integrantes dos grupos $\mathrm{CO}, \mathrm{CP}$ e $\mathrm{Ctr}$ durante as últimas seis sessões da Fase 1.

Após as sessões de administração de morfina, os sujeitos foram perfundidos e as amostras de tecido foram processadas para imunohistoquímica de $\Delta$ FosB. Em seguida são mencionados os resultados das comparações das médias do número de células imunorreativas a $\triangle$ FosB no mPFC utilizando o teste Kruskall-Wallis, região por região, junto com gráficos que ilustram as diferenças entre grupos.

Como pode ser observado na Figura 4, a análise estatística revelou diferenças significativas entre grupos em todas as subáreas estudadas do mPFC. Diferenças entre grupos para Cg1 (Kruskall-Wallis test $\mathrm{H}(2, \mathrm{~N}=19)=7,144 p=0,028)$, com uma mediana de 103,80 para o grupo CO, 94,28 para o CP e 110,20 para o Ctr, e o teste pós-hoc Mann-Whitney com correção de Bonferroni mostrou resultados significativos de CP x $\operatorname{Ctr}(p=0,030)$. Diferenças entre grupos para PrL (Kruskall-Wallis test: $\mathrm{H}(2, \mathrm{~N}=19)=7,337 p=0,026)$, com uma mediana de 11,93 para o grupo CO, 102,93 para o CP e 107,61 para o Ctr, e o teste pós-hoc Mann-Whitney com correção de Bonferroni mostrou resultados significativos de $\mathrm{CO}$ x CP ( $p$ $=0,020)$. Adicionalmente, foram achadas diferenças estatisticamente significativas entre grupos para IL (Kruskall-Wallis test: $\mathrm{H}(2, \mathrm{~N}=19)=10,694 p=0,005)$, com uma mediana de 
126,78 para o grupo CO, 112,97 para o CP e 99,94 para o Ctr, e o teste pós-hoc MannWhitney com correção de Bonferroni mostrou resultados significativos de $\mathrm{CO} \times \operatorname{Ctr}(p$ $=0,003)$.



Figura 4 - Marcação de células imunorreativas a $\triangle \mathrm{FosB}$ no mPFC. O gráfico mostra a mediana (-P25 e $+\mathrm{P} 75)$ de células imunorreativas a $\triangle \mathrm{FosB}$ para os grupos $\mathrm{CO}, \mathrm{CP}$ e Ctr nas subáreas do $\mathrm{mPFC}(\mathrm{Cg} 1$, PrL e IL) no Experimento 1. * $\mathrm{p}<0,05 * * \mathrm{p}<0,01$ para pós-hoc Mann-Whitney com correção Bonferroni.

$\mathrm{Na}$ Figura 5 se pode observar que existem diferenças estatisticamente significativas entre grupos em ambas as subáreas do NAc. A análise estatística comparando as médias do número de células imunorreativas a $\Delta \mathrm{FosB}$ diferenças estatisticamente significativas entre grupos para NAc Core (Kruskall-Wallis test: $\mathrm{H}(2, \mathrm{~N}=19)=15,068 p=0,001)$, com uma mediana de 374,78 para o grupo CO, 306,96 para o CP e 135,17 para o Ctr, e o teste pós-hoc Mann-Whitney com correção de Bonferroni mostrou resultados significativos de CO x CP ( $p$ $=0,006), \mathrm{CO} \times \operatorname{Ctr}(p=0,007)$ e CP x Ctr $(p=0,007)$. Para NAc Shell, foram encontradas diferenças estatisticamente significativas entre grupos (Kruskall-Wallis test: $\mathrm{H}(2, \mathrm{~N}=19)$ $=13,126 p=0,001$ ), com uma mediana de 171,79 para o grupo $\mathrm{CO}, 202,28$ para o $\mathrm{CP}$ e 124,43 para o Ctr, e o teste pós-hoc Mann-Whitney com correção de Bonferroni mostrou resultados significativos de CO x CP $(p=0,033)$ e $\operatorname{Co} \times \operatorname{Ctr}(p=0,030)$ e $\mathrm{CP} \times \operatorname{Ctr}(p=0,007)$. 




Figura 5 - Marcação de células imunorreativas a $\triangle$ FosB no NAc. A figura mostra a mediana (-25P e $+\mathrm{P} 75$ ) de células imunorreativas a $\triangle \mathrm{FosB}$ para os grupos $\mathrm{CO}, \mathrm{CP}$ e Ctr nas subáreas do NAc (Core e Shell) no Experimento 1. Krusskal-Wallis mediana $* \mathrm{p}<0,05 * * \mathrm{p}<0,01$.

A Figura 6 mostra um exemplo das marcações de $\Delta$ FosB realizadas, ilustrando à esquerda um sujeito do grupo $\mathrm{CO}$ e à direita um do $\mathrm{CP}$.



Figura 6 - Imagem microscópica da marcação de células imunorreativas a $\Delta$ FosB no NAc. A imagem mostra em uma escala de aumento $4 \mathrm{X}$, o número de células imunorreativas a $\triangle \mathrm{FosB}$ por $\mathrm{mm}^{2}$ no $\mathrm{CPu}$ Core e Shell em sujeitos dos grupos CO (à esquerda) e CP (à direita) no Experimento 1.

$\mathrm{A}$ análise estatística comparativa nas subáreas do $\mathrm{CPu}$ revelaram que existem

diferenças significativas entre grupos tanto no $\mathrm{CPu}$ Lateral, como no $\mathrm{CPu}$ Medial, como pode ser observado na Figura 7. Diferenças entre grupos para CPu Lateral (Kruskall-Wallis test: H $(2, \mathrm{~N}=19)=11,314 p=0,003)$, com uma mediana de 100,33 para o grupo $\mathrm{CO}, 105,89$ para o 
CP e 41,58 para o Ctr, e o teste pós-hoc Mann-Whitney com correção de Bonferroni mostrou resultados significativos de $\mathrm{CO} \times \mathrm{Ctr}(p=0,007)$ e $\mathrm{CP} \times \mathrm{Ctr}(p=0,007)$. Para CPu Medial, foram encontradas diferenças estatisticamente significativas entre grupos (Kruskall-Wallis test: $\mathrm{H}(2, \mathrm{~N}=19)=10,773 p=0,005)$, com uma mediana de 114,56 para o grupo $\mathrm{CO}, 112,99$ para o CP e 58,09 para o Ctr, e o teste pós-hoc Mann-Whitney com correção de Bonferroni mostrou resultados significativos de $\mathrm{CO} \times \mathrm{Ctr}(p=0,007)$ e $\mathrm{CP} \times \mathrm{Ctr}(p=0,007)$.

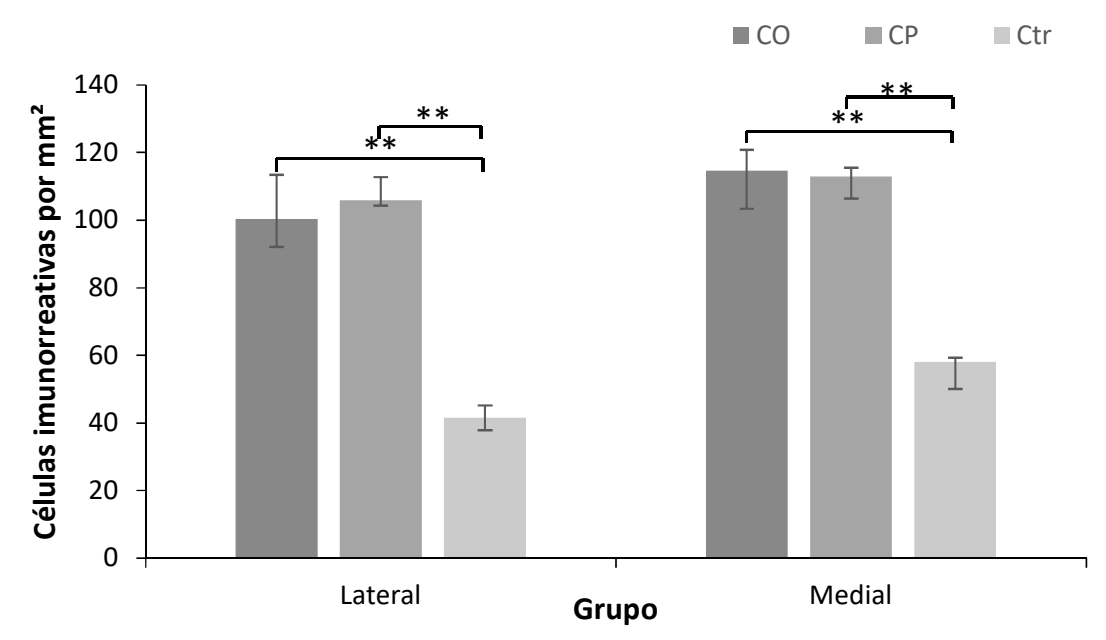

Figura 7 - Marcação de células imunorreativas a $\triangle \mathrm{FosB}$ no Caudado Putamen $(\mathrm{CPu})$. O gráfico mostra a mediana (-P25 e +P75) de células imunorreativas a $\triangle \mathrm{FosB}$ para os grupos $\mathrm{CO}, \mathrm{CP}$ e Ctr nas subáreas do $\mathrm{CPu}$ (Lateral e Medial), no Experimento 1. * $\mathrm{p}<0,05 * * \mathrm{p}<0,01$ para pós-hoc Mann-Whitney com correção Bonferroni.

A Figura 8 mostra a comparação entre as subáreas DG, CA1 e CA3 do Hipocampo.

Foram encontradas diferenças estatisticamente significativas em todas estas. Diferenças entre grupos para DG (Kruskall-Wallis test: $\mathrm{H}(2, \mathrm{~N}=19)=15,068 \mathrm{p}=0,001)$, com uma mediana de 229,69 para o grupo CO, 257,49 para o CP e 202,91 para o Ctr, e o teste pós-hoc MannWhitney com correção de Bonferroni mostrou resultados significativos de $\mathrm{CO}$ x $\mathrm{Ctr}$ (p $=0,007)$ e CP cx Ctr $(p=0,007)$. Para CA1, foram encontradas diferenças estatisticamente significativas entre grupos (Kruskall-Wallis test: $\mathrm{H}(2, \mathrm{~N}=19)=10,566 \mathrm{p}=0,005)$, com uma mediana de 172,85 para o grupo CO, 153,39 para o CP e 105,43 para o Ctr, e o teste pós-hoc Mann-Whitney com correção de Bonferroni mostrou resultados significativos de CO x Ctr (p 
$=0,007)$ e $\mathrm{CP} \times \mathrm{Ctr}(\mathrm{p}=0,007)$. Para CA3, foram encontradas diferenças estatisticamente significativas entre grupos (Kruskall-Wallis test: $\mathrm{H}(2, \mathrm{~N}=19)=15,916 ; \mathrm{p}<0,001)$, com uma mediana de 144,81 para o grupo CO, 71,73 para o CP e 31,49 para o Ctr, e o teste pós-hoc Mann-Whitney com correção de Bonferroni mostrou resultados significativos de CO x CP ( $p$ $=0,001), \mathrm{CO} \times \operatorname{Ctr}(p=0,007)$ e $\mathrm{CP} \times \operatorname{Ctr}(p=0,007)$.

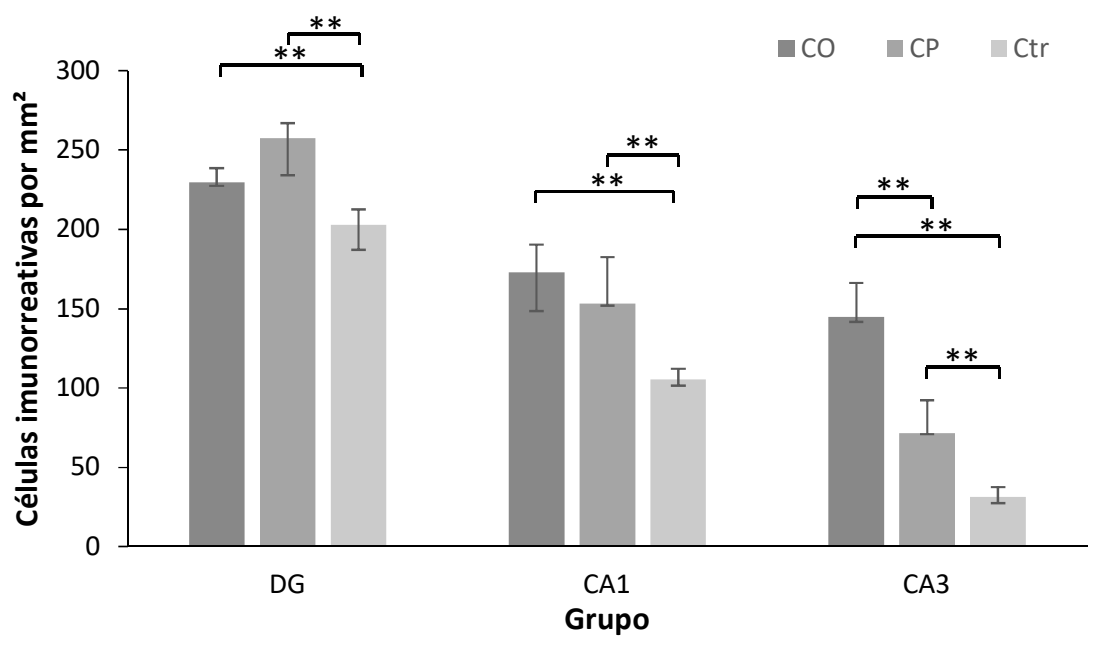

Figura 8 - Marcação de células imunorreativas a $\triangle F o s B$ no Hipocampo. O gráfico mostra a mediana $(-P 25$ e $+P 75)$ de células imunorreativas a $\triangle F o s B$ para os grupos CO, CP e Ctr nas subáreas do Hipocampo (DG, CA1 e CA3), no Experimento 1. * $p<0,05 * * p<0,01$ para pós-hoc Mann-Whitney com correção Bonferroni.

Por último são ilustradas as comparações entre as subáreas Basolateral, Medial e

Central da Amígdala. Como pode ser observado na Figura 9, existem diferenças significativas entre grupos unicamente para as duas primeiras. Diferenças entre grupos para Amígdala Basolateral (Kruskall-Wallis test: $\mathrm{H}(2, \mathrm{~N}=19)=9,430 p=0,009)$, com uma mediana de 160,45 para o grupo $\mathrm{CO}, 125,40$ para o $\mathrm{CP}$ e 127,06 para o Ctr, e o teste pós-hoc MannWhitney com correção de Bonferroni mostrou resultados significativos de CO x CP ( $p$ $=0,012)$ e perto da significância estatística, $\mathrm{CO}$ x Ctr $(0,053)$. Para Amígdala Central, foram encontradas diferenças estatisticamente significativas entre grupos (Kruskall-Wallis test: H $(2, \mathrm{~N}=19)=8,754 p=0,013)$, com uma mediana de 187,90 para o grupo $\mathrm{CO}, 145,55$ para o CP e 150,89 para o Ctr, e o teste pós-hoc Mann-Whitney com correção de Bonferroni 
mostrou resultados significativos de $\operatorname{CO} \times \operatorname{Ctr}(p=0,015)$ e perto da significância estatística, CO x CP (0,052). Para Amígdala Medial, não foram encontradas diferenças estatisticamente significativas entre grupos (Kruskall-Wallis test: $\mathrm{H}(2, \mathrm{~N}=19)=5,224 p=0,073)$, com uma mediana de 165,49 para o grupo CO, 139,34 para o CP e 127,27 para o Ctr.

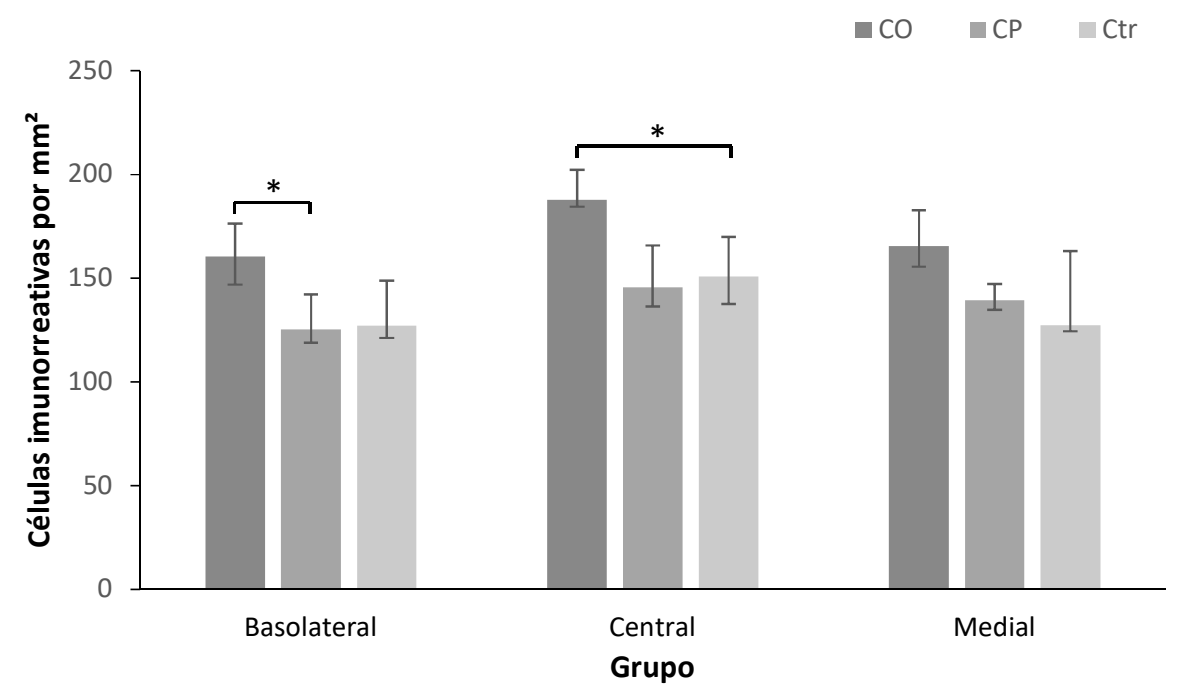

Figura 9 - Marcação de células imunorreativas a $\triangle \mathrm{FosB}$ na Amígdala. $\mathrm{O}$ gráfico mostra a mediana ($\mathrm{P} 25$ e $+\mathrm{P} 75$ ) de células imunorreativas a $\triangle \mathrm{FosB}$ para os grupos $\mathrm{CO}, \mathrm{CP}$ e Ctr nas subáreas da Amígdala (Basolateral, Central e Medial), no Experimento 1. ${ }^{*} \mathrm{p}<0,05 * * \mathrm{p}<0,01$ para pós-hoc Mann-Whitney com correção Bonferroni.

Em resumo, os resultados apresentados do Experimento 1 mostram que a o grupo $\mathrm{CO}$ expressou maior quantidade de $\Delta \mathrm{FosB}$ comparado com o $\mathrm{CP}$ e $\mathrm{Ctr}$ no Core e CA3; e o grupo $\mathrm{CP}$ expressou maior quantidade de $\Delta \mathrm{FosB}$ comparado com o $\mathrm{CO}$ e $\mathrm{Ctr}$ no Shell e no DG. No $1 \mathrm{CPu}, \mathrm{mCPu}$ e $\mathrm{CA} 1$, o grupo $\mathrm{CO}$ e $\mathrm{CP}$ tiveram maior expressão que o $\mathrm{Ctr}$ (mas não ouve diferença entre estes). Adicionalmente, no PrL e BLA o grupo CO teve maior expressão que o CP e no IL e CeA o grupo CO teve maior expressão que o Ctr.

Por serem muitas variáveis dependentes (13 sub-áreas) e duas independentes (tipo de contingência de administração e droga), elaborou-se uma tabela que mostra todos os resultados possíveis derivados das comparações entre os grupos. Acredita-se que a Tabela 3 possa auxiliar o acompanhamento dos resultados e a discussão. 
Tabela 3. Resultados possíveis e sua interpretação (mudança de expressão de DelafosB) de acordo com as variáveis independentes manipuladas (infusão de droga e contingência de administração)

\begin{tabular}{|c|c|c|c|}
\hline $\begin{array}{l}\mathrm{CO}=\mathrm{CP} \\
\mathrm{CO}=\mathrm{Ctr} \\
\mathrm{CP}=\mathrm{Ctr}\end{array}$ & Não & Não & Nem a droga, nem a contingência alteraram $\Delta \mathrm{FosB}$ \\
\hline $\begin{array}{l}\mathrm{CO}=\mathrm{CP} \\
\mathrm{CO} \neq \mathrm{Ctr} \\
\mathrm{CP}=\mathrm{Ctr}\end{array}$ & Não & Não & $\begin{array}{l}\text { Nem a droga, nem a contingência alteraram } \Delta \mathrm{FosB} \text {. A } \\
\text { diferença explicada por outra variável }\end{array}$ \\
\hline $\begin{array}{l}\mathrm{CO}=\mathrm{CP} \\
\mathrm{CO}=\mathrm{Ctr} \\
\mathrm{CP} \neq \mathrm{Ctr}\end{array}$ & Não & Não & $\begin{array}{l}\text { Nem a droga, nem a contingência alteraram } \Delta \mathrm{FosB} \text {. A } \\
\text { diferença explicada por outra variável }\end{array}$ \\
\hline $\begin{array}{l}\mathrm{CO}=\mathrm{CP} \\
\mathrm{CO} \neq \mathrm{Ctr} \\
\mathrm{CP} \neq \mathrm{Ctr}\end{array}$ & Sim & Não & $\begin{array}{l}\text { A droga alterou } \Delta \text { FosB independentemente da } \\
\text { contingência }\end{array}$ \\
\hline $\begin{array}{l}\mathrm{CO} \neq \mathrm{CP} \\
\mathrm{CO} \neq \mathrm{Ctr} \\
\mathrm{CP} \neq \mathrm{Ctr}\end{array}$ & Sim & Sim & $\begin{array}{l}\text { A contingência operante e Pavloviana alterou } \Delta \text { FosB de } \\
\text { forma diferencial }\end{array}$ \\
\hline $\begin{array}{l}\mathrm{CO} \neq \mathrm{CP} \\
\mathrm{CO} \neq \mathrm{Ctr} \\
\mathrm{CP}=\mathrm{Ctr}\end{array}$ & Sim & Sim & A droga alterou a expressão de $\Delta \mathrm{FosB}$ só sob $\mathrm{CO}$ \\
\hline $\begin{array}{l}\mathrm{CO} \neq \mathrm{CP} \\
\mathrm{CO}=\mathrm{Ctr} \\
\mathrm{CP} \neq \mathrm{Ctr}\end{array}$ & Sim & Sim & A droga alterou $\Delta$ FosB só sob contingência Pavloviana \\
\hline $\begin{array}{l}\mathrm{CO} \neq \mathrm{CP} \\
\mathrm{CO}=\mathrm{Ctr} \\
\mathrm{CP}=\mathrm{Ctr}\end{array}$ & Não & Não & $\begin{array}{l}\text { Nem a droga, nem a contingência alteraram } \Delta \text { FosB. A } \\
\text { diferença explicada por outra variável }\end{array}$ \\
\hline
\end{tabular}

\section{Discussão}

O objetivo do Experimento 1 foi explorar o efeito da administração de morfina sob contingência operante e Pavloviana sobre a expressão gênica de $\Delta \mathrm{FosB}$ em diferentes áreas do cérebro implicadas na dependência às drogas. Para isso, ratos de três grupos foram expostos a um esquema acoplado. Sob esse esquema, cada vez que um animal do grupo CO girava uma roda operante sob algum valor de FR na presença de um estímulo, uma infusão de morfina era liberada como consequência; ao mesmo tempo, a droga era também infundida na presença do mesmo estímulo no sujeito do grupo $\mathrm{CP}$ e o do grupo $\mathrm{Ctr}$ a ele acoplados. 
Posteriormente, os ratos foram perfundidos e amostras de tecido das áreas de interesse foram tomadas para análise imunohistoquímica de $\Delta \mathrm{FosB}$.

Os resultados do Experimento 1 confirmam os achados em todas as áreas reportadas pelo estudo de Perrotti et al. (2008), reportando que a morfina pode induzir a expressão de $\triangle$ FosB no CPF, estriado dorsal, NAc Core e Shell, hipocampo DG e CA3 e amígdala BLA e CeA. Ainda, de forma mais detalhada, os resultados mostram as subáreas do CPF e estriado dorsal em que a morfina pode induzir a expressão de $\triangle \mathrm{FosB}$, PrL e IL do CPF, e CPu do estriado dorsal.

Os resultados do Experimento 1 mostraram que a expressão de $\Delta$ FosB no NAc Core e CA3 foi maior no grupo CO comparado com os animais dos outros dois grupos. Estes dados são consonantes com a literatura que mostra que autoadministração repetida de uma droga produz mudanças gênicas (no SNC) diferentes às causadas pela administração repetida da mesma droga de forma passiva (Choi et al., 2011; Jacobs et al., 2002, 2003, 2005; Krawczyk, 2002; Kuzmin \& Johansson, 1999; Lüscher \& Malenka, 2011; Miguéns et al., 2008; Thomas et al., 2003; Winstanley et al., 2007). Em contrapartida, os resultados também mostraram que a expressão de $\Delta$ FosB no NAc Shell e DG foi maior no grupo CP comparado com os animais dos outros dois grupos. Na literatura atual não foram encontrados estudos que reportem que a administração passiva de uma droga possa produzir uma maior mudança de expressão gênica em comparação com a autoadministração da mesma. Ainda, dentro dos limites do conhecimento bibliográfico, este é o primeiro estudo que avalia as diferenças de expressão de $\Delta$ FosB na autoadministração e administração passiva utilizando morfina.

A expressão de $\Delta$ FosB no PrL, BLA e CeA foi maior no grupo CO comparado com o grupo Ctr, mas não comparado com o CP. Parece existir um padrão ou tendência que não conseguiu ser confirmado estatisticamente neste estudo, em que a expressão de $\Delta$ FosB é 
$\mathrm{CO}>\mathrm{CP}>\mathrm{Ctr}$ nestas três subáreas mencionadas. As variáveis que não mostrem uma diferença clara entre contingência operante e a Pavloviana não são relevantes para os objetivos desta pesquisa, ergo, não serão discutidos.

Ainda, os resultados deste experimento parecem sustentar a proposta de que $\Delta$ FosB seria um IEG marcador do efeito reforçador de drogas no NAc e PFC (e.g Colby et al., 2003; Zachariou et al., 2006).

$\mathrm{O}$ PFC regula funções executivas relacionadas com diferentes aspectos de comportamentos de meta dirigida (Tran-Tu-Yen, Marchand, Pape, Scala, \& Coutureau, 2009), e outras tarefas de aprendizagem operante, como sequência de respostas que levam a obter um reforçador (Barbey, Krueger \& Grafman, 2009), memória de trabalho (Corbit \& Balleine, 2003a), processamento de informação emocional, aprendizagem e memória (Hayden \& Platt, 2010). Os resultados do Experimento 1 para o PFC revelaram que que a autoadministração de morfina aumentou a expressão de $\Delta$ FosB dos animais do grupo $\mathrm{CO}$, quando comparados com os animais dos grupos $\mathrm{CP}$ no $\mathrm{Cg} 1$, e dos animais do grupo $\mathrm{CO}$, quando comparados com os animais dos grupos Ctr no IL.

O PrL tem sido associado à memória de trabalho e mediação de associações respostaconsequência (Corbit \& Balleine, 2003a), entre outros. As diferencias entre os grupos CO e CP é consistente com a atribuição dessa função, pois os sujeitos do grupo $\mathrm{CO}$, mas não os do grupo $\mathrm{CP}$, foram treinados sob uma contingência operante (resposta-consequência). Entretanto, como não foram observadas diferenças entre o grupo $\mathrm{Ctr}$ e os grupos $\mathrm{CO}$ e $\mathrm{CP}$, não é possível atribuir aos efeitos incondicionados ou condicionados da droga a disparidade entre contingência operante e Pavloviana, nem às contingências de aprendizagem sob as quais cada grupo estava sendo treinado. Assim, os resultados parecem indicar que a administração de morfina não altera a expressão de $\Delta \mathrm{FosB}$ nesta subárea. 
Os resultados também mostraram que no $\mathrm{Cg} 1$ o grupo Ctr apresentou uma maior expressão de $\Delta$ FosB comparado com o grupo CP. O Cg1 tem uma função altamente relevante para a aprendizagem das consequências que produz um comportamento, tendo um papel no processamento de informação emocional, aprendizagem e memória relacionados com um reforçador (Hayden \& Platt, 2010). Entretanto, de acordo com os resultados apresentados, a expressão de $\Delta$ FosB não foi alterada pelos efeitos da droga, implicando que esta proteína não seria um marcador de interesse no Cg1 na administração de morfina, a diferencia dos outros subnúcleos do CPF. Ainda, esta expressão não se vê afetada pela administração de morfina em contingência operante ou Pavloviana.

Por outro lado, os resultados no IL, o qual está associado à aprendizagem operante, mais especificamente, às tarefas de meta dirigida (Tran-Tu-Yen, Marchand, Pape, Scala, \& Coutureau, 2009), mostraram uma diferença entre o grupo CO e o Ctr e CP e Ctr, mas não entre CO e CP. Este dado está em concordância com o estudo de Perrotti et al. (2008) que indica que a expressão de $\triangle$ FosB no PFC é aumentada pela administração de morfina, esclarece que esta expressão não depende do tipo de contingência de aprendizagem em que a morfina foi administrada. Ainda, junto com os resultados de Cg1 e PrL, se especifica as subáreas do PFC que são susceptíveis a expressão de $\Delta$ FosB induzida pela administração de morfina, o qual não se encontra descrito na literatura.

Os resultados no NAc foram os de maior interesse para a proposta de Winstanley et al. (2007), que postula que a administração da droga sob contingência operante pode causar algumas mudanças neurais, como expressão de $\Delta \mathrm{FosB}$, que não se dariam em igual forma sob CP. A expressão de $\Delta \mathrm{FosB}$ no Core dos sujeitos do grupo $\mathrm{CO}$ foi maior comparado com os grupos $\mathrm{CP}$ e Ctr, porém a expressão desse IEg no Shell foi maior no grupo $\mathrm{CP}$ do que nos grupos $\mathrm{CO}$ e $\mathrm{Ctr}$, indicando que a contingência sob a qual a morfina é administrada produz alterações diferencias nessas subáreas do NAC. 
De acordo com a literatura, mudanças no Core são críticas para a aquisição de informação de estímulos ambientais que podem modular o comportamento, estando implicado em tarefas de meta dirigida (Saddoris, Stamatakis, \& Carelli, 2011), aprendizagem de tarefas espaciais (Parkinson, Willoughby, Robbins \& Everitt, 2000), PIT e devaluação (Corbit \& Balleine, 2001, 2005, 2011), e tarefas de escolha de reforçadores com atraso (Cardinal \& Cheung, 2005). Os resultados obtidos para o Core estão alinhados com as funções descritas deste. A maior expressão de $\Delta \mathrm{FosB}$ no Core após a contingência operante de morfina na presença de um estímulo, quando comparado com a contingência Pavloviana na presença do mesmo estímulo, sugere que tanto o tipo de contingência quanto a droga, influenciaram este resultado, de modo que a droga tivesse aumentado a expressão desta proteína no Core. Este resultado é inédito na literatura. Se esperava encontrar diferenças na expressão $\Delta$ FosB entre os grupos CO e CP em algumas áreas, como no PFC, como reportado Zachariou et al. (2006), mas foi surpreendente este achado no Core, pois no estudo de Perrotti et al. (2008), realizado com COC, se reporta que não ouve diferença entre autoadministração e administração passiva na expressão $\Delta$ FosB no NAc.

O Shell está envolvido em processos de motivação e é frequentemente descrito como o centro do prazer responsável pelo processamento da sensação de gosto no reforço positivo (West \& Carelli, 2016), assim como por ser sensível a estímulos salientes presentes no ambiente (Ambroggi, Ghazizadeh, Nicola, \& Fields, 2011). Uma maior expressão de $\Delta$ FosB no Shell após a administração passiva de morfina, quando comparado com a autoadministração da mesma, sugere que tanto a contingencia de administração quanto a droga estiveram envolvidos como fatores neste resultado, e que para o grupo $\mathrm{CP}$ a exposição à morfina em conjunto com S1 durante o treino Pavloviano poderia ter incrementado a saliência deste conjunto de estímulos, causando uma maior ativação do Shell, tanto pela sensação de prazer causada pela morfina, como pela associação com S1. 
Ainda que já tinha sido reportado na literatura alterações da expressão de $\Delta \mathrm{FosB}$ no NAc após autoadministração e administração passiva de COC (Perrotti et al., 2008), não encontramos dados que mostrassem o efeito diferencial da contingência de administração de morfina, operante ou pavloviana, sobre a indução desse IEG no Core e Shell do NAc. Em conjunto, os resultados obtidos para o Core e Shell oferecem uma perspectiva em concordância com a literatura que reporta estas duas subaéreas codificam informação associada a um reforçador de forma diferencial, sendo no Core ligado a aspectos operantes e no Shell a aspectos Pavlovianos da aprendizagem (e.g Saddoris et al., 2011; West \& Carelli, 2016).

Os resultados para ambas as subáreas do CPu avaliadas neste estudo, são chamativos: a morfina causou mudanças em ambas as subáreas avaliadas, $1 \mathrm{CPu}$ e $\mathrm{mCPu}$, independentemente da contingência de administração. De acordo à literatura, o $1 \mathrm{CPu}$ recebe inputs do córtex somatossensorial e motor, tendo papel na mediação e programação de movimentos, como mudanças na frequência, duração e amplitude dos movimentos em geral, incluindo os envolvidos no aprendizado S-R, sendo que sua lesão prejudica a aprendizagem de contingência S-R (Fricker, Annett, Torres, \& Dunnett, 1996). Por outro lado, o mCPu recebe inputs do mPFC e está implicado na mediação de funções como aprendizagem de sequências e seleção de estratégias, sendo que a sua lesão impede a aprendizagem de tarefas que envolvem aprendizagem de posição e de dicas ou estímulos presentes no ambiente, como no labirinto de Morris e no de oito braços (Devan, McDonald, \& White, 1999). Estes resultados estão em concordância com o estudo de Perrotti et al. (2008), confirmando o aumento na expressão de $\Delta \mathrm{FosB}$ na autoadministração de morfina para estas subáreas que conformam o $\mathrm{CPu}$. Ainda, especifica as subáreas que são sensíveis a expressão deste IEG, o qual não estava reportado com tal detalhe, e mostra que esta expressão na $1 \mathrm{CPu}$ e mCPu não varia em razão da contingência em que a morfina seja administrada. 
No Hipocampo, a expressão de $\Delta$ FosB no DG e CA3 foi alterada pela contingência sob a qual a droga foi administrada; no CA1 foram também observadas mudanças da expressão desse IEG, porém decorrentes do efeito da droga e independente da contingência de administração. Subáreas como CA1 e CA3 têm sido reportadas como críticas para as associações entre uma droga e estímulos ambientais (Gajewski, Eagle \& Robison, 2017),

O DG tem sido reportado por ter funções de codificação conjuntiva (conjunctive encoding processes), separação de padrões espaciais e separação de padrões contextuais (Kesner, 2013). Em outras palavras, o DG estaria implicado na associação entre estímulos e a discriminação destes. Os resultados para esta subárea mostram que o grupo CO e CP tiveram uma maior marcação de $\Delta$ FosB que o grupo Ctr, mas não houve diferença entre contingência operante e Pavloviana. Este resultado confirma que a administração de morfina no DG pode causar grande expressão $\Delta \mathrm{FosB}$, como descrito por Perrotti et al., (2008). O dado sugere que o DG é susceptível ao efeito farmacológico que a morfina causa sobre o organismo e não a contingência de aprendizagem, estando em concordância com as funções atribuídas a esta subárea, pois estando implicada na associação entre estímulos, se esperaria que ambas as contingências tivessem um impacto nesta subárea, como mostra o resultado.

A CA1 é subárea descrita frequentemente pela sua relevância para a recuperação de memória contextual e aprendizagem da ordem temporal de eventos, como em uma tarefa de identificação de estímulos em sequência (Barrientos \& Tiznado, 2016). Sabe-se que o CA1 expressa $\Delta$ FosB quando morfina é administrada (Perrotti et al., 2008), porem dado que ambas as contingências aqui estudadas envolvem a aprendizagem da ordem temporal de eventos, não se esperavam diferenças entre os grupos $\mathrm{CO}$ e CP. Em alinhamento com esta ideia, os resultados mostraram que, de forma similar ao $\mathrm{DG}, \Delta \mathrm{FosB}$ foi induzido nos grupos $\mathrm{CO}$ e $\mathrm{CP}$ em maior medida que no controle, porém sem ter diferença entre os dois primeiros. Isto 
indica que o CA1 é sensível à administração de morfina, mas é independente do tipo de contingência em que esta seja administrada.

Por outro lado, o CA3, uma subárea caracterizada (entre outras funções) pelo seu papel no processamento sequencial de informação em cooperação com CA1 e no processamento de aspectos geométricos do ambiente em cooperação com o DG (Kesner, 2007). Os resultados mostram que nesta subárea o grupo CO apresentou uma maior marcação de $\Delta$ FosB comparado com os grupos $\mathrm{CP}$ e $\mathrm{Ctr}$. Ainda, o grupo $\mathrm{CP}$ também apresentou uma marcação maior deste IEG em comparação com o Ctr. Este resultado confirma o reportado previamente, que indica que a administração de morfina pode induzir a expressão de $\Delta$ FosB no CA3 (Perrotti, et al., 2008) e mostra que esta expressão é susceptível do tipo de contingência em que esta é administrada. Isto sugere que o efeito escalonado da manipulação comportamental sobre a expressão de $\Delta \mathrm{FosB}(\mathrm{CO}>\mathrm{CP}>\mathrm{Ctr})$ poderia ser resultado da sequência de informação mais complexa da contingência operante $\left(\mathrm{Sd} \rightarrow \mathrm{R} \rightarrow \mathrm{S}^{\mathrm{R}}\right)$, quando comparada com a da pavlovianda $(\mathrm{S} \rightarrow \mathrm{R})$.

Na Amígdala observamos mudanças na expressão de $\triangle$ FosB nas subáreas BLA e CeA, mas não na MeA, após a autoadministração de morfina, mas não após sua administração passiva.

A BLA possui conexões eferentes dirigidas ao NAc Core e Shell e se acredita que seja necessária para que em conjunto se possa mediar a motivação implicada na aprendizagem relacionada a estímulos ambientais/contextuais (Martinez, Carvalho-Netto, Ribeiro-Barbosa, Baldo, \& Canteras, 2011; Setlow, Holland \& Gallagher, 2002) e na aprendizagem de associações entre estímulos em comportamento de meta dirigida (Holland \& Gallagher, 2003). De forma similar, na CeA, uma subárea a qual está implicada na atenção da aprendizagem e está fortemente ligada à motivação em eventos relacionados a estímulos via 
ação reguladora do sistema dopaminérgico mesolímbico (Haney, Calu, Takahashi, Huges e Schoenbaum, 2010). Os resultados mostram que em relação à expressão de $\Delta \mathrm{FosB}$, para a BLA o grupo $\mathrm{CO}$ foi diferente do $\mathrm{CP}$, mas não do $\mathrm{Ctr}$, e na $\mathrm{CeA}$, o grupo $\mathrm{CO}$ foi diferente comparado com o Ctr, mas não quando comparado com o CP. Estes dados estão em concordância com o estudo de Perrotti et al. (2008), reportando que a administração de morfina pode produzir um aumento na expressão de $\Delta$ FosB na BLA e CeA.

De forma rigorosa, estes dado da BLA e CeA implicam que nem a morfina nem a contingência influenciaram a expressão de $\Delta$ FosB nestas subáreas e que estas diferenças seriam explicadas por outras varáveis alheias a este estudo, porém seria de grande interesse conferir estes resultados em um futuro estudo, pois o teste pós-hoc na BLA para CO x Ctr foi 0,053, e na CeA, para $\mathrm{CO}$ x CP foi 0,052 , estando próximos a ser considerados diferentes em termos estatísticos. Se fosse considerado que na BLA e na CeA o grupo CO foi diferente de $\mathrm{CP}$ e Ctr, isto implicaria que a morfina aumentou a expressão de $\Delta \mathrm{FosB}$ unicamente sob CO, e estaria em concordância com a função destas áreas na aprendizagem e motivação relacionados a estímulos ambientais, tendo em conta o treino discriminativo que o grupo $\mathrm{CO}$ teve.

Os resultados do MeA mostraram que não houve diferenças entre grupos. Isto sugere que nem morfina nem o tipo de contingência pela qual esta foi administrada afeta a expressão de $\Delta$ FosB nesta subárea. A MeA tem um papel no processamento de cheiros e feromônios, estando também envolvida em respostas aversivas, comportamento social e sexual (Carlson, 2012). Esta função não parece estar relacionada ao comportamento de administração de drogas, porém a MeA foi incluída dentro do estudo para fazer uma avaliação mais completa da amígdala. 
Em resumo, os resultados obtidos no Experimento 1, mostram que a autoadministração de morfina ocasionou uma maior expressão de $\Delta$ FosB que a administração passiva desta, nas subáreas Core, CA3 e BLA, enquanto a contingência Pavloviana da mesma droga causou uma maior expressão no Shell e no DG. Alguns destes resultados, como os do Core e Shell, estão em concordância com dados reportados previamente na literatura sobre estas subáreas estarem envolvidas na codificação de informação associada a um reforçador de forma diferencial em relação ao tipo de contingência em que uma droga é repetidamente administrada (Saddoris et al., 2011; West \& Carelli, 2016). Dentro do limite da literatura conhecida, o estudo aqui apesentado é o único que tem avaliado a expressão de $\Delta \mathrm{FosB}$ na contingência operante e Pavloviana de morfina.

Outros dados aqui apresentados confirmam resultados reportado préviamente na literatura, como os do estudo de Perrotti et al (2008), que mostra às subáreas em que a morfina causa expressão de $\Delta$ FosB. Por outro lado, em relação a este mesmo estudo, os autores concluem que a indução de $\Delta \mathrm{FosB}$ no NAc não está em função do tipo de administração que uma droga é administrada, que estaria aparentemente em oposição aos resultados apresentados mostrando que o Core e o Shell induziram diferencialmente a expressão deste IEG em relação à contingencia em que a morfina foi administrada. Porém, nesse estudo, esta conclusão foi tomada segundo dados de um experimento realizado com COC. Adicionalmente, os mesmos autores concluem neste estudo que diferentes drogas podem causar a expressão de $\Delta \mathrm{FosB}$ em diferentes subáreas cerebrais, portanto os resultados deste experimento em relação ao Core e Shell não estariam em contradição.

Os resultados como os do NAc Core e Shell são de grande relevância. Dado que no Core o grupo $\mathrm{CO}$ teve uma maior expressão de $\Delta \mathrm{FosB}$ que a contingência Pavloviana e no Shell foi de forma invertida. Isto sugere que os tipos de contingência podem produzir em um 
organismo não são questão de "tudo ou nada", nem apenas que a administração de uma droga sob contingência operante pode induzir mais $\Delta \mathrm{FosB}$ que a administração da mesma sob contingência Pavloviana, ou vice-versa, mas que a indução de $\Delta \mathrm{FosB}$ pode variar em diferentes subáreas cerebrais, segundo o tipo de contingência sob a qual uma droga é administrada. Adicionalmente, além do Core e NAc, resultados similares foram achados para outras subáreas, o PrL, CA3, BLA e CeA, mostraram uma maior marcação de $\Delta$ FosB sob contingência operante que sob $\mathrm{CP}$, e o DG apresentou uma maior marcação de $\Delta \mathrm{FosB}$ sob contingência Pavloviana que sob a operante. De forma geral, estas subáreas estão implicadas na dependência às drogas por mecanismos associados ao processamento de informação relacionada a estímulos presentes no ambiente e no comportamento de meta dirigido. 


\section{Experimento 2. Procedimento de Respostas de Busca e Administração de Morfina nas Associações por Contingências Pavloviana e Operante}

Nos estudos de Patarroyo, Felício e García-Mijares (2014), ratos do grupo CO foram expostos a treino discriminativo, obtendo infusões de morfina ao responder na presença de um estímulo luminoso (S1). Desta forma, os animais dos grupos CP e Ctr acoplados, receberam treino Pavloviano da relação de contingência entre a presencia de uma S1e a infusão endovenosa de uma substância, morfina (CP) ou salina (CTR), ao mesmo tempo que os sujeitos CO se auto administravam a morfina na presença da luz. Os resultados desse experimento indicaram que sob esse procedimento a probabilidade condicional na relação US-CS (luz-morfina) durante o condicionamento Pavloviano para os sujeitos CP foi igual ou inferior a 0,2 . Isto porque os animais do grupo $\mathrm{CO}$ responderam em torno de $20 \%$ das vezes que S1 foi apresentado. Mesmo assim, a discriminação foi alta para esse grupo, pois responderam $0 \%$ das vezes na ausência de S1. A despeito da baixa frequência de respostas, o grupo $\mathrm{CO}$, demonstrou bom controle de estímulo no teste de transferência (responderam preferencialmente na presença do $\mathrm{S} 1$ associado com morfina). O grupo $\mathrm{CP}$, porém, não ficou sob controle se S1 (responderam igualmente na presença e na ausência de S1), mesmo que recebeu o mesmo número de infusões da droga na presença de S1 do que o grupo CO. Os autores discutem esses resultados em termos da relação de contingência entre S1-morfina no treinamento do grupo $\mathrm{CP}$, pois mesmo que as probabilidades condicionais morfina-S1, morfina-nãoS1, não morfina-S1 e não morfina-nãoS1 fossem as mesmas para ambos os grupos, a probabilidade de apenas 0,2 de apresentação de morfina na presença de S1 não foi suficiente para estabelecer o aprendizado sob treino pavloviano. 
Considerando as limitações do procedimento de Patarroyo, Felício e García-Mijares (2014), para o estudo adequado da relação entre a contingência de treino e o controle de estímulos sobre a autoadministração e procura por drogas, ponto principal deste teste, o objetivo principal do Experimento 2 foi desenvolver um procedimento melhorado para o estudo do controle de estímulos associado por contingência Pavloviana ou por contingência operante sobre as respostas de busca e autoadministração de morfina, implementando a probabilidade CS-US (S1-morfina) durante o contingência operante para 100\%. Para tanto, o procedimento foi modificado para que as probabilidades fossem morfina-S1 =1, morfina-Não $\mathrm{S} 1=0$, Não morfina-S1 =0 e morfina-Não $\mathrm{S} 1=1$. Espera-se que as mudanças permitam observar aquisição de controle de S1 sob o responder do grupo CP no teste de transferência, isto é, o fenômeno PIT seja observado como documentado amplamente na literatura (e.g., Estes, 1948; Holland, 2004; Rescorla, 1994).

\section{Sujeitos}

Foram usados 24 ratos albinos machos da cepa Wistar. As cirurgias foram realizadas quando os sujeitos atingiram $280 \mathrm{~g}-300 \mathrm{~g}$ de peso. Sete dias após a recuperação da cirurgia, os animais foram distribuídos aleatoriamente em três grupos: Administração por Contingência Operante $(\mathrm{CO}, \mathrm{n}=8)$, Administração por Contingência Pavloviana $(\mathrm{CP}, \mathrm{n}=8)$ e Controle $(\mathrm{Ctr}$, $\mathrm{n}=8$ ), formando trios com um sujeito de cada grupo. 


\section{Fases Experimentais}

\section{Fase 1. Treino Associativo de Morfina e S1 em Esquema Acoplado}

A resposta de girar 90 graus uma roda operante foi modelada em esquema CRF para o grupo $\mathrm{CO}$. Os animais dos grupos $\mathrm{CP}$ e $\mathrm{Ctr}$ foram colocados em caixas operantes iguais às do grupo CO (com a exceção da ausência do receptáculo) ${ }^{9}$.

Cada vez que um sujeito do grupo CO introduziu a cabeça no receptáculo, este recebeu uma infusão i.v. de morfina em dose eficaz para autoadministração $(0,75 \mathrm{mg} / \mathrm{kg})$, e os sujeitos do grupo CP e do grupo Ctr acoplados a ele receberão sob contingência Pavloviana uma injeção i.v da droga na mesma dose ou de veículo (1,0 ml/kg), respectivamente. Para cada trio, as infusões de droga ou salina foram acompanhadas pela apresentação simultânea ${ }^{10}$ de S1, uma luz estímulo verde $(1 \mathrm{~W})$ por 30 s, período no qual as respostas do sujeito do grupo $\mathrm{CO}$ foram registradas, mas não tiveram consequências programadas. Um time out (TO) de 1min seguirá cada apresentação de S1. Cada sessão teve duração máxima de $2 \mathrm{~h}$ programadas, mas poderão terminar antecipadamente para um trio se o membro do grupo CO conseguir atingir 20 infusões para o seu grupo. Esta fase teve uma duração de três sessões.

\footnotetext{
${ }^{9}$ As rodas operantes foram localizadas unicamente nas caixas dos sujeitos do grupo CO para evitar o reforçamento acidental (Pear \& Eldridge, 1984) da resposta fazer girar a roda operante nos sujeitos dos outros grupos.

${ }^{10}$ A apresentação de S1 é acionada simultaneamente ao bombeio da morfina e salina, porém, dado que a infusão demora três segundos em ser completamente realizada, a apresentação de S1 é realmente precedente à infusão, em outras palavras, um estímulo condicionado precedente e contiguo.
} 


\section{Fase 2. Treino Discriminativo em Contingência Operante ou Pavloviana de}

\section{Morfina}

O treino discriminativo para os sujeitos do grupo CO consistirá em 30 apresentações de 30s de S1 (luz verde) e 30 de apresentações de 30s S2 (luz branca). As respostas foram registradas quando os sujeitos giravam 90 graus uma roda operante. Uma resposta na presença de S1 por parte do sujeito CO tinha como consequência uma infusão (i.v.) contingente de morfina em dose eficaz para autoadministração $(0,75 \mathrm{mg} / \mathrm{kg})$, e os sujeitos do grupo CP e do grupo Ctr acoplados a ele receberam sob contingência Pavloviana uma injeção i.v da droga na mesma dose ou de veículo $(1,0 \mathrm{ml} / \mathrm{kg})$, respectivamente. Para cada trio, simultânea à resposta do sujeito $\mathrm{CO}$, as infusões de droga ou salina foram acompanhadas pela apresentação de S1 por 30s. Dessa forma, a apresentação de S1 para os grupos CP e Ctr estava sob o controle das respostas emitidas pelos ratos do grupo $\mathrm{CO}^{11}$. S2 foi apresentado simultaneamente aos ratos de cada trio e as respostas na presença deste dos ratos CO não tiveram consequências programadas.

As apresentações de S1 e S2 foram programadas para se apresentarem de forma pseudoaleatória durante a sessão, de modo que apareceram no máximo duas vezes consecutivamente. O critério de estabilidade estabelecido para passar de fase foram duas sessões consecutivas sem aumento ou diminuição sistemática de infusões, ou seja $\pm 10 \%$ de variação do número de infusões por sessão.

\footnotetext{
${ }^{11}$ Note-se que para o sujeito CO as apresentações de S1 são sempre 30, pois se encontra em treino discriminativo, em quanto que o sujeito CP, S1 é unicamente apresentado quando uma infusão de morfina é administrada. Desta forma, mesmo que o número de S1 não seja igual para os sujeitos destes grupos, se garante que o $100 \%$ das vezes S1 é apresentado para o sujeito CP, este recebe morfina.
} 
Fase 3. Treino de Encadeamento das Respostas de Busca e Autoadministração de Morfina.

Os sujeitos não estiveram mais acoplados a partir desta fase e as infusões não foram acompanhadas por S1. Inicialmente foi treinada a resposta de autoadministração de morfina. Uma única barra retrátil (contrabalanceando lado esquerdo e direito) foi disponibilizada para os ratos de todos grupos. Durante duas sessões a resposta de apertar esta barra em esquema CRF teve como consequência uma dose de morfina, seguida por 30s de timeout (TO), no qual a barra não estava disponível. Posteriormente foi treinada a resposta de busca por morfina encadeada à resposta de autoadministração previamente treinada. A barra contralateral foi disponibilizada no início das sessões de encadeamento. Uma resposta nesta barra (Barra Bbusca) tinha como consequência a disponibilização da outra barra (primeiro elo da cadeia), e resposta nesta segunda barra (Barra A- autoadministração) teve como consequência uma infusão de morfina (segundo elo da cadeia), seguida pela retração de ambas as barras (TO 30s). Após cada TO a primeira barra foi reintroduzida sinalizando que a contingência do encadeado de busca-autoadministração estava disponível novamente. Ambos componentes (barras) do encadeado estavam em esquema CRF durante duas sessões. O esquema de reforço para cada elo da cadeia foi incrementado para FR2 (fixed ratio) durante duas sessões, e posteriormente para FR3 até ser atingido o critério de estabilidade (duas sessões consecutivas sem aumento ou diminuição sistemática da frequência de respostas - diferença $\leq 10 \%$ ). Estas sessões tiveram uma duração de 35 min, podendo terminar antecipadamente para um trio se o membro do grupo $\mathrm{CO}$ conseguisse atingir 20 infusões para o seu trio. 
Fase 4. Teste de Transferência Sob o Controle de S1 nas Respostas de Busca e Autoadministração de Morfina

Para o teste de transferência, ambas as barras, B e A, estavam disponíveis permanentemente para todos sujeitos. Tentativas discretas de S1 e S2 foram apresentadas para cada trio durante a sessão, da mesma forma que na Fase 2. As respostas nas barras foram registradas, porém estavam em condições de extinção ${ }^{12}$. O teste foi realizado em uma única sessão de duração de $2 \mathrm{~h}$.

\section{Análise de dados}

Para analisar o desempenho dos sujeitos durante a Fase 3 (frequência de respostas e administrações de morfina), e o desempenho dos sujeitos durante a Fase 4, ID atingido durante o teste nas respostas de busca e autoadministração de morfina, persistência nas respostas de busca e autoadministração de morfina durante a sessão de extinção, e latência ${ }^{13}$ à primeira resposta; foram realizados testes não paramétricos para amostras independentes. $\mathrm{O}$ teste de Kruskall-Wallis foi realizado para detectar diferenças estatísticas, e quando achadas estas $(p<0,05)$, o teste U de Mann-Whitney com fator de correção Bonferroni foi utilizado como post hoc. Todas as análises estatísticas foram executadas fazendo uso do software aplicativo IBM SPSS ${ }^{\circledR}$.

\section{Resultados}

12 Usualmente é administrado um veículo no lugar da droga para as sessões de extinção, mas foi decidido não usar infusões em geral para evitar que o som produzido pela bomba de infusão funcionasse como reforçador condicionado.

${ }^{13} \mathrm{O}$ sorteio de S1 e S2 não afetou a latência aqui apresentada, pois foi tomada desde o momento de aparição de S1 ou S2 até a primeira vez que uma Resposta de Busca ou Autoadministração é emitida durante a duração de um intervalo (de S1 ou S2), sendo restado o tempo anterior se foi um S diferente o apresentado. 
Para a Fase 1, a média de infusões foi 5,86 $(S D=0,813)$, o que está de acordo com o Experimento 1 e com o padrão de autoadministração de morfina por ratos sob esquemas fixos relatado pela literatura (Mierzejewski et al., 2003; Suto et al., 2011).

Na Figura 10 são mostrados os índices discriminativos (ID) das últimas seis sessões da Fase 2 dos ratos CO. A figura mostra que todos os animais atingiram $90 \%$ ou mais de ID a partir da sessão 5, que se manteve estável na sessão 6.

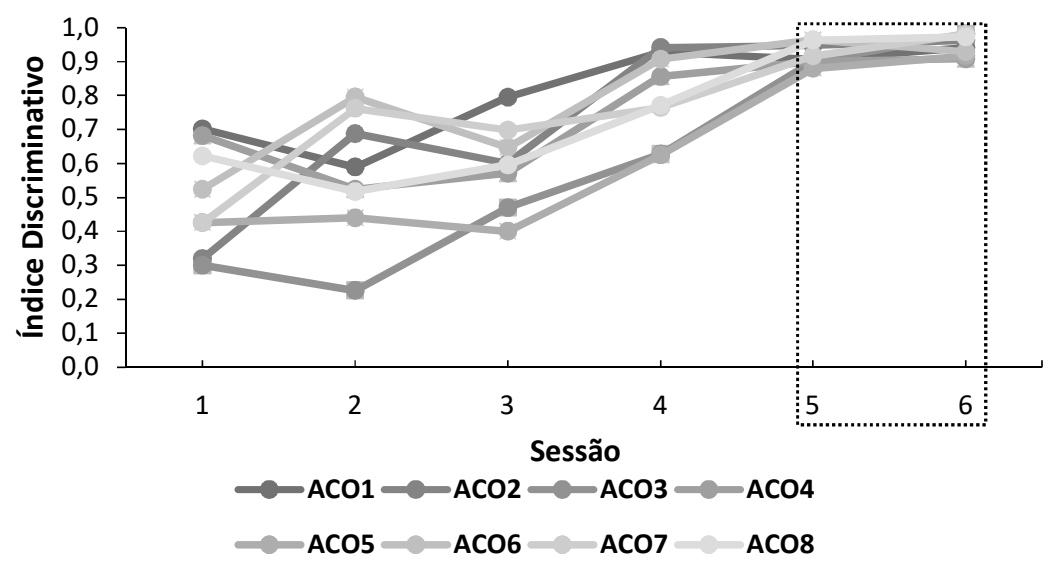

Figura 10 - Índice discriminativo durante a Fase 2 do Experimento 2. O gráfico mostra o ID dos sujeitos integrantes do grupo CO durante as últimas seis sessões da Fase 2 (Treino Discriminativo em contingência operante ou Pavloviana de Morfina). Pode-se observar que o ID vai aumentando até chegar a $90 \%$ ou superior nas últimas duas sessões.

Como mostrado na Figura 11, durante a Fase 3 (Treino de Encadeamento das Respostas de Busca e Autoadministração de Morfina), os sujeitos de todos os grupos atingiram estabilidade de resposta de autoadministração, com média de infusões $(M=5,17 S D$ $=0,734)$. Ainda, não foram encontradas diferenças estatisticamente significativas entre grupos nas Respostas de Busca (Kruskall-Wallis test: $\mathrm{H}(2, \mathrm{~N}=21)=5,926 p=0,052)$, com 
uma média de 7,19 para o grupo CO, 8,92 para o CP e 6,07 para o Ctr. Tampouco foram encontradas diferenças nas Respostas de Autoadministração (Kruskall-Wallis test: H (2, N= 21) $=4,883 p=0,087$ ), com uma média de 7,72 para o grupo $\mathrm{CO}, 9,31$ para o $\mathrm{CP}$ e 8,14 para o Ctr. Respostas Totais (Kruskall-Wallis test: $\mathrm{H}(2, \mathrm{~N}=21)=5,658 p=0,059)$, com uma media de 7,78 para o grupo CO, 10,01 para o CP e 8,21 para o Ctr; nem nas Infusões por sessão entre os grupos (Kruskall-Wallis test: $\mathrm{H}(2, \mathrm{~N}=21)=1,739 p=0,419)$, com uma média de 13,22 para o grupo CO, 12,84 para o CP e 10,79 para o Ctr.

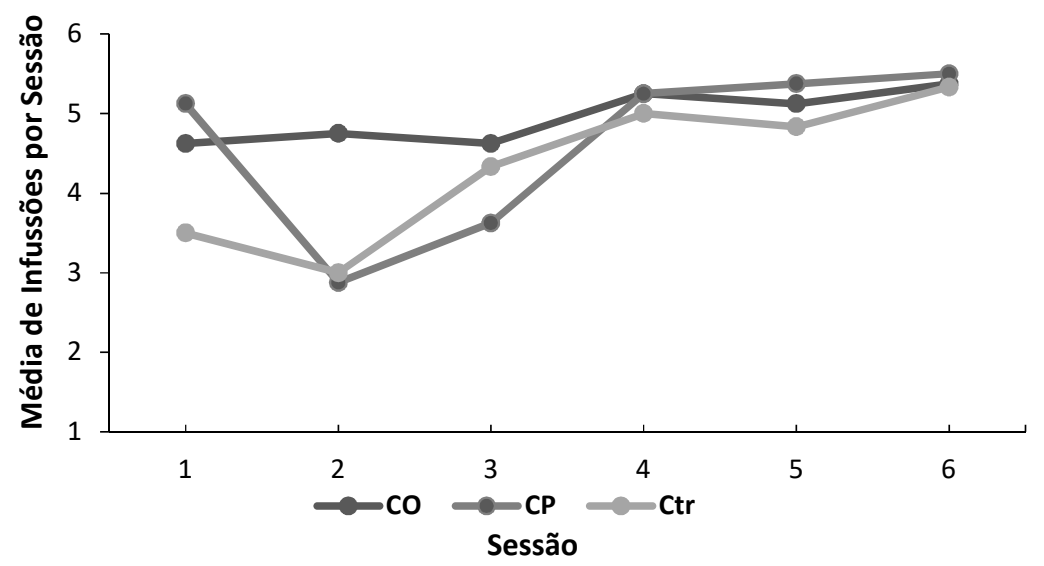

Figura 11 - Média de infusões durante a Fase 3 do Experimento 2. O gráfico mostra a média de infusões de morfina dos sujeitos integrantes dos grupos $\mathrm{CO}, \mathrm{CP}$ e $\mathrm{Ctr}$ durante as últimas seis sessões da Fase 3 (Treino de Encadeamento das Respostas de Busca e Autoadministração de Morfina). Pode-se observar que o número de infusões tente se estabilizar durante as últimas sessões.

Na Figura 12 são mostrados os dados da frequência de respostas na barra busca (B) e na barra de administração (A) na presença de S1. Nota-se na figura que os animais do grupo $\mathrm{CO}$ responderam mais na barra $\mathrm{B}$ (primeiro elo da cadeia) na presença de $\mathrm{S} 1$ do que os outros dois grupos. De fato, o teste Kruskall-Wallis revelou diferenças significativas entre a frequência de respostas e na barra B dos grupos. Diferenças entre grupos para a frequência total de respostas em S1 (Kruskall-Wallis test: $\mathrm{H}(2, \mathrm{~N}=21)=10,349 p=0,006)$, com uma mediana de 52,5 para o grupo CO, 25,5 para o CP e 14,5 para o Ctr, e o teste pós-hoc MannWhitney com correção de Bonferroni mostrou resultados significativos de CO x CP ( $p$ 
$=0,042)$ e $\mathrm{CP} \times \mathrm{Ctr}(\mathrm{p}=0,024)$. Para a frequência de respostas na Barra B, foram encontradas diferenças estatisticamente significativas entre grupos (Kruskall-Wallis test: $\mathrm{H}(2, \mathrm{~N}=21)$ $=15,637 p<0,001$ ), com uma mediana de 46,00 para o grupo $\mathrm{CO}, 6,00$ para o $\mathrm{CP}$ e 7,50 para o Ctr, e o teste pós-hoc Mann-Whitney com correção de Bonferroni mostrou resultados significativos de $\mathrm{CO} \times \mathrm{CP}(p<0,001)$ e $\mathrm{CP} \times \mathrm{Ctr}(\mathrm{p}=0,001)$. Para a frequência de respostas na Barra A em S1 (autoadministração) não foram encontradas diferenças estatisticamente significativas entre grupos (Kruskall-Wallis test: $\mathrm{H}(2, \mathrm{~N}=21)=5,417 p=0,067)$, com uma mediana de 7,00 para o grupo CO, 19,00 para o $\mathrm{CP}$ e 6,00 para o $\mathrm{Ctr}$.

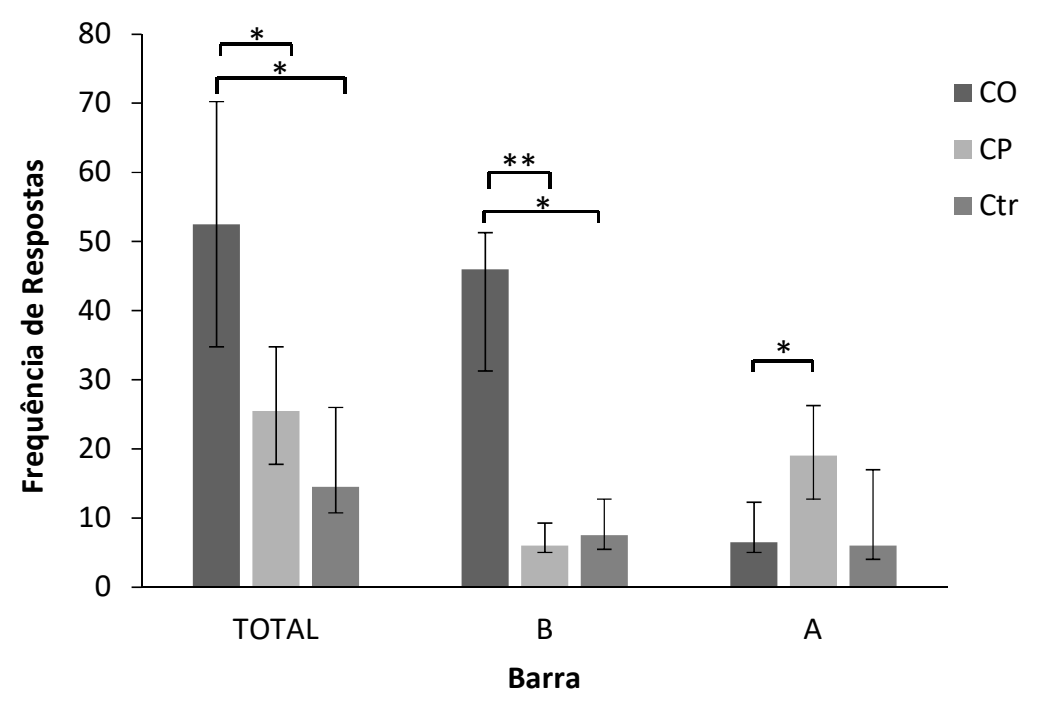

Figura 12 - Frequência de respostas de busca e autoadministração na presença de S1. Os dados representam a mediana (-P25 e +P75) da frequência de respostas na barra A, na barra B e o a frequência total (a somatória das repostas em ambas as barras), na presença de $\mathrm{S} 1$, dos sujeitos dos grupos CO, CP e Ctr durante a Fase 4. * p <0,05 ** p <0,01 para pós-hoc Mann-Whitney com correção Bonferroni.

Na Figura 13 são mostrados os dados da frequência das respostas totais, na presença de S1 e S2. Diferenças entre grupos para a frequência total de respostas (Kruskall-Wallis test: $\mathrm{H}(2, \mathrm{~N}=21)=10,349 p=0,006)$, com uma mediana de 59,5 para o grupo $\mathrm{CO}, 35,00$ para o CP e 24,00 para o Ctr, e o teste pós-hoc Mann-Whitney com correção de Bonferroni mostrou resultados significativos de $\mathrm{CO} \times \mathrm{CP}(p=0,001)$ e $\mathrm{CP} \times \mathrm{Ctr}(\mathrm{p}=0,001)$.Para a frequência de 
respostas totais na Barra $\mathrm{B}$, foram encontradas diferenças estatisticamente significativas entre grupos (Kruskall-Wallis test: $\mathrm{H}(2, \mathrm{~N}=21)=15,637 p<0,001)$, com uma mediana de 52,50 para o grupo CO, 25,50 para o CP e 14,50 para o Ctr, e o teste pós-hoc Mann-Whitney com correção de Bonferroni mostrou resultados significativos de CO x CP $(p=0,036)$, e CO x $\operatorname{Ctr}(p=0,048)$. Para a frequência de respostas totais na Barra A em S1 (autoadministração), não foram encontradas diferenças estatisticamente significativas entre grupos (KruskallWallis test: $\mathrm{H}(2, \mathrm{~N}=21)=5,417 p=0,067)$, com uma mediana de 8,00 para o grupo CO, 11,00 para o CP e 13,00 para o Ctr.

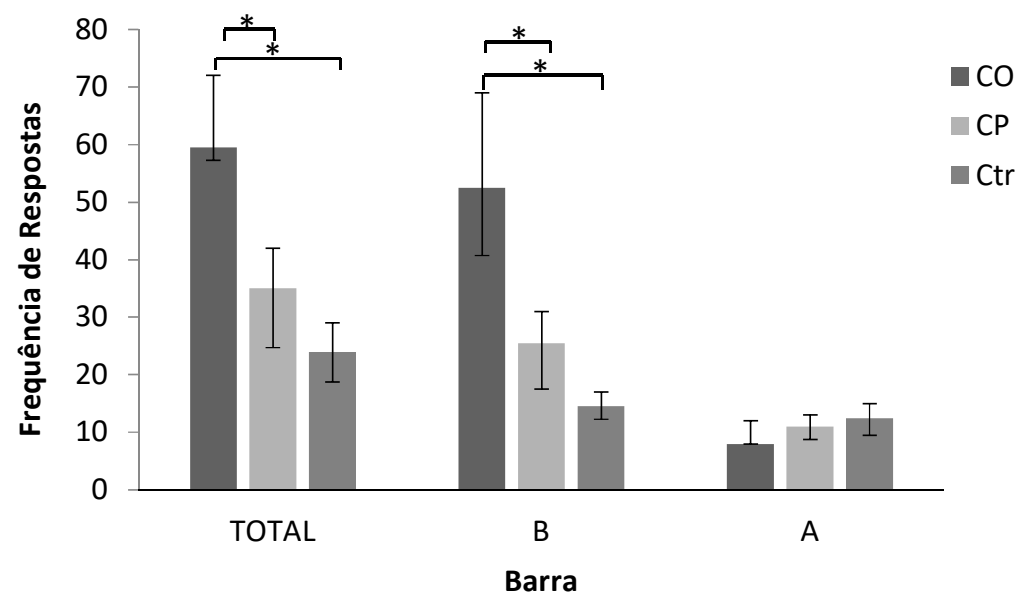

Figura 13 - Frequência total de respostas de busca e autoadministração. Os dados representam a mediana (-P25 e +P75) da frequência de respostas na barra A, na barra B e o a frequência total (a somatória das repostas em ambas as barras), na presença de $\mathrm{S} 1$ e $\mathrm{S} 2$, dos sujeitos dos grupos $\mathrm{CO}, \mathrm{CP}$ e Ctr durante a Fase 4. ${ }^{*} \mathrm{p}<0,05 * * \mathrm{p}<0,01$ para pós-hoc Mann-Whitney com correção Bonferroni.

Na Figura 14 são mostrados os Índices Discriminativos (respostas em S1/respostas totais) da frequência total de respostas, frequência de respostas na Barra B e frequência de respostas na barra A de cada grupo na Fase 4. O índice discriminativo permite observar o controle de S1 sobre ambas as respostas de interesse, busca e autoadministração. Foram observadas diferenças entre grupos no ID Total em S1 (Kruskall-Wallis test: H (2, N=22) $=15,932 p=0,000$ ), com uma mediana de 87,13 para o grupo CO, 71,57 para o CP e 57,63, e o teste pós-hoc Mann-Whitney com correção de Bonferroni mostrou resultados significativos 
de $\mathrm{CO} \times \mathrm{CP}(p=0,003), \mathrm{CO} \times \mathrm{Ctr}(p=0,002)$, e $\mathrm{CP} \times \mathrm{Ctr}(p=0,037)$. Em relação aos indices discriminativos de cada barra, a análise mostrou que houve diferença entre os grupos no controle de S1 sob as respostas emitidas na barra B (Kruskall-Wallis test: H (2, N=22) $=14,000 p=0,001)$ e na Barra A (Kruskall-Wallis test: $\mathrm{H}(2, \mathrm{~N}=22)=13,584 ; p=0,001)$. As análises pós-hoc revelaram que S1 controlou as respostas emitidas pelo grupo CO na barra B quando comparado com $\mathrm{CP}(\mathrm{p}<0,001)$ e $\mathrm{Crt}(\mathrm{p}=0,007)$, mas não se observaram diferenças entre os grupos $\mathrm{CP}$ e $\mathrm{Crt}(\mathrm{p}=1)$. Por outro lado, quando foi comparado o ID na barra A, a análise revelou que o grupo CP obteve índices significativamente maiores do que os grupo $\mathrm{CO}(\mathrm{p}=0,013)$ e do que o grupo $\mathrm{Crl}(\mathrm{p}=0,002)$, mas não houve diferenças entre os grupos $\mathrm{CO}$ e $\operatorname{Crtl}(p=0,243)$.

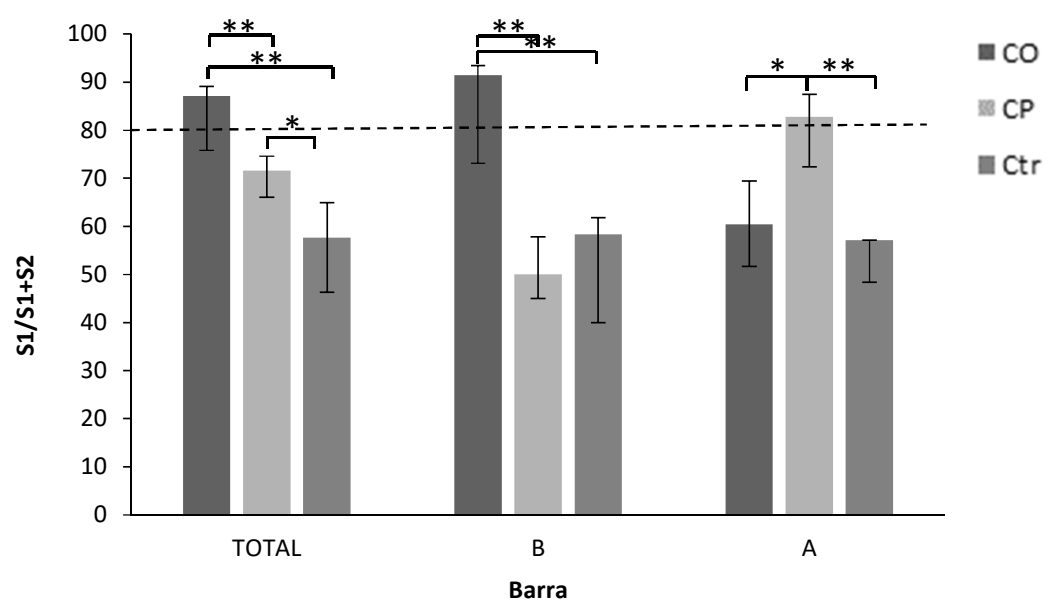

Figura 14 - Discriminação de S1 na Fase 4. O gráfico mostra o ID das de respostas de busca, respostas de administração e respostas totais, como mediana (-P25 e +P75), dos sujeitos integrantes dos grupos CO, CP e Ctr durante a Fase 4 (Teste de Transferência Sob o Controle de S1 nas Respostas de Busca e Autoadministração de Morfina). ${ }^{*} \mathrm{p}<0,05 * * \mathrm{p}<0,01$ para pós-hoc Mann-Whitney com correção Bonferroni.

A análise dos IDs por sujeito (Figura 15) permite observar com maior detalhe o controle de S1 (índice discriminativo) sobre as respostas emitidas nas barras B e A. Nota-se que $\mathrm{S} 1$ controlou as respostas de responder em $\mathrm{B}$, mas não em $\mathrm{A}$, de todos os animais do grupo CO. Por outro lado, mais da metade dos animais do grupo CP obteve ID maior a $80 \%$ 
na barra A. As respostas de apenas um animal do grupo Ctr ficaram sob controle de S1. Desta forma, é evidente que houve controle diferencial de S1 sobre as respostas emitidas pelos animais dos diferentes grupos.

B



A



Figura 15 - Índice discriminativo por sujeito nas barras de busca e administração. O gráfico mostra por sujeitos o ID das de respostas de busca e de administração, dos sujeitos integrantes dos grupos $\mathrm{CO}, \mathrm{CP}$ e Ctr durante a Fase 4.

Na Figura 16, mostra-se a distribuição das respostas em percentual entre as barras B e A na presença de S1 e S2, para cada grupo. Nota-se clara diferença de distribuição das respostas entres os grupos. Todos os animais do grupo CO mostraram preferência pela Barra B quando S1 estava presente. Em torno do $90 \%$ das respostas foram emitidas na barra B, indicando uma forte preferência por essa barra. A análise estatística (Kruskall-Wallis test: $\mathrm{H}$ $(2, \mathrm{~N}=22)=1,609 \mathrm{p}=0,447)$ revelou diferenças significativas entre dois grupos em relação à preferência pelas barras na presença de S1, e o pós-hoc mostrou resultados significativos de CO x CP $(p<0,001)$ e CO x Ctr $(p=0,013)$. A análise estatística não revelou diferenças entre grupos na presença de S2 (Kruskall-Wallis test: $\mathrm{H}(2, \mathrm{~N}=22)=16,273 \mathrm{p}=0,00)$. A diferença entre os grupos em relação à preferência por $\mathrm{B}$, o teste pós-hoc mostrou que a mediana do grupo $\mathrm{CO}$ foi maior do que as dos grupos $\mathrm{CP}$ e $\mathrm{Ctr}(\mathrm{p}=0,001$ e $\mathrm{p}=0,002$, respectivamente), 
porém não houve diferenças entre os grupos $\mathrm{CP}$ e $\mathrm{Crt}(\mathrm{p}=0,143)$. Como mostrado na mesma figura, foi também observada diferença entre os grupos em relação à preferência por A, independentemente do controle de S1 e S2 (Kruskall-Wallis test: H (2, N=22) =15,043 p $=0,001)$. Novamente, a prova pós-hoc encontrou diferenças entre $\mathrm{CO}$ e $\mathrm{CP}(\mathrm{p}=0,000)$ e entre $\mathrm{CO}$ e $\mathrm{Ctr}(\mathrm{p}=0,002)$, mas não entr $\mathrm{CP}$ e $\mathrm{Ctr}(\mathrm{p}=0,425)$.

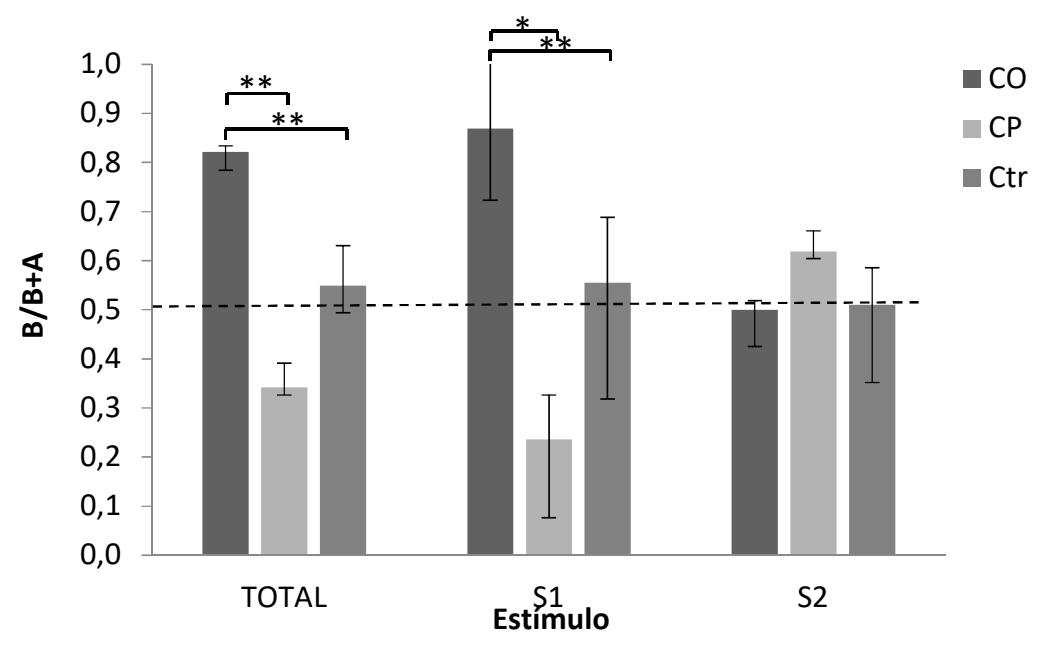

Figura 16 - Preferência por B na presença dos estímulos discriminativos. Os dados mostram a distribuição das respostas entre a barra B e a barra A como mediana (-P25 e +P75) do índice de preferência (frequência de respostas em $\mathrm{B} /$ frequência de resposta em $\mathrm{B}$ + frequência de resposta em A) na presença de S1 e S2 na Fase 4 do Experimento 2, dos grupos CO, CP e Ctr. ${ }^{*} \mathrm{p}<0,05 * *$ p $<0,01$ para pós-hoc Mann-Whitney com correção Bonferroni.

Como mostrado na Figura 17, onde se mostram os dados individuais, todos os ratos do grupo $\mathrm{CO}$, mas nenhum do grupo $\mathrm{CP}$, preferiram a barra B quando S1 foi apresentado. Já os animais do grupo CP mostraram maior variabilidade, sendo que a maioria preferiu a barra A na presença desse estímulo. Quanto o grupo Ctr não se observa algum padrão. 
S1



S2

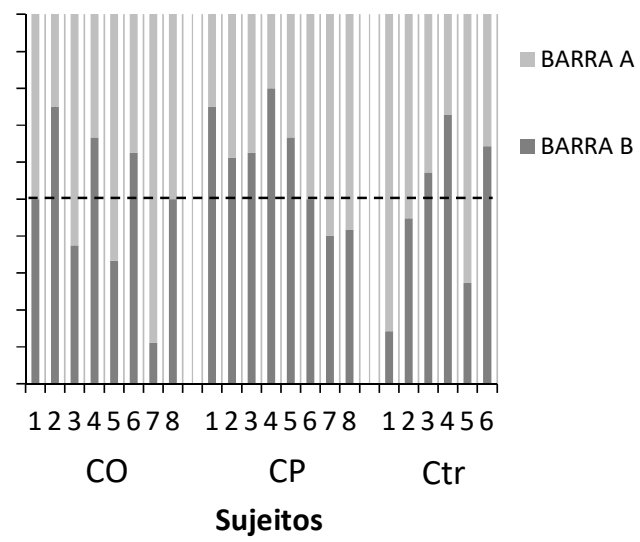

Figura 17 - Porcentagem de respostas de busca e administração em S1 e S2. O gráfico mostra a proporção de respostas na barra de busca (B) e de administração (A) na presença de S1 e S2, dos grupos $\mathrm{CO}, \mathrm{CP}$ e Ctr, durante a Fase 4.

Por último, na Figura 18 podem ser observadas a latência da primeira resposta emitida diante S1 e de S2 durante a Fase 4. A análise Kruskall-Wallis revelou diferenças na latência de resposta em B (Kruskall-Wallis test: $\mathrm{H}(2, \mathrm{~N}=22)=13,589 p=0,001)$ e em A (KruskallWallis test: $\mathrm{H}(2, \mathrm{~N}=22)=15,605 p=0,000)$ na presença de $\mathrm{S} 1$, e em A na presença de $\mathrm{S} 2$ (Kruskall-Wallis test: H $(2, \mathrm{~N}=22)=11,503 p=0,003)$. Não houve diferenças de latência de respostas em B na presença de $\mathrm{S} 2$ (Kruskall-Wallis test: $\mathrm{H}(2, \mathrm{~N}=22)=5,671 p=0,059)$. As análises pós-hoc revelaram que na presença de S1 a latência em B do grupo CO foi menor do que as latências dos grupos $\mathrm{CP}(\mathrm{p}=0,001)$ e $\mathrm{Ctr}(\mathrm{p}=0,002)$, mas foi maior em $\mathrm{A}(\mathrm{p}<0,001$ e $p=0,002$, respectivamente). Ainda, foi observado que na presença de $S 2$, a latência de resposta em A do grupo $\mathrm{CO}$ foi maior do que a dos grupos $\mathrm{CP}(\mathrm{p}=0,01)$ e $\mathrm{Ctr}(\mathrm{p}=0,29)$. 


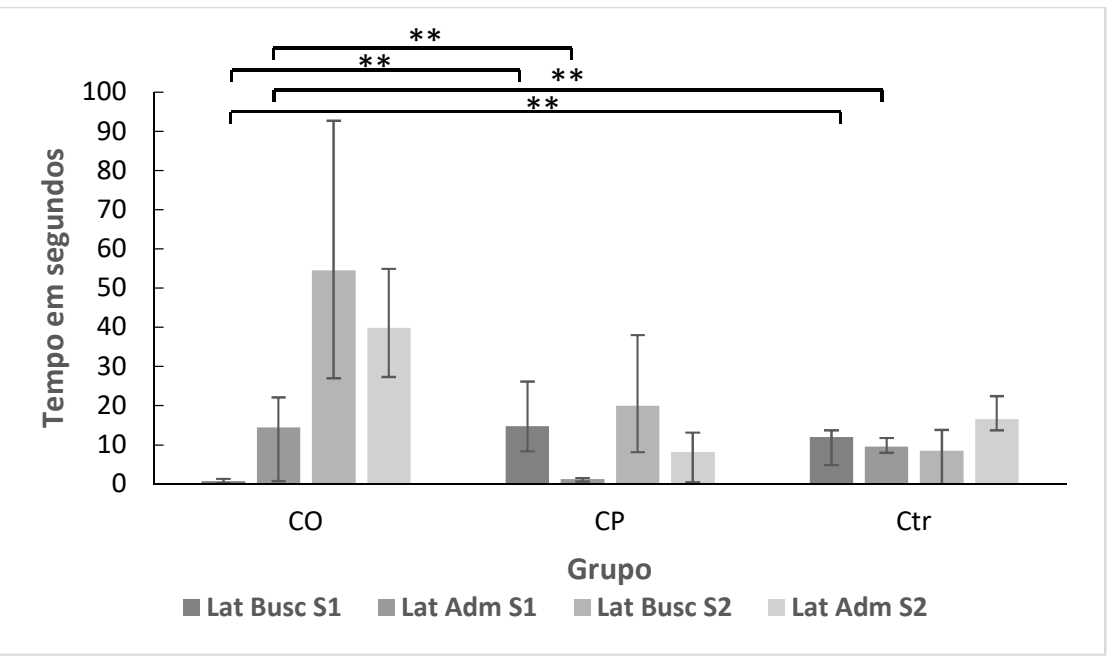

Figura 18 - Latência da primeira resposta na Fase 4. Os dados mostram a mediana (-P25 e +P75) do tempo em segundos transcorridos desde a $1^{\mathrm{a}}$ apresentação de $\mathrm{S} 1$ ou S2 e a emissão da $1^{\mathrm{a}}$ resposta na barra A ou na barra B, para cada grupo CO, CP e Ctr durante a Fase 4. ${ }^{*} \mathrm{p}<0,05 * * \mathrm{p}<0,01$.

Em resumo, os resultados apresentados do Experimento 2 mostram que: a) durante a

Fase 1 os animais receberam um número de infusões de morfina normal dentro do reportado na literatura, b) os sujeitos do grupo CO atingiram 90\% ou mais de ID durante a a Fase 2, c) os animais dos três grupos atingiram estabilidade no número de infusões de morfina durante a Fase 3, e não foram encontradas diferenças entre grupos nas respostas de busca e administração; d) Durante a Fase 4, os sujeitos do grupo CO mostraram maior número de respostas de busca e respostas totais na presença de $\mathrm{S} 1$ comparados com os grupos $\mathrm{CP}$ e Ctr; e) No teste de transferência da Fase 4, o grupo CO mostrou um ID superior a $80 \%$ nas respotas de busca e respostas totais na presença de $\mathrm{S} 1$, sendo diferente dos grupos $\mathrm{CP}$ e $\mathrm{Ctr}$, porém o grupo CP mostrou um ID superior a $80 \%$ nas respostas de administração na presença de $\mathrm{S} 1$, sendo diferente dos grupos $\mathrm{CO}$ e Ctr; e) o grupo CO mostrou preferência pela resposta de busca na presença de $\mathrm{S} 1$ e nas respostas totais quando comparado com os grupos $\mathrm{CP}$ e $\mathrm{Ctr}$ durante a fase 4; e f) no teste de transferência, a latência de resposta de busca na presença de $\mathrm{S} 1$ foi menor no grupo $\mathrm{CO}$ comparado com o $\mathrm{CP}$ e $\mathrm{Ctr}$, enquanto que a latência de resposta de administração na presença de S1 foi menor no grupo CP comparado com o CO e Ctr. 
A Tabela 4 mostra todos os resultados possíveis derivados das comparações entre os grupos. Acredita-se que a tabela possa auxiliar o acompanhamento dos resultados e a discussão.

Tabela 4. Resultados possíveis e sua interpretação (mudança nos parâmetros comportamentais índice discriminativo ou preferência) de acordo com as variáveis independentes manipuladas (infusão de droga e contingência de administração na Fase I)

\begin{tabular}{|c|c|c|c|}
\hline RESULTADO & DROGA & CONTINGÊNCIA & INTERPRETAÇÃO \\
\hline $\begin{array}{l}\mathrm{CO}=\mathrm{CP} \\
\mathrm{CO}=\mathrm{Ctr} \\
\mathrm{CP}=\mathrm{Ctr}\end{array}$ & Não & Não & $\begin{array}{l}\text { Ausência de PIT. O estímulo controlou a } \\
\text { resposta na Fase } 4 \text { independentemente da } \\
\text { droga ou da contingência }\end{array}$ \\
\hline $\begin{array}{l}\mathrm{CO}=\mathrm{CP} \\
\mathrm{CO} \neq \mathrm{Ctr} \\
\mathrm{CP}=\mathrm{Ctr}\end{array}$ & Não & Não & $\begin{array}{l}\text { Ausência de PIT. O estímulo controlou a } \\
\text { resposta na Fase } 4 \text { independentemente da } \\
\text { droga ou da contingência. A diferença } \\
\text { explicada por outra variável }\end{array}$ \\
\hline $\begin{array}{l}\mathrm{CO}=\mathrm{CP} \\
\mathrm{CO}=\mathrm{Ctr} \\
\mathrm{CP} \neq \mathrm{Ctr}\end{array}$ & Não & Não & $\begin{array}{l}\text { Ausência e PIT. O estímulo controlou a } \\
\text { resposta na Fase } 4 \text { independentemente da } \\
\text { droga ou da contingência. A diferença } \\
\text { explicada por outra variável }\end{array}$ \\
\hline $\begin{array}{l}\mathrm{CO}=\mathrm{CP} \\
\mathrm{CO} \neq \mathrm{Ctr} \\
\mathrm{CP} \neq \mathrm{Ctr}\end{array}$ & Sim & Não & $\begin{array}{l}\text { Houve PIT. O estimulo controlou a } \\
\text { resposta de autoadministração na Fase } 4 \\
\text { independentemente do treino da Fase } 2 .\end{array}$ \\
\hline $\begin{array}{l}\mathrm{CO} \neq \mathrm{CP} \\
\mathrm{CO} \neq \mathrm{Ctr} \\
\mathrm{CP} \neq \mathrm{Ctr}\end{array}$ & Sim & Sim & $\begin{array}{l}\text { Houve PIT. O estímulo controlou a } \\
\text { resposta de autoadministração dos animais } \\
\text { na Fase } 4 \text { de acordo com o treino da Fase } \\
2 \text {. }\end{array}$ \\
\hline $\begin{array}{l}\mathrm{CO} \neq \mathrm{CP} \\
\mathrm{CO} \neq \mathrm{Ctr} \\
\mathrm{CP}=\mathrm{Ctr}\end{array}$ & Sim & Sim & $\begin{array}{l}\text { Ausência de PIT. O estímulo controlou } \\
\text { apenas a resposta do grupo CO na Fase } 3 \text {. }\end{array}$ \\
\hline $\begin{array}{l}\mathrm{CO} \neq \mathrm{CP} \\
\mathrm{CO}=\mathrm{Ctr} \\
\mathrm{CP} \neq \mathrm{Ctr}\end{array}$ & Sim & $\mathrm{Sim}$ & $\begin{array}{l}\text { PIT apenas pode ser avaliado após } \\
\text { observação dos valores. O treino da Fase } 3 \\
\text { teve efeito diferencial sobre o desempenho } \\
\text { na Fase } 4 \text { dos grupos CO e CP. }\end{array}$ \\
\hline $\begin{array}{l}\mathrm{CO} \neq \mathrm{CP} \\
\mathrm{CO}=\mathrm{Ctr} \\
\mathrm{CP}=\mathrm{Ctr}\end{array}$ & Não & Não & $\begin{array}{l}\text { Ausência de PIT. O controle do estímulo } \\
\text { na Fase } 4 \text { apenas pode ser avaliado após } \\
\text { observação dos valores. }\end{array}$ \\
\hline
\end{tabular}




\section{Discussão}

Este experimento teve como objetivo estabelecer e aperfeiçoar um protocolo de autoadministração de drogas em esquema acoplado para comparar de forma adequada a administração sob condicionamento operante e pavloviano separando as respostas de busca e autoadministração de droga. O experimento consistiu em quatro fases: a) Fase 1, Treino associativo de morfina e S1 em esquema acoplado; b) Fase 2, Treino discriminativo sob contingência operante ou Pavloviana de morfina em esquema acoplado; c) Fase 3, Treino de encadeamento das respostas de busca e autoadministração de morfina; e Fase 4, Teste de transferência do controle de S1.

Durante a Fase 2, cada vez que um sujeito do grupo CO respondia na roda operante tinha como consequência uma infusão de morfina e simultaneamente o sujeito do grupo CP e o do grupo Ctr a ele acoplados receberam sob contingência Pavloviana uma injeção i.v da droga na mesma dose ou de veículo, respectivamente. Cada infusão foi sinalizada pela apresentação simultânea de S1. Como no Experimento 1, a média de infusões ficou na faixa relatada pela literatura, assim como o número de sessões em que a o ID do grupo CO fícou estável (Mierzejewski et al., 2003; Suto et al., 2011).

Na Fase 3 não foram observadas diferenças entre os grupos, indicando que o treino realizado na Fase 1 não teve efeito sobre a aquisição da pressão de barra. Isto é, a taxa de respostas e média de infusão dos animais dos três grupos foi similar a despeito da experiência prévia com morfina e com diferentes contingências de sua administração. Portanto, a Fase 2 parece não ter ocasionado efeitos de tolerância aos efeitos reforçadores da morfina. Ainda, esses dados validam os obtidos na Fase 4, uma vez que grandes diferenças no número de infusões entre grupos durante esta fase poderiam alterar o responder durante a seguinte. 
Os resultados do teste de transferência (Fase 4) indicaram que os estímulos antecedentes adquiriram controle sobre a resposta de pressão de barra dos animais do grupo $\mathrm{CO}$ e CP, mas não dos animais do grupo Crt (ID de respostas totais e de respostas na presença de S1), indicando transferência de controle desses estímulos para um novo operante, no caso do grupo $\mathrm{CO}$, e PIT para o grupo $\mathrm{CP}$. Entretanto, o controle de S1 sobre a pressão à barra foi dependente das contingências manipuladas na Fase 2. S1 controlou as respostas dos ratos do grupo CO só na barra B (aqui denominada "Busca"), primeiro elo da cadeia da Fase 3 e apenas consequênciada com a apresentação da barra A (aqui denominada “Autoadministração"). Ainda foi observado que os animais desse grupo mostraram preferência por essa barra na presença de S1, mas não de S2. Por outro lado, S1 controlou as respostas dos animais do grupo $\mathrm{CP}$ só na barra A, porém não foi observada preferência por essa barra na presença de nenhum dos estímulos.

A transferência do controle de S1 da resposta de girar a roda para a resposta topograficamente diferente de apertar a barra é um fenômeno esperado e relacionado ao conceito bem conhecido na literatura de classes de respostas. Uma classe de respostas ou classe operante é um conjunto de respostas operantes que podem variar em sua topografia, mas que produzem a mesma consequência (Catania, 1999). Classes operantes são, assim, funcionalmente equivalente, e essa equivalência é o que define a classe (Barnes-Holmes \& Barnes-Holmes, 2000). Portanto, uma vez que pressionar a barra era mantida pela mesma consequência do que girar a rodar (i.e., morfina), pode-se dizer que ambas topografias eram da mesma classe operante. De fato, o controle de S1 sob a pressão de barra seria um indicador importante desses dois comportamentos serem funcionalmente equivalentes. Deste modo, a transferência de controle observada no desempenho dos animais do grupo CO indica que os procedimentos de treino estabeleceram os controles esperados e adequados sobre o comportamento dos animais. 
Por outro lado, o controle de S1 sob a resposta de pressão de barra dos animais do grupo CP é indicador de PIT. Os processos comportamentais envolvidos na PIT não estão claramente caracterizados na literatura, porém, assim como nas classes operantes, o estímulo comum (i.e., o mesmo estímulo ter função de SR e o US) é uma das variáveis que facilita sua ocorrência (Alarcon, Bonardi \& Delamater 2018; Cartoni et al., 2016; Delamater \& Oakeshott, 2007).

De caráter complexo é explicar o controle diferencial de S1 sobre as respostas nas barras A e B dos animais dos grupos CO e CP. Primeiro se pretende explicar o controle de S1 sobre o comportamento do grupo CP e depois o do grupo CO.

A contingência pavloviana da Fase 2 estabelecia relação direta entre os eventos S1 e a infusão de morfina (relação de contingência) e de contiguidade (relação de contiguidade ${ }^{14}$ ).

Na Fase 3, a infusão de morfina era seguida apenas depois da pressão da barra A, sendo que a pressão da barra B apenas produzia a barra A. Assim, a pressão da barra A estabelecia uma relação de contingência e contiguidade entre os eventos mais semelhante à da Fase 2 do que a pressão da barra $\mathrm{B}$, que não era contigua nem tinha relação direta de contingência com a infusão de morfina.

Delamater e Oakeshott (2007) relatam um experimento onde ratos foram primeiro treinados sob relações pavlovianas CS1-US1 e CS2-US2 e operantes R1-US1 e R2-US2; depois, de forma semelhante como a realizada neste experimento, observaram a resposta (R1 ou R2) na presença desses estímulos. Os autores observaram que na presença de CS1 os animais emitiam R1 e na presença de S2 emitiam R2. Adicionalmente, Corbit e Balleine (2003b) utilizando comida, e LeBlanc et al. (2012) utilizando COC, realizaram experimentos

${ }^{14}$ Após S1 ter adquirido o controle do responder dos ratos do grupo CO, o tempo entre a apresentação de $\mathrm{S} 1$ e a infusão de morfina era menor a $1 \mathrm{~s}$. 
para avaliar PIT em que ratos passaram inicialmente por uma fase em que recebiam comida ou COC, respectivamente, de forma passiva na presença de um CS. Posteriormente aprenderam um encadeado de respostas com duas barras, uma de busca e outra de administração, para ter acesso à comida ou se autoadministrar a COC. Ambas as barras estiveram presentes ao mesmo tempo durante a fase de teste de transferência e os autores reportaram que na presença do CS, os sujeitos apresentaram uma maior frequência de respostas na resposta de administração. Esses resultados, junto com evidências de que o desempenho observado em experimentos de PIT dependem do aprendizado da relação temporal entre o CS e o US (Matell \& Della Valle, 2018), suportam a ideia de que o controle de S1 sobre a barra A foi função da relação de contingência e de contiguidade da resposta nessa barra com a infusão de morfina.

Diferente do grupo $\mathrm{CP}$, ao grupo $\mathrm{CO}$ foi ensinada a relação entre $\mathrm{S} 1$ e infusão de morfina por meio de um treino operante em que respostas na presença de S1 sinalizavam a resposta de girar a roda operante. Como já discutimos, a transferência da resposta de girar a roda operante a um novo operante, pressionar barras, pode ser explicado usando-se o conceito de classe operante. A questão de maior interesse é por que S1 controlou a resposta discriminativa e a preferência pela barra B dos ratos desse grupo. Uma explicação plausível é que S1 controlou toda a cadeia comportamental ensinada na Fase 3. Isto é, não apenas o último elo da cadeia (responder na barra A) entrou na classe operante mantida pela morfina, mas também o elo inicial (responder na barra B). Assim, uma vez que pressionar a barra B é a primeira resposta a ser emitida na cadeia, então na presença de $\mathrm{S} 1$, os animais do grupo CO pressionavam essa barra. Essa proposta é coerente com o estudo de Bachá-Mendez Reid e Mendoza-Soylovna (2016), que sugere que sequencias comportamentais de duas respostas podem se conformar como unidades comportamentais integradas, que são mantidas pelo reforço "primário" (i.e., a comida fortalece toda a cadeia comportamental e não apenas a 
resposta do último elo). Também é consistente com dados de Thrailkill \& Bouton (2015, 2016) que mostram que a extinção da resposta de procura (primeiro elo da cadeia) diminui o controle do estímulo sobre a resposta de consumo (segundo e último elo da cadeia) a ela associada e vice-versa (a extinção da resposta de consumo altera o controle do estímulo sobre a resposta de procura).

Infelizmente, no momento não está realizada a análise da sequência de respostas que permita mostrar que os animais emitiam toda a cadeia comportamental, porém, os dados estão registrados e a análise será feita para complementar a publicação destes dados. Entretanto, considerando que os animais adquiriram e mantiveram a cadeia comportamental na Fase 3, é coerente e parcimonioso assumir que depois de pressionarem a barra A, os animais pressionariam a barra $\mathrm{B}$.

O dado que mostra que a frequência de respostas do grupo $\mathrm{CO}$ foi maior do que a do resto dos grupos durante a Fase 4 parece menos complexo de interpretar. Essa diferença não poderia ser explicada apenas pelas características motoras da resposta treinada na Fase 2, nem pelo desempenho na Fase 3, pois como já apontado, a frequência de respostas (i.e.,número de infusões) foi semelhante entre os grupos. Uma possível explicação para este resultado é que o CS associado à morfina durante as Fases 1 e 2 foi de curta duração (30 s), o que causaria segundo alguns autores um responder operante diminuído durante o teste de transferência na Fase 4 (Lovibond, 1981; van Dyne, 1971) em comparação com um CS de alta duração, o qual aumentaria esta taxa de respostas (Estes, 1943, 1948; Crombag et al., 2008). Outra possível explicação poderia ser que mesmo que tanto a contingência operante, quanto a Pavloviana, podem prover as condições para ter resistência a extinção no teste de transferência (Nevin \& Grace, 2000, 2005), aumentando temporalmente a taxa de respostas observadas (Catania, 1999), esta resistência à extinção se pode ver afetada por muitas variáveis (Lattal \& Lattal, 2012) que teriam sido diferentes para as condições dos treinos dos grupos $\mathrm{CO}$ e $\mathrm{CP}$, causando 
esta diferença na taxa de respostas na Fase 4. Por exemplo, o grupo CO teve maior treino instrumental que o $\mathrm{CP}$, tendo em conta as fases 1 e 2, nas quais o $\mathrm{CP}$ não teve nenhum tipo de controle sobre a morfina. Segundo alguns autores (Holmes et. al., 2010; Lattal \& Lattal, 2012), esta quantidade de treino instrumental, poderia ter causado que o grupo $\mathrm{CO}$ apresentasse uma maior taxa de respostas durante a Fase 4, a qual se realizou em condições de extinção.

A latência da primeira resposta acompanhou o controle de S1 sobre a pressão à barra. O grupo $\mathrm{CO}$ mostrou menor latência de resposta na barra $\mathrm{B}$ na presença de $\mathrm{S} 1$ e o grupo $\mathrm{CP}$ mostrou a menor latência na barra A na presença de S1. Com frequência, a latência de resposta não é encontrada como uns dos parâmetros avaliados em estudos de controle de estímulos, porém, a latência pode oferecer valiosos dados sobre o valor reforçador de um estímulo (Domjan, 2015; Zeaman, 1949) e a aprendizagem da relação CS-US (Catania, 1999; Supes et al., 1966). Os resultados da latência de resposta em conjunto com os resultados de ID, preferência de resposta e frequência de respostas, parecem apontar a um padrão, em que o tipo de contingência teria causado que o controle de estímulos que se desenvolveu no grupo CO e CP tenha algumas diferenças. Quando S1 esteve presente na Fase 4, no grupo CO a latência de resposta foi menor na barra B, teve uma maior taxa de respostas na barra B e uma clara preferência por esta, assim como um alto ID nesta mesma resposta; por outro lado, no grupo CP, a latência de resposta foi menor na barra A e a taxa de respostas, preferência de resposta e ID foram maiores para a barra A.

Em resumo, nossos dados sugerem que o controle de estímulos ambientais sobre a cadeia comportamental inerente a qualquer autoadministração de droga (i.e.,procura da droga seguida de consumo) é função das contingências comportamentais sob as quais foi estabelecida a relação desse estímulo com a droga. Também indicam que tanto autoadministrada, quanto administrada de forma passiva, o controle de estímulos do ambiente 
é transferido para novos comportamentos de autoadministração reforçados pela mesma droga, mesmo quando esses novos comportamentos são adquiridos na ausência desses estímulos. Ainda, os dados sugerem que o controle de estímulos estabelecido pela contingência operante foi mais efetivo que o estabelecido pela contingência Pavloviana.

Os dados produzidos por este experimento mostram a adequação do modelo de administração acoplado (Catania, 1999; Sanchis-Segura\& Spanagel, 2006) para o estudo do efeito das contingências de treino operante e respondente sobre os comportamentos do dependente de drogas. O delineamento experimental dos estudos prévios (Patarroyo, Felício e García-Mijares, 2014) não tinha permitido uma probabilidade S1-morfina de 100\% para o grupo CP durante o treino em associação Pavloviana, nem permitia separar as respostas de busca e autoadministração, o que poderia explicar que naquele estudo não tenha sido observado PIT ao não ter se formado a relação CS-US para esse grupo (Estes, 1948; Holland, 2004; Rescorla, 1994).

De fato, como apontado por Sanchis-Segura e Spanagel (2006), o processo de administração de uma droga inclui várias fases, como busca/forrageio, compra/aquisição e finalmente o consumo. Portanto é importante que estudos que visam compreender a dependência às drogas estudem estas respostas por separado, pois como mostrado neste experimento, não todas as respostas no processo de consumo de uma droga são afetadas da mesma forma por estímulos que foram associados a estas em diferentes histórias de associação.

Finalmente, ainda destacando que o modelo e o delineamento utilizados neste experimento sejam adequados estudo para estudar o controle de estímulos, é importante notar as suas limitações. A Fase 4 dispunha simultânea e permanentemente as barras de busca e administração, o que permitiu coletar os valiosos dados destas respostas por separado e 
observar os resultados discutidos, porém, ao estarem apresentadas ao mesmo tempo, não se apresentou mais uma situação de cadeia de respostas, como treinado previamente, mas uma situação de escolha. Portanto, a barra de busca não teve mais uma função de busca per se, e entrou em concorrência com a barra de administração. 


\section{Experimento 3. Associações por Contingências Pavloviana e Operante nas Respostas de Busca e Administração de COC e a na Expressão de $\Delta$ FosB}

O Experimento 3 teve dois objetivos, o primeiro foi observar e comparar o possível efeito diferencial nas respostas de busca e autoadministração de COC na presença de um estímulo associado a esta droga por contingência operante ou Pavloviana, avaliando o controle que estímulos ambientais associados à COC podem exercer em diferentes histórias de administração. O segundo objetivo foi verificar o efeito da autoadministração e administração passiva de COC sobre a expressão gênica de $\Delta \mathrm{FosB}$ em diferentes áreas do cérebro implicadas na dependência às drogas.

Neste experimento foram realizadas algumas mudanças metodológicas em relação ao experimento 1 e 2 , que são resumidas a seguir.

Primeiro, a droga administrada foi COC em vez de morfina. Os resultados do Experimento 2 mostraram que a morfina controlou o comportamento de autoadministração dos ratos, porém as taxas de respostas mantidas foram baixas. Por outro lado, a COC tem efeitos estimulantes sobre o comportamento e tipicamente produz altas taxas de resposta (Arroyo, Markou, Robbins \& Everitt, 1988; Negus \& Mello, 2003) e potencial para causar uma forte dependência (Deroche-Gamonet, 2004; Kreek et al., 2012; Roberts, Morgan \& Liu, 2007). No delineamento de treino utilizado neste estudo, maiores taxas de respostas estão correlacionadas a maior número de pareamentos entre o efeito da droga e o $\mathrm{S} 1$, facilitando a aprendizagem das contingências (Catania, 1999), consequentemente facilitando a transferência do pareamento respondente à contingência operante (i.e.,PIT).

Segundo, foram usados ratos Lewis em vez de wistar. Ratos Lewis são uma cepa susceptível a rápida aquisição de dependência (e.g., Kosten \& Ambrósio, 2002; Sánchez- 
Cardoso et al., 2009). Assim, procurou-se aumentar a probabilidade da droga ser uma consequência reforçadora para os animais.

Terceiro, a técnica imunohistoquímica foi realizada após duas fases fundamentais, após as contingências Pavloviana e operantes serem estabelecidas (Fase 2) e após finalizadas todas as fases de treino, tendo realizado o teste transferência. Isto permitiu ter medidas comportamentais, medidas imunohistoquímica e de autorradiografia nos momentos em que as contingências de aprendizagem estavam recém estabelecidas em cada etapa do experimento.

\section{Sujeitos}

Foram usados no total 34 ratos albinos machos da cepa Lewis $(\mathrm{CO}=12, \mathrm{CP}=12, \mathrm{Ctr}$ $=10$ ), experimentalmente ingênuos. As cirurgias foram realizadas quando os sujeitos atingiram $280 \mathrm{~g}-300 \mathrm{~g}$ de peso. Sete dias após a recuperação da cirurgia, os animais foram distribuídos aleatoriamente em três grupos: Contingência Operante $(\mathrm{CO})$, por Contingência Pavloviana (CP) e Controle (Ctr), formando trios com um sujeito de cada grupo. Para realizar os testes imunohistoquímica os encéfalos de metade dos grupos foram removidos após a Fase $2(\mathrm{CO}=6, \mathrm{CP}=6, \mathrm{Ctr}=5)$, e a outra metade após a Fase 4 .

\section{Fases Experimentais}

As fases experimentais 1, 2, 3 e 4 são similares as do experimento 2. As principais variações são ajustes aos esquemas de reforço dada a natureza ativadora da $\mathrm{CoC}$ em comparação à morfina utilizada nos experimentos anteriores.

\section{Fase 1. Treino Associativo de COC e S1 em Esquema Acoplado}

A resposta de girar 90 graus uma roda operante foi modelada por quatro dias consecutivos em esquema $\mathrm{CRF}$ para o grupo $\mathrm{CO}$, sendo incrementado gradativamente para FR10 (FR2, FR5, FR10). Os animais dos grupos CP e Ctr foram colocados em caixas 
operantes iguais às do grupo $\mathrm{CO}$ (com a exceção da ausência do receptáculo). Cada vez que um sujeito do grupo $\mathrm{CO}$ respondeu na roda operante, uma infusão endovenosa de COC em dose eficaz para autoadministração $(0,75 \mathrm{mg} / \mathrm{kg})$ foi administrada automaticamente por meio do cateter alocado cirurgicamente. Os animais dos grupos $\mathrm{CP}$ e Ctr receberam simultaneamente uma dose de COC ou salina, respectivamente. O estímulo S1 (buzzer) esteve sempre presente nas sessões desta fase para todos grupos.

Cada sessão teve duração máxima de $2 \mathrm{~h}$ programadas, podendo terminar antecipadamente para um trio se o membro do grupo $\mathrm{CO}$ atingir 20 infusões para o seu grupo. O critério de estabilidade estabelecido para passar de fase foram duas sessões consecutivas sem aumento ou diminuição sistemática de infusões, ou seja $\pm 10 \%$ de variação do número de infusões por sessão.

\section{Fase 2. Treino Discriminativo em contingência operante ou Pavloviana de COC}

O treino discriminativo para os sujeitos do grupo CO consistiu em aproximadamente 21 sessões de $2 \mathrm{~h}$ utilizando a roda operante como operando e um buzzer como estímulo discriminativo. Os animais do grupo CO foram treinados em um esquema múltiplo de dois componentes, esquema FR10 e extinção. O esquema FR10 funcionou na presença do buzzer (S1) e a extinção funcionou na ausência deste (S2). As apresentações dos componentes tiveram uma duração de $180 \mathrm{~s}$ e foram apresentados de forma pseudoaleatória, sendo programados para cada um se apresentar no máximo três vezes consecutivas. O responder nos últimos $10 \mathrm{~s}$ de cada componente teve como consequência o aumento deste em $10 \mathrm{~s}$ até nenhuma resposta fosse apresentada, isto com o objetivo de que a contingência do treino fosse bem estabelecida e evitar assim um efeito de carry over. Para os animais acoplados CP e Ctr as infusões de COC foram simultâneas (às dos sujeitos $\mathrm{CO}$ ) e sinalizadas por S1, sendo controladas sempre pelos sujeitos do grupo CO. As apresentações de S2 também foram 
simultâneas para os membros de cada trio. Este arranjo permitiu que os grupos $\mathrm{CO}$ e CP tivessem o mesmo número de apresentações de COC pareadas com $\mathrm{S} 1,100 \%$ das vezes.

O critério de estabilidade estabelecido para passar de fase foram duas sessões consecutivas sem aumento ou diminuição sistemática de infusões, ou seja $\pm 10 \%$ de variação do número de infusões por sessão.

Fase 3. Treino de Encadeamento das Respostas de Busca e Autoadministração de COC

Os sujeitos não permaneceram mais acoplados durante esta fase e as infusões não foram acompanhadas por S1. Inicialmente foi treinada a resposta de autoadministração de COC: uma única barra retrátil (contrabalanceando lado esquerdo e direito) foi disponibilizada para os ratos de todos os grupos. Durante duas sessões a resposta de apertar esta barra teve como consequência uma dose de $\mathrm{COC}$, seguida por 10s de timeout (TO), no qual a barra não esteve disponível, com o fim de evitar uma possível overdose. Posteriormente foi treinada a resposta de busca por COC encadeada à resposta de autoadministração previamente treinada. A barra contralateral foi disponibilizada no início das sessões de encadeamento. Uma resposta nesta barra (Barra B -busca) teve como consequência a disponibilização da outra barra (primeiro elo da cadeia), e resposta nesta segunda barra (Barra A - autoadministração) teve como consequência uma infusão de COC (segundo elo da cadeia), seguida pela retração de ambas as barras (TO 10s). Após cada TO a barra B foi reintroduzida sinalizando que a contingência do encadeado de busca-autoadministração estará disponível novamente. Ambos os componentes (barras) do encadeamento estiveram em esquema CRF durante duas sessões, sendo incrementado gradativamente para FR10 (FR2, FR5, FR10), até ser atingido o critério de estabilidade (duas sessões consecutivas sem aumento ou diminuição sistemática da 
frequência de respostas - diferença $\leq 10 \%$ ). Estas sessões tiveram uma duração de $2 \mathrm{~h}$, podendo terminar antecipadamente quando um sujeito atingir 20 infusões.

Fase 4. Teste de Transferência Sob Controle de S1 nas Respostas de Busca e Autoadministração de COC

Para o teste de transferência, ambas as barras estiveram disponíveis permanentemente para todos sujeitos. Tentativas discretas de S1 e S2 foram apresentadas de forma simultânea para cada trio durante a sessão, da mesma forma que na Fase 2. As respostas em ambas as barras foram registradas, porém estiveram sempre em condições de extinção. Este teste teve uma duração de $2 \mathrm{~h}$.

\section{Fase 5. Imunohistoquímica $\Delta \mathrm{Fos}$}

Foi realizada a contagem de células imunorreativas à proteína $\Delta \mathrm{FosB}$ para as áreas neurais de maior interesse (ver Tabela 2) utilizando o software Image Pro Plus ${ }^{\circledR}$. Comparado com o Experimento 1, neste experimento foi possível realizar a contagem de células imunorreativas após as fases experimentais 2 e 4, permitindo fazer a comparação entre grupos e intragrupo em dois momentos relevantes, justo após a contingência discriminativa foi treinada (Fase 2), ou seja, quando as contingências de CO e CP se mantinham puras para o grupos, e após o teste de extinção (Fase 4), sendo que para esse então todos animais de todos grupos tinham aprendido a se autoadministrar a droga, porem nunca sendo treinada uma contingência operante no grupo de contingência Pavloviana.

O procedimento imunohistoquímico é explicado com detalhe na secção de Métodos e Equipamentos do presente trabalho. Em resumo, uma hora após o término da última sessão de administração da droga, os sujeitos foram perfundidos para fixar os tecidos. Os cérebros foran removidos e posteriormente processados para obter cortes frontais seriados, com $30 \mu \mathrm{m}$ 
de espessura usando um micrótomo de congelação. Os cortes foram incubados inicialmente em uma solução de tampão fosfato de potássio $0,02 \mathrm{M}$ contendo triton X-100 a $0,3 \%$, soro normal de cabra a $2 \%$ e anticorpo policlonal $\Delta$ FosB, $\left(102\right.$, SC-48/Sta Cruz Biothecnology $\left.{ }^{\circledR}\right)$. O complexo antígeno-anticorpo foi localizado utilizando-se uma variação do sistema formado pelo complexo avidina-biotina, e após a incubação com o anticorpo primário, os cortes foram incubados em uma solução contendo anticorpo biotinilado anti-IgG de coelho, feito em cabra, e em seguida, colocados em uma solução contendo o composto avidina-biotina-HRP, para ligar a peroxidase ao complexo antígeno-anticorpo. Posteriormente se realizou a revelação do complexo antígeno-anticorpo incubando os cortes em uma solução contendo 50mg de tetrahidrocloreto de 3-3' diaminobenzidina-DAB, 0,6mg de glicose oxidase (Sigma), $2 \mathrm{ml}$ de uma solução aquosa de sulfato de níquel a 10\% e 40mg de cloreto de amônia em 100ml de tampão fosfato de sódio $0,1 \mathrm{M}$, e em seguida, foi adicionado $\beta$-D-glicose, interrompendo a reação após 10 min aproximadamente. Os cortes foram então montados em lâminas recobertas com gelatina para poder obter as imagens de microscopia que foram analisadas.

Tabela 2. Áreas Neurais Estudadas no Experimento 3

\begin{tabular}{llll}
\hline \multicolumn{1}{c}{ ÁREA } & \multicolumn{1}{c}{ SUBÁREA } & \\
\hline Córtex Pre-Frontal (PFC) & Córtex Lateral Orbital (LO) & & \\
Córtex Pre-Frontal Medial (mPFC) & Córtex Cingulado (Cg1) & Córtex Prelímbico (PrL) & Córtex Infralímbico (IL) \\
Nucleo Acumbens (NAc) & Core & Shell & \\
Caudado Putamen (CPu) & Lateral & Basolateral & \\
Hippocampo & Giro Dentado (DG) & Corno de Amon 1 (CA1) & Corno de Amon 3 (CA3) \\
Amígdala & Basolateral & Central & Medial \\
\hline
\end{tabular}

\section{Análise de dados}

A diferença de expressão de $\Delta \mathrm{FosB}$ das diferentes subáreas entre grupos foi calculada realizando testes não paramétricos para amostras independentes. O teste de Kruskall-Wallis foi realizado para detectar diferenças estatísticas, e quando achadas estas $(p<0,05)$, o teste $\mathrm{U}$ 
de Mann-Whitney com fator de correção bonferroni foi utilizado como post hoc. Para comparar as diferenças intragrupo para as fases 2 e 4 foram realizados Testes de de Wilcoxon (Willcoxon Signed-Ranks Test). Para analisar o desempenho dos sujeitos durante a Fase 3 (frequência de respostas e administrações de COC), e o desempenho dos sujeitos durante a Fase 4, ID atingido durante o teste nas respostas de busca e autoadministração de COC, persistência nas respostas de busca e autoadministração de COC durante a sessão de extinção, e latência ${ }^{15}$ à primeira resposta; foram realizados testes não paramétricos para amostras independentes. O teste de Kruskall-Wallis foi realizado para detectar diferenças estatísticas, e quando achadas estas $(p<0,05)$, o teste U de Mann-Whitney com fator de correção bonferroni foi utilizado como post hoc. Todas as análises estatísticas foram executadas fazendo uso do software aplicativo IBM SPSS ${ }^{\circledR}$.

\section{Resultados}

Os resultados deste experimento são mais extensos que os dos experimentos anteriores, dado que incluem resultados comportamentais e bioquímicos. É importante lembrar que o objetivo deste experimento não foi a replicação dos outros experimentos anteriores e comparar os resultados comportamentais e bioquímicos entre morfina e COC, mesmo sendo uma ideia tentadora. Porém, além de ter sido realizado com sujeitos da cepa Lewis no lugar de Wistar, como nos dois experimentos anteriores, e ter sido usada COC no lugar de morfina como droga para as infusões, o protocolo experimental sofreu algumas pequenas alterações de adaptação aos efeitos da nova droga estudada.

Este experimento consistiu em cinco fases, que incluem, duas fases em esquema acoplado para o treino discriminativo, uma terceira fase de treino de autoadministração sem

\footnotetext{
${ }^{15} \mathrm{O}$ sorteio de S1 e S2 não afetou a latência aqui apresentada, pois foi tomada desde o momento de aparição de S1 ou S2 até a primeira vez que uma Resposta de Busca ou Autoadministração é emitida durante a duração de um intervalo (de S1 ou S2), sendo restado o tempo anterior se foi um S diferente o apresentado.
} 
estarem os grupos acoplados, e uma fase de teste de transferência (PIT). O que é chamado de Fase 5 faz referência ao protocolo imuno-histoquímico, realizado de igual forma ao Experimento 1, em dois momentos cruciais do experimento, justo após culminada a Fase 2, i.e.,quando os animais dos três grupos tiveram aprendido as associações nas suas respectivas contingências, operante ou Pavloviana, e após o teste de transferência da Fase 4. Desta forma só a metade dos 34 sujeitos foram expostos a todas as fases experimentais, pois a outra metade foi perfundida após a Fase 2 para tomar as amostras necessárias para a imunohistoquímica.

Para a primeira fase, a média de infusões $(M=19,35 S D=0,903)$ esteve entre o esperado, com a maioria dos sujeitos se administrando as 20 infusões máximas por sessão, o que permitiu passar rapidamente para a seguinte fase.

Como pode ser observado na Figura 19, a qual ilustra os índices discriminativos (ID) das últimas seis sessões durante a Fase 2, todos os animais do grupo CO atingiram ID superior ou igual a $90 \%$. Além da estabilidade e o critério de ID, os sujeitos continuavam recebendo uma média de infusões igual à da sessão anterior, sendo em $\mathrm{CO}$ ou em $\mathrm{CP}$, atingindo o máximo de 20 infusões em quase todas as sessões diárias.




Figura 19 - Índice discriminativo durante a Fase 2 do Experimento 3. O gráfico mostra o ID dos sujeitos integrantes do grupo CO durante as últimas seis sessões da Fase 2 (Treino Discriminativo em contingência operante ou Pavloviana de Morfina). Pode-se observar que o ID vai aumentando até chegar a $90 \%$ ou superior nas últimas duas sessões.

Durante a Fase 3 (Treino de Encadeamento das Respostas de Busca e Autoadministração de Morfina), os sujeitos de todos os grupos aprenderam a tarefa de encadeamento e atingiram estabilidade de respostas de autoadministração, com uma mediana de infusões $(M d=18,01)$. Na Figura 20 pode ser observado a média da taxa de infusões por sessão por grupo das últimas seis sessões na Fase 3. Para esta fase não foram encontradas diferenças estatisticamente significativas entre grupos, para Respostas de Busca, de Autoadministração, nem em infusões. Para Respostas de Busca (Kruskall-Wallis test: H (2, $\mathrm{N}=34)=0,464 p=0,793$ ), com uma mediana de 17,92 para o grupo $\mathrm{CO}, 15,92$ para o CP e 15,25 para o Ctr. Respostas de Autoadministração (Kruskall-Wallis test: H (2, N=34) =2,126 $p=0,345)$, com uma mediana de 19,54 para o grupo CO, 15,08 para o CP e 14,06 para o Ctr. Tampouco em Respostas Totais (Kruskall-Wallis test: $\mathrm{H}(2, \mathrm{~N}=34)=3,256 p=0,196)$, com uma mediana de 20,08 para o grupo $\mathrm{CO}, 13,21$ para o $\mathrm{CP}$ e 16,06 para o Ctr; nem no número de Infusões (Kruskall-Wallis test: $\mathrm{H}(2, \mathrm{~N}=21)=1,739 p=0,419)$, com uma mediana de 13,38 para o grupo CO, 11,86 para o $\mathrm{CP}$ e 9,00 para o Ctr.




Figura 20 - Média de infusões durante a Fase 3 do Experimento 3. O gráfico mostra a média de infusões de $\mathrm{COC}$ dos sujeitos integrantes dos grupos $\mathrm{CO}, \mathrm{CP}$ e Ctr durante as últimas seis sessões da Fase 3 (Treino de Encadeamento das Respostas de Busca e Autoadministração de COC). Pode-se observar que o número de infusões tente se estabilizar durante as últimas sessões.

Na Figura 21 são mostrados os dados da frequência de respostas na barra busca (B) e na barra de administração (A) na presença de S1. Nota-se na figura que os animais do grupo CO responderam mais na barra $\mathrm{B}$ (primeiro elo da cadeia) na presença de S1 do que os outros dois grupos. De fato, o teste Kruskall-Wallis revelou diferenças significativas entre a frequência de respostas na barra B dos grupos. Diferenças entre grupos para a frequência total de respostas em $\mathrm{S} 1$ (Kruskall-Wallis test: $\mathrm{H}(2, \mathrm{~N}=34)=14,617 p=0,001)$, com uma mediana de 122,00 para o grupo CO, 82,00 para o CP e 34,00 para o Ctr, e o pós-hoc mostrou resultados significativos de $\mathrm{CO} \times \mathrm{CP}(p=0,043), \mathrm{CO} \times \mathrm{Ctr}(p=0,001)$. Para a frequência de respostas na Barra $\mathrm{B}$, foram encontradas diferenças estatisticamente significativas entre grupos (Kruskall-Wallis test: $\mathrm{H}(2, \mathrm{~N}=34)=20,199 p<0,001)$, com uma mediana de 98,00 para o grupo $\mathrm{CO}, 45,50$ para o $\mathrm{CP}$ e 15,50 para o $\mathrm{Ctr}$, e o pós-hoc mostrou resultados significativos de $\mathrm{CO} \times \mathrm{CP}(p=0,003), \mathrm{CO} \times \mathrm{Ctr}(p=0,001)$ e $\mathrm{CP} \times \mathrm{Ctr}(p=0,006)$. Para a frequência de respostas na Barra A em S1 (autoadministração), não foram encontradas diferenças estatisticamente significativas entre grupos (Kruskall-Wallis test: $\mathrm{H}(2, \mathrm{~N}=34)$ $=3,206 p=0,201$ ), com uma mediana de 30,00 para o grupo $\mathrm{CO}, 46,00$ para o $\mathrm{CP}$ e 16,00 para o Ctr. 


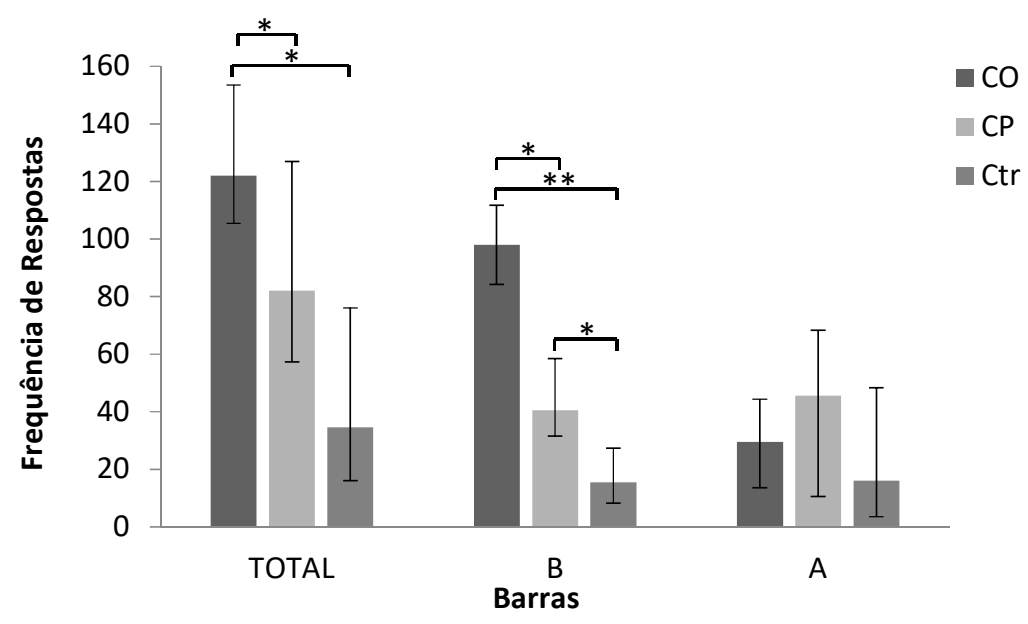

Figura 21 - Frequência de respostas de busca e autoadministração na presença de S1. Os dados representam a mediana (-P25 e +P75) da frequência de respostas na barra A, na barra B e o a frequência total (a somatória das repostas em ambas as barras), na presença de $\mathrm{S} 1$, dos sujeitos dos grupos CO, CP e Ctr durante a Fase $4 .{ }^{*} \mathrm{p}<0,05 * * \mathrm{p}<0,01$ para pós-hoc Mann-Whitney com correção Bonferroni.

Na Figura 13 são mostrados os dados da frequência das respostas totais, na presença

de S1 e S2. Diferenças entre grupos para a frequência total de respostas (Kruskall-Wallis test: $\mathrm{H}(2, \mathrm{~N}=17)=8,710 p=0,013)$, com uma mediana de 138,50 para o grupo $\mathrm{CO}, 106,50$ para o $\mathrm{CP}$ e 72,00 para o Ctr, e o pós-hoc mostrou resultados significativos de $\mathrm{CO} \times \mathrm{Ctr}(p=0,019)$. Para a frequência de respostas totais na Barra B, foram encontradas diferenças estatisticamente significativas entre grupos (Kruskall-Wallis test: $\mathrm{H}(2, \mathrm{~N}=17)=19,258 p \leq$ 0,001), com uma mediana de 122 para o grupo $\mathrm{CO}, 82,00$ para o $\mathrm{CP}$ e 34,50 para o $\mathrm{Ctr}$, e o teste pós-hoc Mann-Whitney com correção de Bonferroni mostrou resultados significativos de CO x CP $(p=0,043)$, e CO x $\operatorname{Ctr}(p=0,001)$. Para a frequência de respostas totais na Barra A em S1 (autoadministração), não foram encontradas diferenças estatisticamente significativas entre grupos (Kruskall-Wallis test: $\mathrm{H}(2, \mathrm{~N}=17)=0,487 p=0,784)$, com uma mediana de 16,00 para o grupo CO, 21,50 para o CP e 36,50 para o $\mathrm{Ctr}$. 


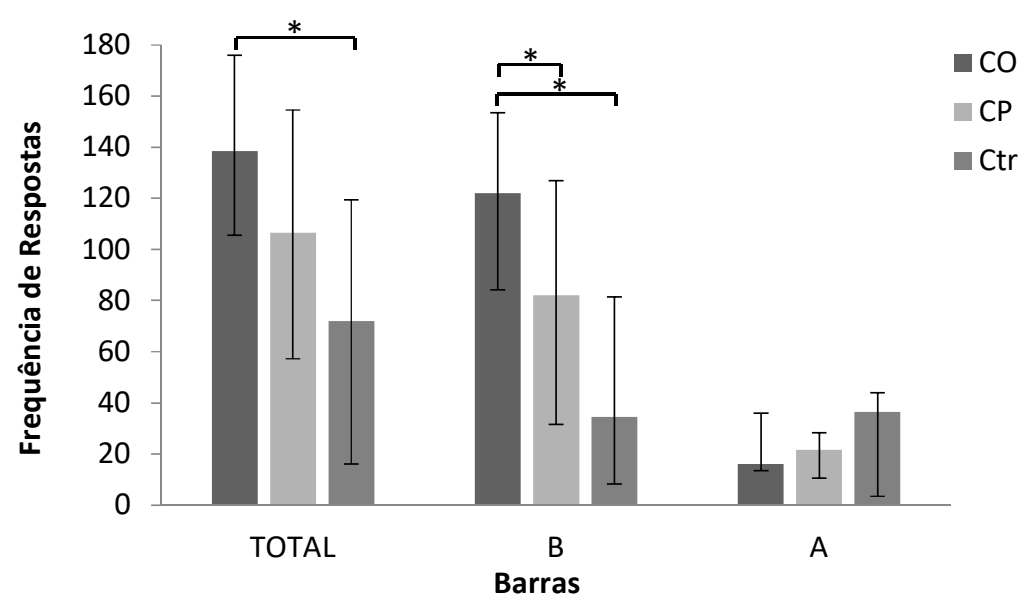

Figura 22 - Frequência total de respostas de busca e autoadministração. Os dados representam a mediana (-P25 e +P75) da frequência de respostas na barra A, na barra B e o a frequência total (a somatória das repostas em ambas as barras), na presença de $\mathrm{S} 1$ e $\mathrm{S} 2$, dos sujeitos dos grupos $\mathrm{CO}, \mathrm{CP}$ e Ctr durante a Fase $4 .{ }^{*} \mathrm{p}<0,05 * * \mathrm{p}<0,01$ para pós-hoc Mann-Whitney com correção Bonferroni.

Na Figura 23 são mostrados os Índices Discriminativos (respostas em S1/respostas totais) da frequência total de respostas, frequência de respostas na Barra B e frequência de respostas na barra A de cada grupo na Fase 4. O índice discriminativo permite observar o controle de S1 sobre ambas as respostas de interesse, busca e autoadministração. Foram observadas diferenças entre grupos no ID Total em S1 (Kruskall-Wallis test: H (2, N=17) $=19,477 p \leq 0,001)$ com uma mediana de 87,13 para o grupo $\mathrm{CO}, 71,57$ para o $\mathrm{CP}$ e 57,63 . Os testes pós-hoc revelaram diferenças significativas entre o grupo $\mathrm{CO}$ e $\mathrm{Ctr}(p<0,001)$, e $\mathrm{CP}$ e $\operatorname{Ctr}(p=0,003)$. Em relação aos IDs de cada barra, a análise mostrou que houve diferença entre os grupos no controle de S1 sob as respostas emitidas na barra B (Kruskall-Wallis test: H (2, $\mathrm{N}=17)=14,927 p=0,001)$ e na Barra A (Kruskall-Wallis test: $\mathrm{H}(2, \mathrm{~N}=17)=12,876 p$ $=0,002$ ). As análises pós-hoc revelaram que S1 controlou as respostas emitidas pelo grupo $\mathrm{CO}$ na barra quando comparado com $\mathrm{CP}(\mathrm{P}=0,002)$ e $\mathrm{Ctr}(\mathrm{p}=0,016)$, mas não se observaram diferenças entre os grupos CP e Crt. Por outro lado, quando foi comparado o ID na barra A, a análise revelou que o grupo CP obteve índices significativamente maiores do que os grupo 
$\mathrm{CO}(\mathrm{p}=0,012)$ e do que o grupo $\mathrm{Crl}(\mathrm{p}=0,003)$, mas não houve diferenças entre os grupos $\mathrm{CO}$ e Crtl.

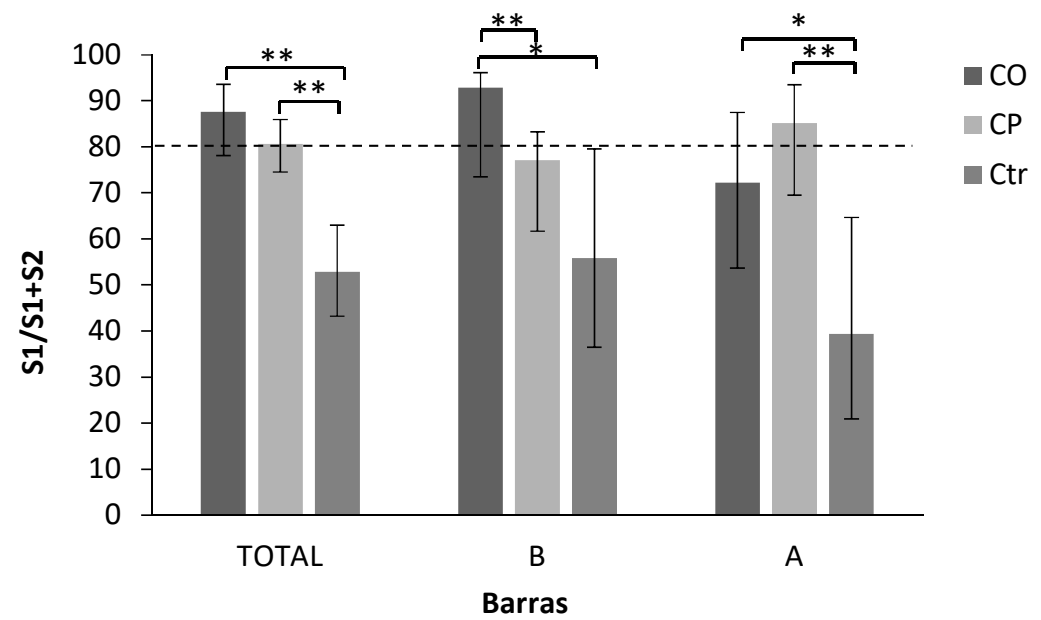

Figura 23 - Discriminação de S1 na Fase 4. O gráfico mostra o ID das de respostas de busca, respostas de administração e respostas totais, como mediana (-P25 e +P75), dos sujeitos integrantes dos grupos $\mathrm{CO}, \mathrm{CP}$ e Ctr durante a Fase 4 (Teste de Transferência Sob o Controle de S1 nas Respostas de Busca e Autoadministração de Cocaína). * $\mathrm{p}<0,05 * * \mathrm{p}<0,01$ para pós-hoc Mann-Whitney com correção Bonferroni.

A análise dos IDs por sujeito (Figura 24) permite observar com maior detalhe o controle de S1 (índice discriminativo) sobre as respostas emitidas nas barras B e A. Nota-se que $\mathrm{S} 1$ controlou as respostas de responder em $\mathrm{B}$, mas não em $\mathrm{A}$, de todos os animais do grupo CO. Por outro lado, perto da metade dos animais do grupo CP obteve ID maior a $80 \%$ na barra A. As respostas de apenas um animal do grupo Ctr ficaram sob controle de S1. Desta forma, é evidente que houve controle diferencial de S1 sobre as respostas emitidas pelos animais dos diferentes grupos. 
B

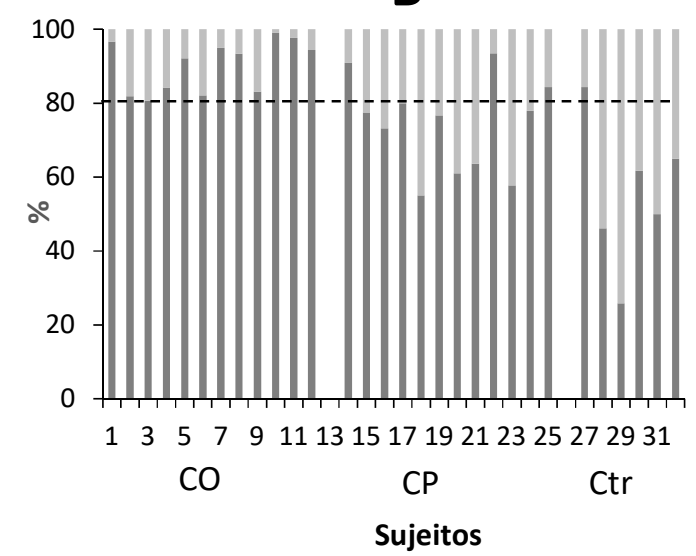

A



Figura 24 - Índice discriminativo por sujeito nas barras de busca e administração. O gráfico mostra por sujeitos o ID das de respostas de busca e de administração, dos sujeitos integrantes dos grupos $\mathrm{CO}, \mathrm{CP}$ e Ctr durante a Fase 4.

Na Figura 25, mostra-se a distribuição das respostas em percentual entre as barras B e A na presença de S1 e S2, para cada sujeito. Todos os animais do grupo CO mostraram preferência pela Barra B quando S1 estava presente, porém só em torno do 70\% das respostas foram emitidas na barra B. A análise estatística (Kruskall-Wallis test: $\mathrm{H}(2, \mathrm{~N}=32)=4,926 p$ $=0,852$ ) revelou que não houve diferenças significativas entre grupos em relação à preferência pelas barras na presença de S1, nem na presença de S2 (Kruskall-Wallis test: H $(2, \mathrm{~N}=32)=3,714 p=0,156)$. A diferença entre os grupos em relação à preferência por $\mathrm{B}, \mathrm{o}$ teste pós-hoc mostrou que a mediana do grupo $\mathrm{CO}$ foi maior do que as dos grupos $\mathrm{CP}$ e $\mathrm{Ctr}$ ( $p=0,001$ e $p=0,002$, respectivamente), porém não houve diferenças entre os grupos CP e Crt $(\mathrm{p}=0,143)$ 


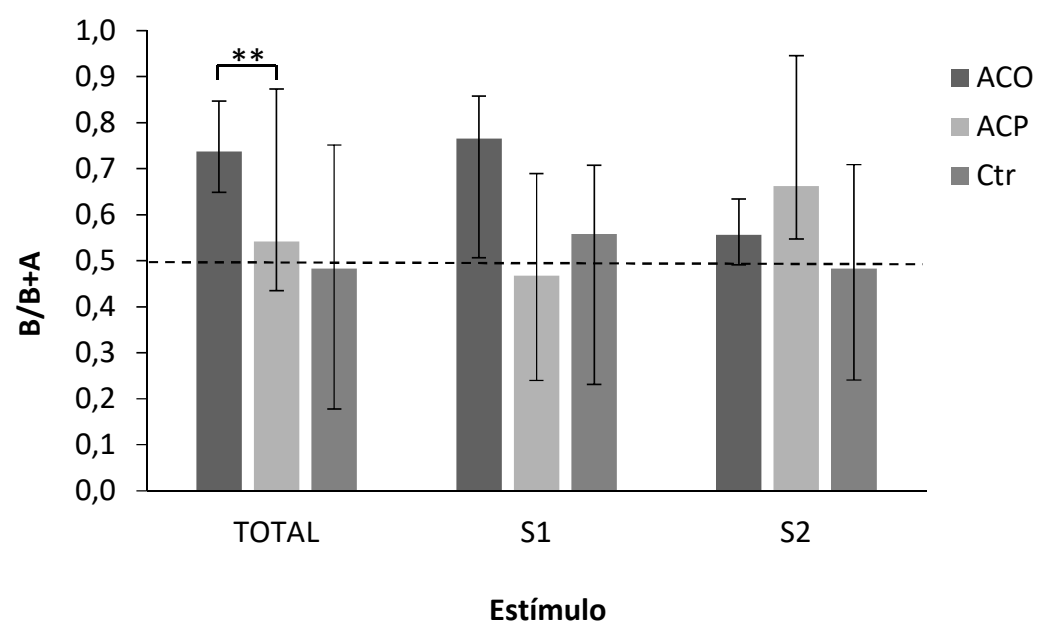

Figura 25 - Preferência por B na presença dos estímulos discriminativos. Os dados mostram a distribuição das respostas entre a barra B e a barra A como mediana (-P25 e +P75) do índice de preferência (frequência de respostas em B/frequência de resposta em B + frequência de resposta em $\mathrm{A}$ ) na presença de S1 e S2 na Fase 4 do Experimento 3, dos grupos CO, CP e Ctr. ${ }^{*} \mathrm{p}<0,05 * * \mathrm{p}<0,01$ para pós-hoc Mann-Whitney com correção Bonferroni.

Como mostrado na Figura 26, onde se mostram os dados individuais, todos os ratos do grupo $\mathrm{CO}$, preferiram a barra $\mathrm{B}$ quando $\mathrm{S} 1$ foi apresentado. Os animais do grupo $\mathrm{CP}$ mostraram maior variabilidade, mostrando que não houve clara preferência por uma das barras, na presença de S1, como grupo, mas de forma individual, pode-se observar que a metade dos sujeitos preferiram a barra A e a outra metade a barra $\mathrm{B}$, de forma similar ao grupo Ctr. 
S1

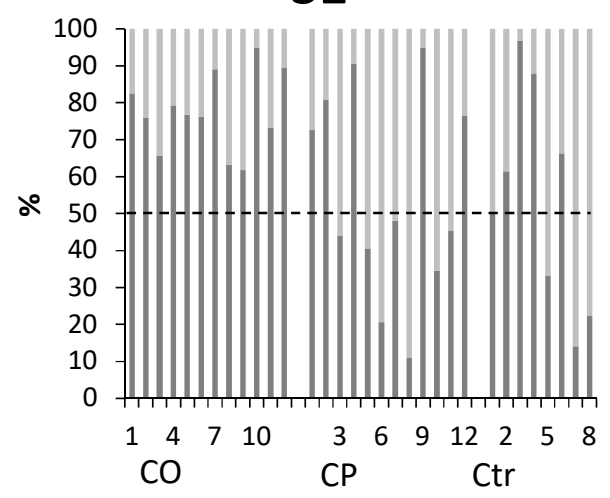

Sujeitos
S2

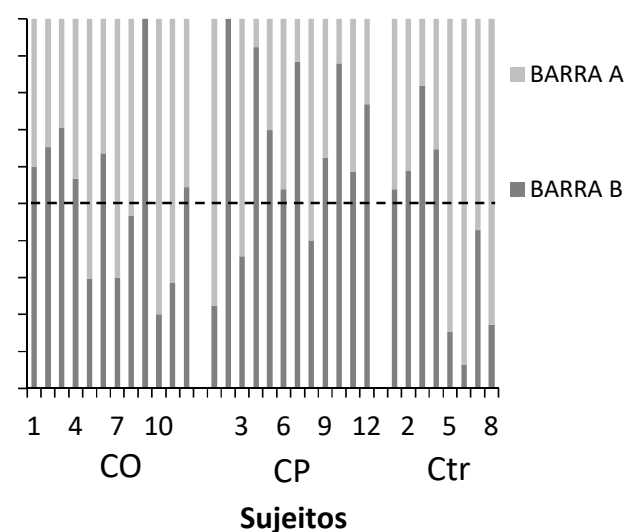

Sujeitos

Figura 26 - Porcentagem de respostas de busca e administração em S1 e S2. O gráfico mostra a proporção de respostas na barra de busca (B) e de administração (A) na presença de S1 e S2, dos grupos $\mathrm{CO}, \mathrm{CP}$ e $\mathrm{Ctr}$, durante a Fase 4.

Na Figura 27 podem ser observadas a latência da primeira resposta emitida diante S1 e de S2 durante a Fase 4. A análise estatística comparando as médias da Latência à Primeira Resposta durante a Fase 4 utilizando o teste Kruskall-Wallis revelou que houve diferenças significativas entre grupos. A análise Kruskall-Wallis revelou diferenças na latência de resposta em B (Kruskall-Wallis test: $\mathrm{H}(2, \mathrm{~N}=17)=7,566 p=0,023)$, mas não em A (Kruskall-Wallis test: $\mathrm{H}(2, \mathrm{~N}=17)=3,977 p=0,137)$ na presença de $\mathrm{S} 1$, nem em B (Kruskall-Wallis test: $\mathrm{H}(2, \mathrm{~N}=17)=1,246 p=0,536)$ ou A na presença de S2 (KruskallWallis test: $\mathrm{H}(2, \mathrm{~N}=22)=11,503 p=0,003)$. Não houve diferenças de latência de respostas em B na presença de S2 (Kruskall-Wallis test: $\mathrm{H}(2, \mathrm{~N}=17)=, 205 p=0,201)$. As análises póshoc revelaram que na presença de $\mathrm{S} 1$, a latência em $\mathrm{B}$ do grupo $\mathrm{CO}$ foi menor do que as latências do grupo $\mathrm{CP}(\mathrm{p}=0,036)$. 


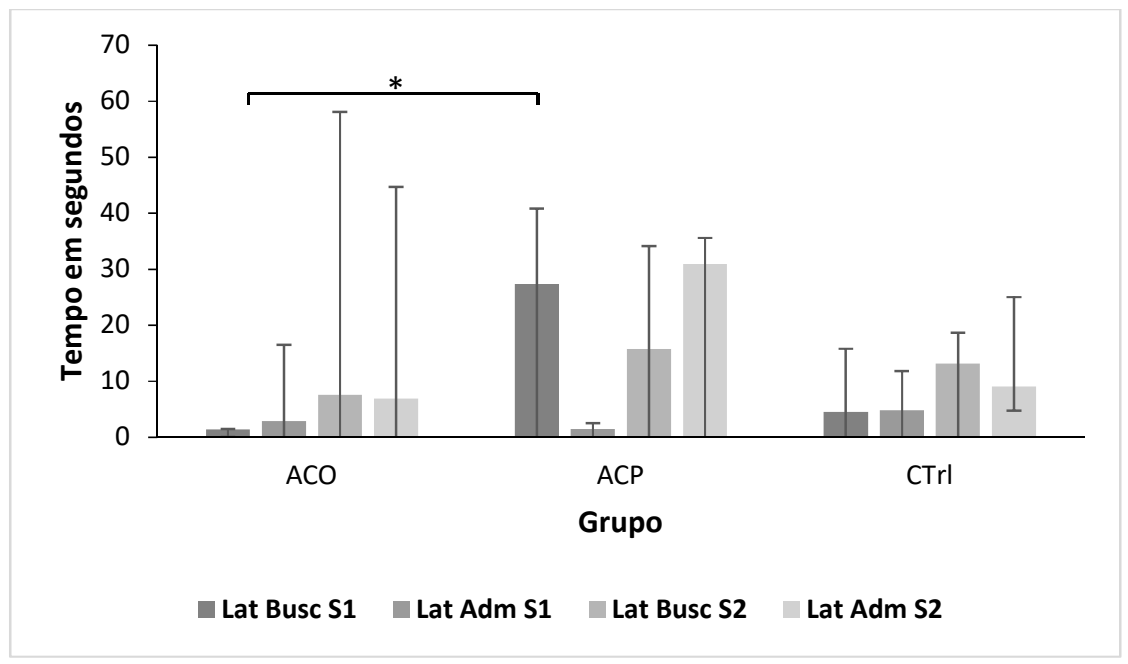

Figura 27 - Latência da primeira resposta na Fase 4. Os dados mostram a mediana (-P25 e +P75) do tempo em segundos transcorridos desde a $1^{\mathrm{a}}$ apresentação de S1 ou S2 e a emissão da $1^{\mathrm{a}}$ resposta na barra A ou na barra B, para cada grupo CO, CP e Ctr durante a Fase 4. ${ }^{*} \mathrm{p}<0,05 * * \mathrm{p}<0,01$ para póshoc Mann-Whitney com correção Bonferroni.

São apresentados os dados bioquímicos das amostras de tecido processadas para imuno-histoquímica de $\Delta$ FosB após a Fase 2 e a Fase 4. O teste de Kruskall-Wallis foi realizado para detectar diferenças estatísticas em todas as subáreas de interesse. Estes resultados são apresentados junto com os gráficos correspondentes. Adicionalmente foram realizados testes de Wilcoxon para comparar os resultados das amostras tomadas após a Fase 2 com aquelas tomadas após a Fase 4.

A análise estatística comparando as médias do número de células imunorreativas a $\triangle$ FosB no PFC LO utilizando o teste Kruskall-Wallis revelou que existem diferenças estatisticamente significativas entre grupos na Fase 2, mas não na Fase 4 (Figura 28). Para a Fase 2, foram encontradas diferenças entre grupos (Kruskall-Wallis test: $\mathrm{H}(2, \mathrm{~N}=34)$ $=14,253 p=0,001$ ), com uma mediana de 23,87 para o grupo $\mathrm{CO}, 17,00$ para o $\mathrm{CP}$ e 8,00 para o Ctr, e o teste pós-hoc Mann-Whitney com correção de Bonferroni mostrou resultados significativos de $\mathrm{CO} \times \mathrm{CP}(p=0,006)$ e $\mathrm{CO} \times \mathrm{Ctr}(p=0,012)$ e $\mathrm{CP} \times \mathrm{Ctr}(0,012)$; enquanto que na Fase 4 não foram encontradas diferenças estatisticamente significativas (Kruskall- 
Wallis test: $\mathrm{H}(2, \mathrm{~N}=17)=5,131 p=0,077)$, com uma mediana de 31,00 para o grupo $\mathrm{CO}$, 28,00 para o CP e 26,75 para o Ctr.
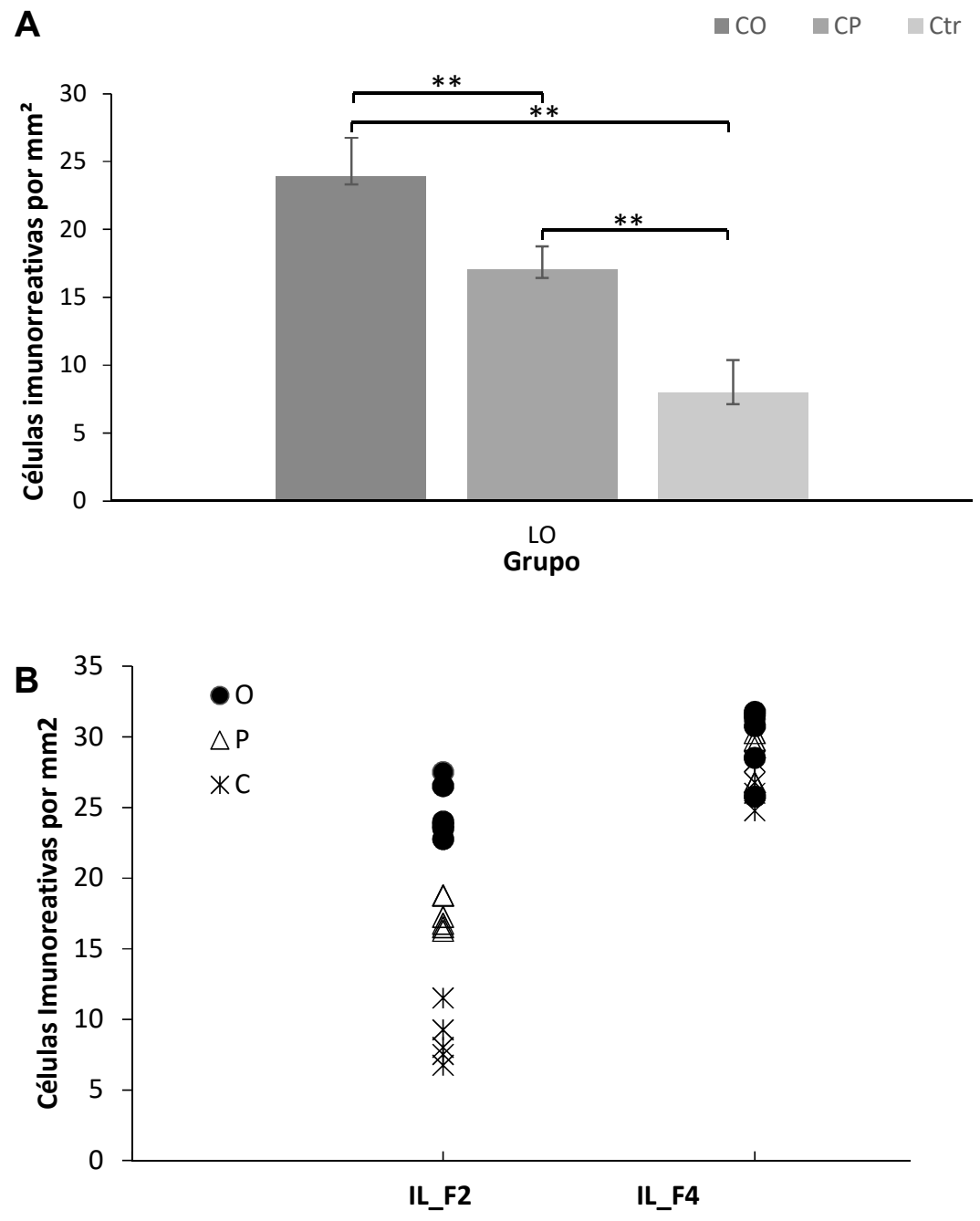

Figura 28 - Células imunorreativas a $\triangle$ FosB no Córtex Pré-frontal nas fases 2 e 4 do Experimento 3. A) O gráfico mostra a mediana (-P25 e $+\mathrm{P} 75)$ de células imunorreativas a $\Delta$ FosB para os grupos CO, $\mathrm{CP}$ e Ctr no Córtex Lateral Orbital (LO) do PFC nas amostras processadas após a Fase 2. * p $<0,05 * *$ p $<0,01$ para pós-hoc Mann-Whitney com correção Bonferroni. B) O gráfico mostra a comparação da marcação de células imunorreativas a $\triangle$ FosB nas amostras processadas após a Fase 2 e a Fase 4 para os grupos CO, CP e Ctr no Córtex Lateral Orbital (LO) do PFC.

De forma similar, para todas as subáreas do mPFC, a análise estatística comparando as médias do número de células imunorreativas a $\Delta$ FosB utilizando o teste Kruskall-Wallis revelou que existem diferenças estatisticamente significativas entre grupos na Fase 2, mas nenhuma na Fase 4, como pode ser observado na Figura 29. Para a Fase 2, diferenças entre 
grupos para Cg1 (Kruskall-Wallis test: $\mathrm{H}(2, \mathrm{~N}=19)=11,912 p=0,003)$, com uma mediana de 20,00 para o grupo CO, 16,00 para o CP e 8,00 para o Ctr, e o teste pós-hoc MannWhitney com correção de Bonferroni mostrou resultados significativos de $\mathrm{CO} \times \operatorname{Ctr}(p$ $=0,012)$ e CP x Ctr (0,012). Diferenças entre grupos para PrL (Kruskall-Wallis test: H (2, N= 19) $=7,542 p=0,023$ ), com uma mediana de 19,25 para o grupo $\mathrm{CO}, 19,62$ para o $\mathrm{CP}$ e 12,50 para o Ctr, e o teste pós-hoc Mann-Whitney com correção de Bonferroni mostrou resultados e perto da significância estatística para $\mathrm{CO}$ x Ctr $(0,051)$ e CP x Ctr (0,051). Adicionalmente, foram achadas diferenças entre grupos para IL (Kruskall-Wallis test: $\mathrm{H}(2, \mathrm{~N}=19)=10,767 p$ $=0,005)$, com uma mediana de 26,00 para o grupo CO, 22,37 para o CP e 17,25 para o Ctr, e o teste pós-hoc Mann-Whitney com correção de Bonferroni mostrou resultados significativos de $\mathrm{CO}$ x $\operatorname{Ctr}(p=0,025)$ e $\mathrm{CP}$ x $\mathrm{Ctr}(p=0,025)$. Na Fase 4 não foram encontradas diferenças estatisticamente significativas no Cg1 (Kruskall-Wallis test: $\mathrm{H}(2, \mathrm{~N}=17)=1,799 p=0,407)$, com uma mediana de 21,75 para o grupo CO, 22,37 para o CP e 20,75 para o Ctr; PrL (Kruskall-Wallis test: $\mathrm{H}(2, \mathrm{~N}=17)=0,901 p=0,637)$, com uma mediana de 20,05 para o grupo CO, 21,62 para o CP e 22,75 para o Ctr; nem no IL (Kruskall-Wallis test: $\mathrm{H}(2, \mathrm{~N}=17$ ) $=0,830 p=0,660$ ), com uma mediana de 23,62 para o grupo $\mathrm{CO}, 24,5$ para o $\mathrm{CP}$ e 24,50 para o Ctr.

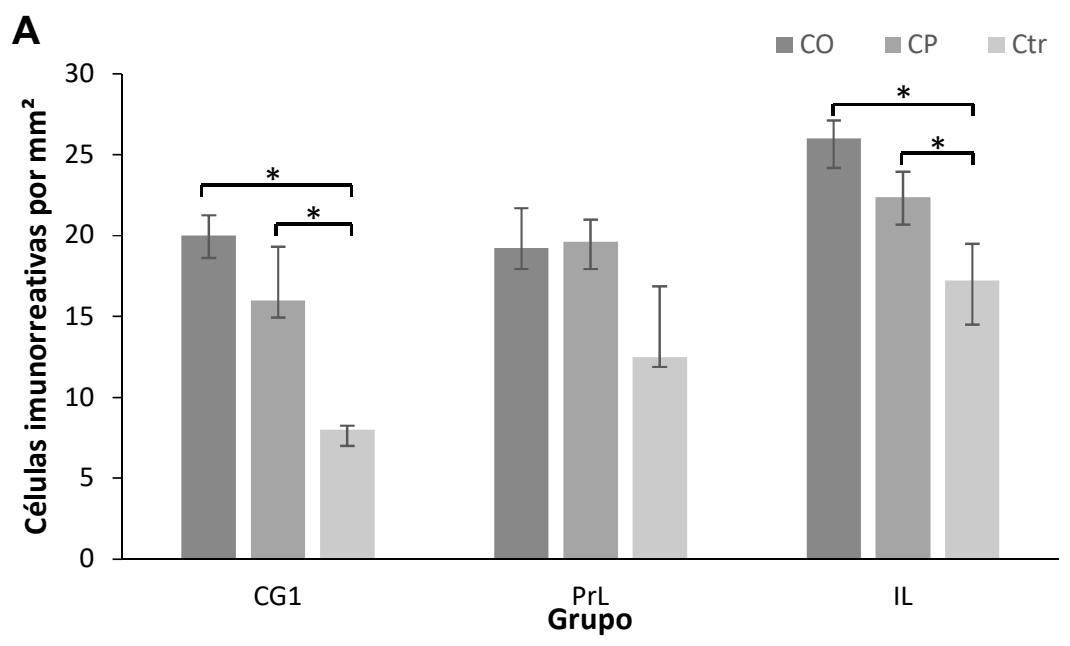




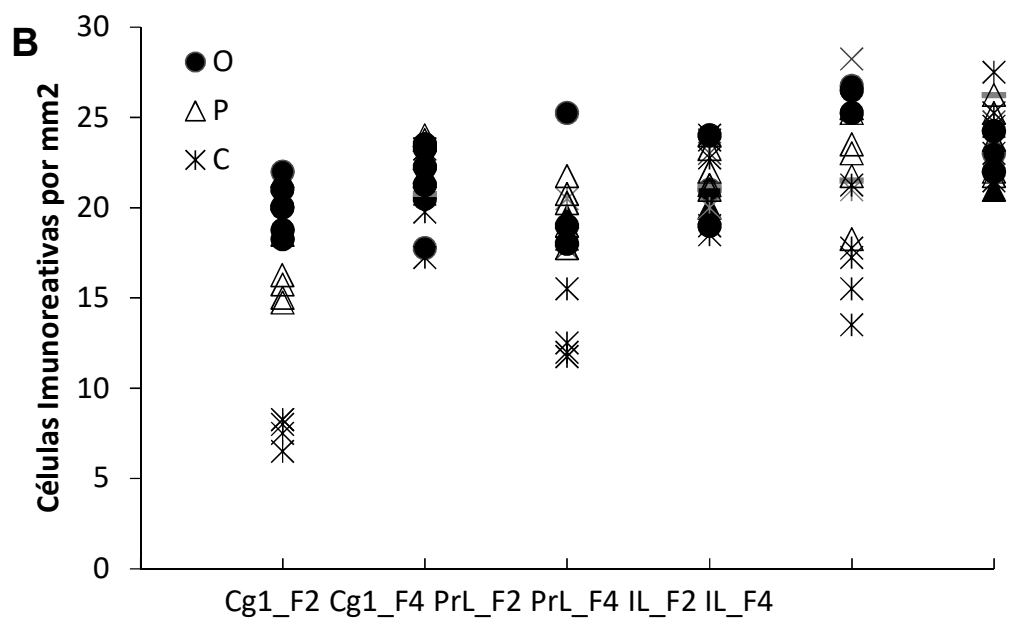

Figura 29 - Marcação de células imunorreativas a $\triangle$ FosB no Córtex Pre-Frontal Medial (mPFC) no Experimento 3. A) O gráfico mostra a mediana (-P25 e +P75) de células imunorreativas a $\Delta$ FosB para os grupos CO, CP e Ctr nas subáreas do mPFC (Cg1, PrL e IL) nas amostras processadas após a Fase 2. $* \mathrm{p}<0,05 * * \mathrm{p}<0,01$ para pós-hoc Mann-Whitney com correção Bonferroni. B) O gráfico mostra a comparação da marcação de células imunorreativas a $\triangle \mathrm{FosB}$ nas amostras processadas após a Fase $2 \mathrm{e}$ a Fase 4 para os grupos CO, CP e Ctr nas subáreas do mPFC (Cg1, PrL e IL).

Ao serem observados os resultados da análise estatística comparando as médias do número de células imunorreativas a $\triangle$ FosB no NAc utilizando o teste Kruskall-Wallis (Figura 30), foi revelado que existem diferenças estatisticamente significativas entre grupos em ambas as subáreas na Fase 2, mas nenhuma na Fase 4. Para a Fase 2, diferenças entre grupos para NAc Core (Kruskall-Wallis test: $\mathrm{H}(2, \mathrm{~N}=19)=10,290 p=0,006)$, com uma mediana de 28,62 para o grupo CO, 27,37 para o CP e 14,25 para o Ctr, e o teste pós-hoc Mann-Whitney com correção de Bonferroni mostrou resultados significativos de $\mathrm{CO}$ x $\mathrm{Ctr}(p=0,012)$, e $\mathrm{CP}$ x $\operatorname{Ctr}(p=0,012)$. Diferenças entre grupos para NAc Shell (Kruskall-Wallis test: H (2, N=19) $=10,327 p=0,006$ ), com uma mediana de 34,00 para o grupo $\mathrm{CO}, 29,37$ para o $\mathrm{CP}$ e 15,75 para o Ctr, e o teste pós-hoc Mann-Whitney com correção de Bonferroni mostrou resultados significativos de $\mathrm{CO}$ x $\operatorname{Ctr}(p=0,012)$, e $\mathrm{CP} \times \mathrm{Ctr}(p=0,012)$. Na Fase 4 não foram encontradas diferenças estatisticamente significativas no NAc Core (Kruskall-Wallis test: H $(2, \mathrm{~N}=17)=3,120 p=0,210)$, com uma mediana de 31,37 para o grupo $\mathrm{CO}, 28,12$ para o $\mathrm{CP}$ e 
27,75 para o Ctr; nem para NAc Shell (Kruskall-Wallis test: $\mathrm{H}(2, \mathrm{~N}=17)=0,171 p=0,918)$, com uma mediana de 28,50 para o grupo CO, 30,50 para o CP e 29,00 para o Ctr.
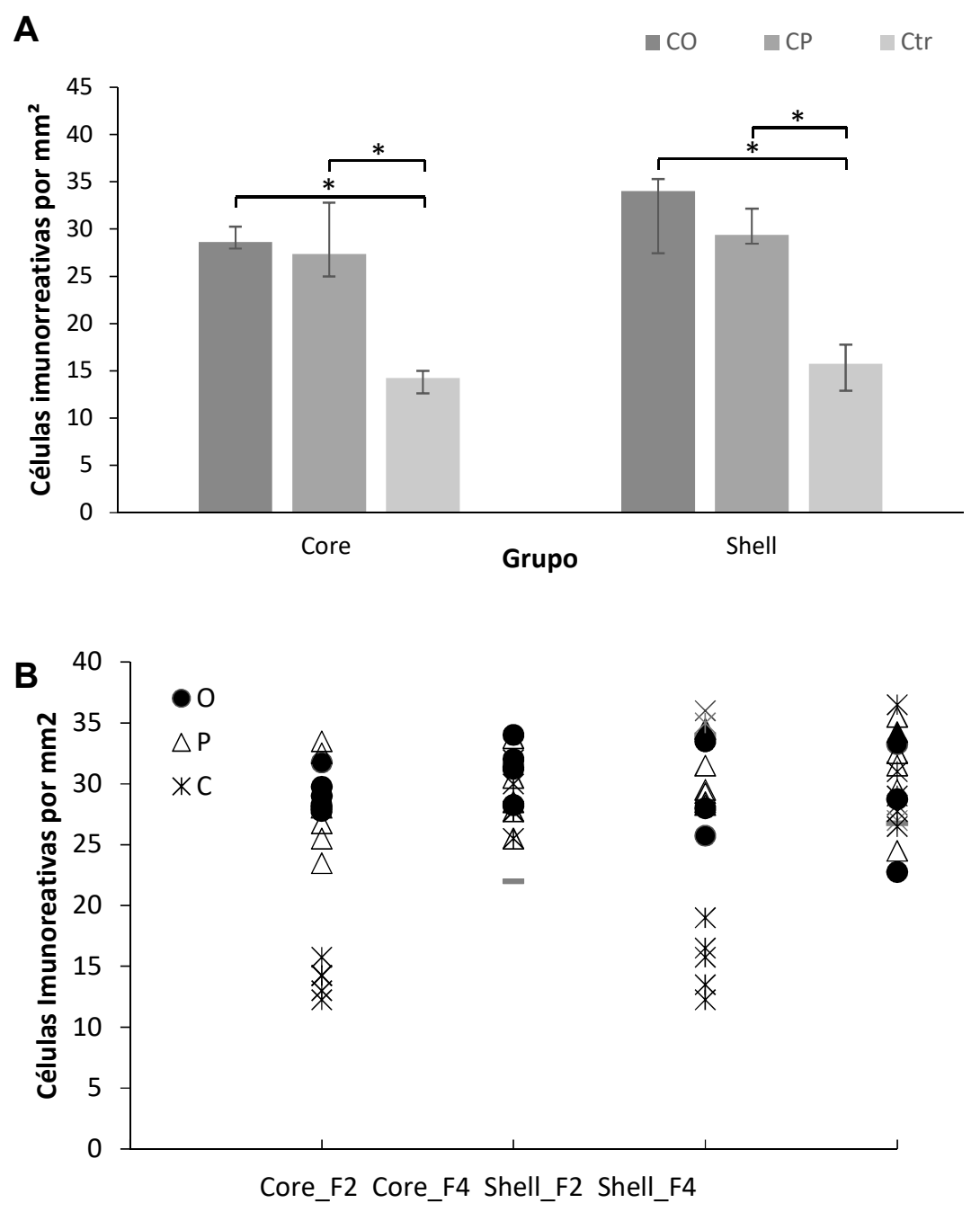

Figura 30 - Marcação de células imunorreativas a $\triangle$ FosB no Núcleo Acumbente (NAc) no Experimento 3. A) O gráfico mostra a mediana (-P25 e +P75) de células imunorreativas a $\Delta$ FosB para os grupos CO, CP e Ctr nas subáreas do NAc (Core e Shell) nas amostras processadas após a Fase 2. * $\mathrm{p}<0,05 * * \mathrm{p}<0,01$ para pós-hoc Mann-Whitney com correção Bonferroni. B) O gráfico mostra a comparação da marcação de células imunorreativas a $\triangle$ FosB nas amostras processadas após a Fase 2 e a Fase 4 para os grupos CO, CP e Ctr nas subáreas do NAc (Core e Shell).

Para análise estatística comparando as médias do número de células imunorreativas a $\Delta$ FosB no $\mathrm{CPu}$ utilizando o teste Kruskall-Wallis, também não foi diferente ao observado nas outras áreas, revelando que existem diferenças estatisticamente significativas entre grupos em 
ambas as subáreas na Fase 2, mas nenhuma na Fase 4, como pode ser observado na Figura 31. Para a Fase 2, diferenças entre grupos para CPu Lateral (Kruskall-Wallis test: $\mathrm{H}(2, \mathrm{~N}=$ 19) $=7,144 p=0,028$ ), com uma mediana de 30,50 para o grupo CO, 27,37 para o CP e 14,25 para o Ctr, e o teste pós-hoc Mann-Whitney com correção de Bonferroni mostrou resultados significativos de $\mathrm{CO} \times \mathrm{Ctr}(p=0,012)$. Diferenças entre grupos para CPu Lateral (KruskallWallis test: $\mathrm{H}(2, \mathrm{~N}=19)=10,434 p=0,005)$, com uma mediana de 47,25 para o grupo CO, 45,37 para o CP e 36,25 para o Ctr, e o teste pós-hoc Mann-Whitney com correção de Bonferroni mostrou resultados significativos de $\mathrm{CO} \times \mathrm{Ctr}(p=0,012)$, e $\mathrm{CP} \times \mathrm{Ctr}(p=0,012)$. Na Fase 4 não foram encontradas diferenças estatisticamente significativas no $\mathrm{CPu}$ Lateral (Kruskall-Wallis test: $\mathrm{H}(2, \mathrm{~N}=17)=0,962 p=0,618)$, com uma mediana de 32,37para o grupo CO, 28,12 para o CP e 27,75 para o Ctr; nem para CPu Medial (Kruskall-Wallis test: H $(2, \mathrm{~N}=17)=0,110 p=0,946)$, com uma mediana de 49,87 para o grupo CO, 51,12 para o CP e 51,50 para o $\mathrm{Ctr}$.

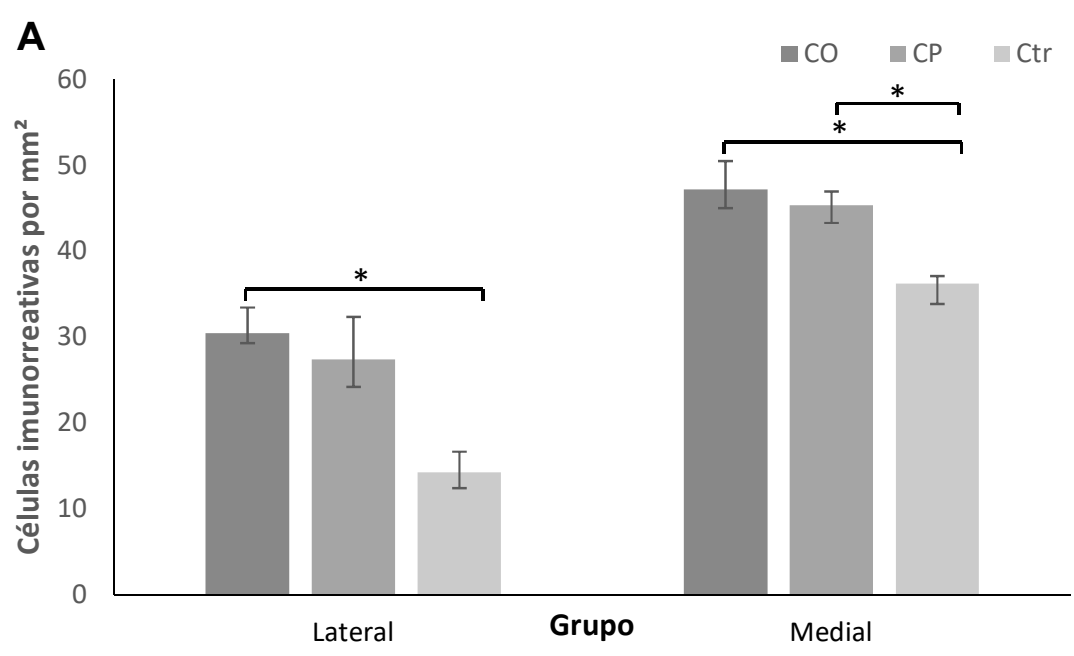




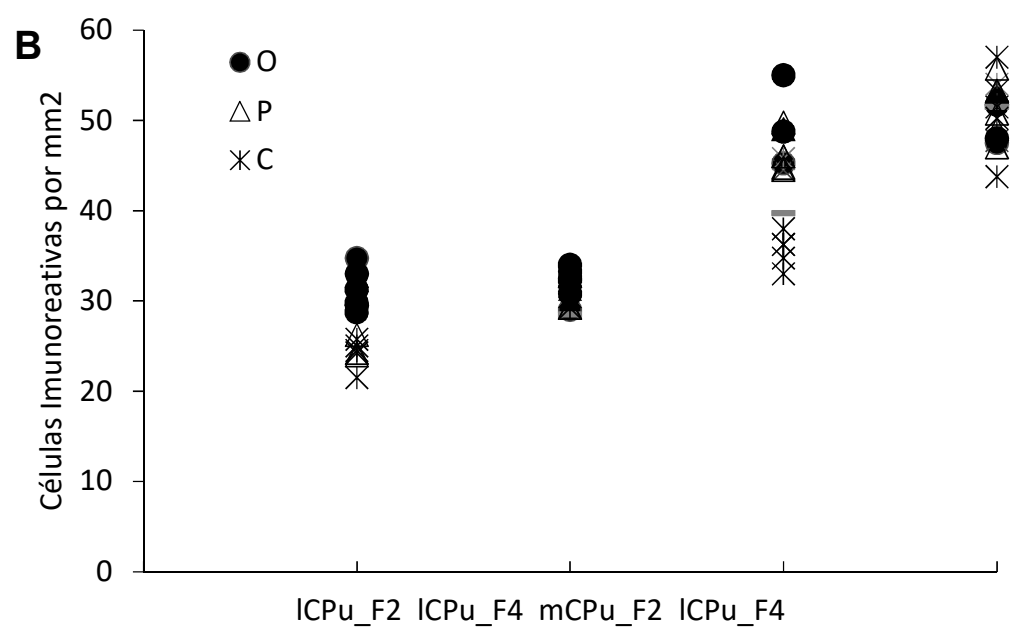

Figura 31 - Marcação de células imunorreativas a $\triangle$ FosB no Caudado Putamen $(\mathrm{CPu})$ no Experimento 3. A) O gráfico mostra a mediana (-P25 e $+\mathrm{P} 75)$ de células imunorreativas a $\Delta$ FosB para os grupos $\mathrm{CO}$, $\mathrm{CP}$ e Ctr nas subáreas do CPu (Lateral e Medial) nas amostras processadas após a Fase $2 . * \mathrm{p}<0,05 * *$ $\mathrm{p}<0,01$ para pós-hoc Mann-Whitney com correção Bonferroni. B) O gráfico mostra a comparação da marcação de células imunorreativas a $\triangle$ FosB nas amostras processadas após a Fase 2 e a Fase 4 para os grupos $\mathrm{CO}, \mathrm{CP}$ e Ctr nas subáreas do $\mathrm{CPu}$ (Lateral e Medial).

A análise estatística comparando as médias do número de células imunorreativas a

$\Delta$ FosB no Hipocampo utilizando o teste Kruskall-Wallis revelou que existem diferenças estatisticamente significativas entre grupos para as subáreas DG e CA1 na Fase 2, mas nenhuma na Fase 4, como pode ser observado na Figura 32. Para a Fase 2, diferenças entre grupos para DG (Kruskall-Wallis test: $\mathrm{H}(2, \mathrm{~N}=19)=7,970 p=0,019)$, com uma mediana de 23,62 para o grupo CO, 19,50 para o CP e 19,75 para o Ctr, e o teste pós-hoc Mann-Whitney com correção de Bonferroni mostrou resultados significativos de $\mathrm{CO}$ x CP $(p=0,045)$, e perto da significância estatística, CO x Ctr (0,051). Diferenças entre grupos para CA1 (KruskallWallis test: $\mathrm{H}(2, \mathrm{~N}=19)=10,447 p=0,005)$, com uma mediana de 26,50 para o grupo CO, 23,12 para o CP e 18,00 para o Ctr, e o teste pós-hoc Mann-Whitney com correção de Bonferroni mostrou resultados significativos de $\mathrm{CO} \times \mathrm{Ctr}(p=0,012)$ e $\mathrm{CP} \times \mathrm{Ctr}(0,012)$. Adicionalmente, foram achadas diferenças entre grupos para CA3 (Kruskall-Wallis test: H (2, $\mathrm{N}=19)=3,005 p=0,223$ ), com uma mediana de 21,00 para o grupo $\mathrm{CO}, 24,50$ para o $\mathrm{CP}$ e 21,75 para o Ctr. Na Fase 4 não foram encontradas diferenças estatisticamente significativas 
no DG (Kruskall-Wallis test: $\mathrm{H}(2, \mathrm{~N}=17)=3,121 p=0,210)$, com uma mediana de 25,00 para o grupo CO, 23,50 para o $\mathrm{CP}$ e 22,75 para o Ctr; CA1 (Kruskall-Wallis test: $\mathrm{H}$ (2, N= 17) $=0,206 p=0,902$ ), com uma mediana de 23,50 para o grupo $\mathrm{CO}, 23,37$ para o $\mathrm{CP}$ e 23,35 para o Ctr; nem no para CA3 (Kruskall-Wallis test: $\mathrm{H}(2, \mathrm{~N}=17)=0,246 p=0,884)$, com uma mediana de 23,87 para o grupo CO, 23,87 para o $\mathrm{CP}$ e 24,00 para o $\mathrm{Ctr}$.
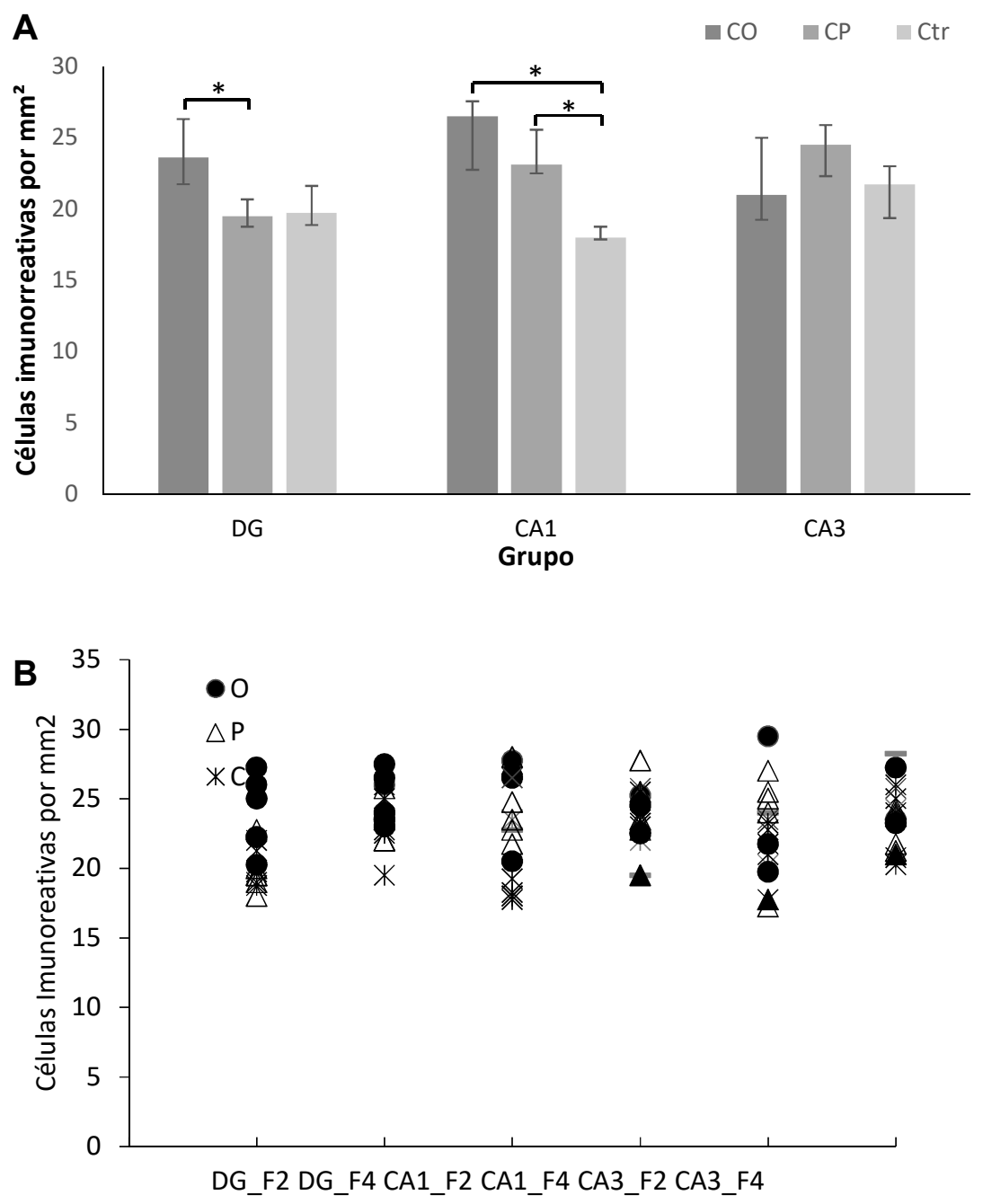

Figura 32 - Marcação de células imunorreativas a $\triangle$ FosB no Hipocampo no Experimento 3. A) O gráfico mostra a mediana (-P25 e +P75) de células imunorreativas a $\triangle \mathrm{FosB}$ para os grupos $\mathrm{CO}, \mathrm{CP}$ e Ctr nas subáreas do Hipocampo (DG, CA1 e CA3) nas amostras processadas após a Fase 2. * p <0,05 ** $\mathrm{p}<0,01$ para pós-hoc Mann-Whitney com correção Bonferroni. B) O gráfico mostra a comparação da marcação de células imunorreativas a $\triangle F o s B$ nas amostras processadas após a Fase 2 e a Fase 4 para os grupos $\mathrm{CO}, \mathrm{CP}$ e Ctr nas subáreas do Hipocampo (DG, CA1 e CA3). 
Os resultados da última área aqui apresentados são os da Amígdala. Se observam diferenças entre grupos em duas das suas subáreas, Basolateral e Central, para a Fase 2, porém nenhuma na Fase 4. A Figura 33 mostra a comparação das médias do número de células imunorreativas a $\Delta$ FosB na Amígdala. Para a Fase 2, diferenças entre grupos para Amígdala Basolateral (Kruskall-Wallis test: $\mathrm{H}(2, \mathrm{~N}=19)=13,346 p=0,001)$, com uma mediana de 72,87 para o grupo $\mathrm{CO}, 55,87$ para o $\mathrm{CP}$ e 46,75 para o $\mathrm{Ctr}$, e o teste pós-hoc Mann-Whitney com correção de Bonferroni mostrou resultados significativos de $\mathrm{CO}$ x $\mathrm{CP}(p$ $=0,025), \mathrm{CO} \times \operatorname{Ctr}(p=0,012)$ e $\mathrm{CP} \times \operatorname{Ctr}(p=0,012)$. Diferenças entre grupos para a Amígdala Central (Kruskall-Wallis test: $\mathrm{H}(2, \mathrm{~N}=19)=10,430 p=0,005)$, com uma mediana de 29,62 para o grupo CO, 18,00 para o CP e 16,70 para o Ctr, e o teste pós-hoc MannWhitney com correção de Bonferroni mostrou resultados significativos de $\mathrm{CO}$ x CP ( $p$ $=0,012)$, e $\mathrm{CO}$ x Ctr $(0,012)$. Não foram achadas diferenças entre grupos para a Amígdala Medial (Kruskall-Wallis test $\mathrm{H}(2, \mathrm{~N}=19)=8,686 p=0,013)$, com uma mediana de 29,62 para o grupo CO, 18,00 para o CP e 16,70 para o Ctr, e o teste pós-hoc Mann-Whitney com correção de Bonferroni mostrou resultados significativos de $\mathrm{CO}$ x $\mathrm{Ctr}(p=0,025)$. Na Fase 4 não foram encontradas diferenças estatisticamente significativas na Amígdala Basolateral (Kruskall-Wallis test: $\mathrm{H}(2, \mathrm{~N}=17)=2,170 p=0,338)$, com uma mediana de 77,87 para o grupo CO, 73,62 para o CP e 70,65 para o Ctr; Amígdala Central (Kruskall-Wallis test: H (2, $\mathrm{N}=17)=0,052 p=0,974$ ), com uma mediana de 34,50 para o grupo $\mathrm{CO}, 34,00$ para o $\mathrm{CP}$ e 33,75 para o Ctr; nem no para a Amígdala Medial (Kruskall-Wallis test: $\mathrm{H}(2, \mathrm{~N}=17)=0,285$ $p=0,867$ ), com uma mediana de 16,00 para o grupo $\mathrm{CO}, 16,00$ para o $\mathrm{CP}$ e 16,75 para o $\mathrm{Ctr}$. 

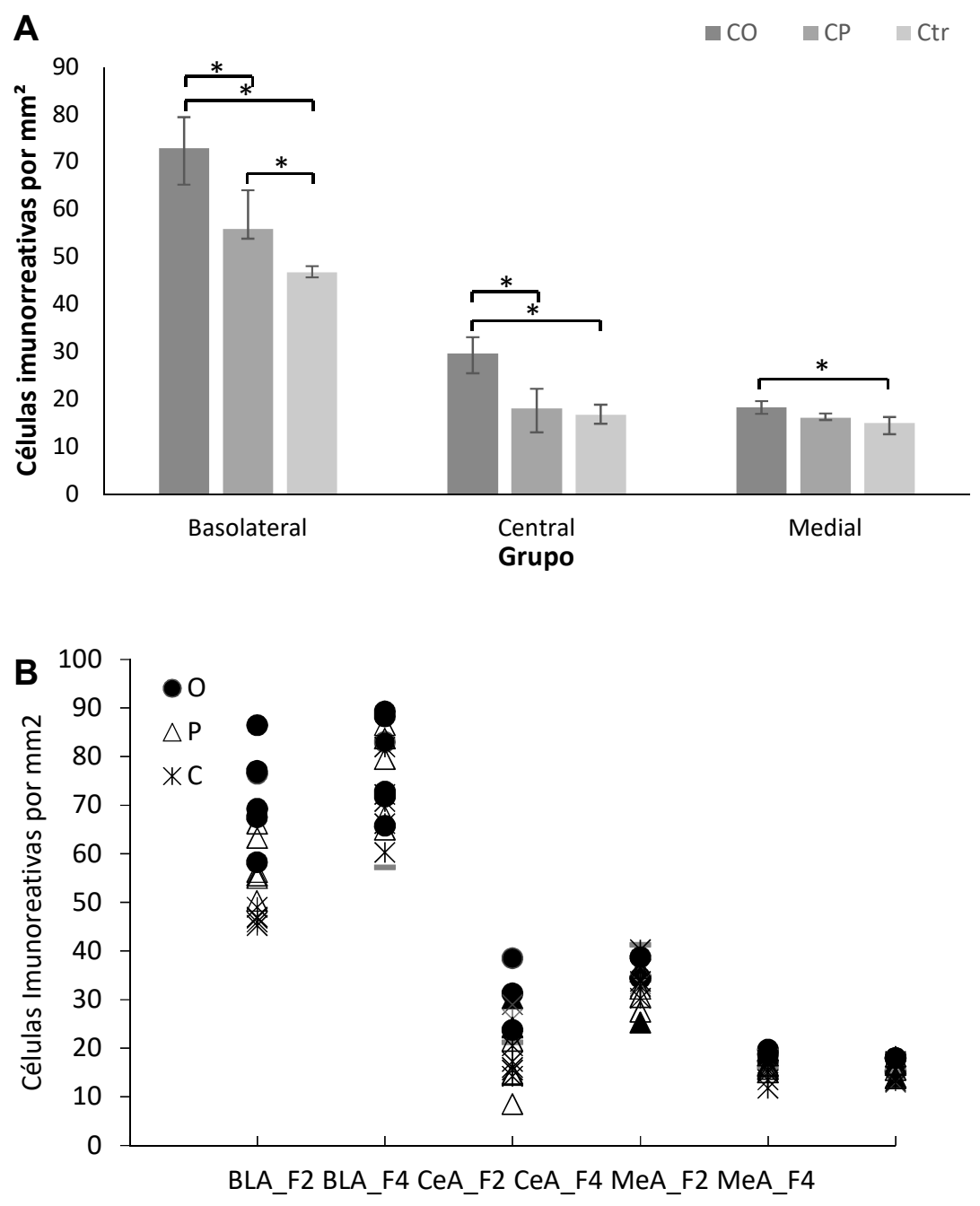

Figura 33 - Marcação de células imunorreativas a $\triangle$ FosB na Amígdala no Experimento 3. A) O gráfico mostra a mediana (-P25 e +P75) de células imunorreativas a $\triangle \mathrm{FosB}$ para os grupos $\mathrm{CO}, \mathrm{CP}$ e $\mathrm{Ctr}$ nas subáreas da Amígdala (Basolateral, Central e Medial) nas amostras processadas após a Fase 2. * p $<0,05$ ** $\mathrm{p}<0,01$ para pós-hoc Mann-Whitney com correção Bonferroni. B) O gráfico mostra a comparação da marcação de células imunorreativas a $\Delta$ FosB nas amostras processadas após a Fase 2 e a Fase 4 para os grupos CO, CP e Ctr nas subáreas da Amígdala (Basolateral, Central e Medial).

Foram realizados testes de Wilcoxon para comparar em cada subárea, as medianas das fases 2 e 4 em todos os grupos. As tabelas dos Anexos 1, 2 e 3 contém a informação dos valores das medianas, do estatístico $Z$ de Wilcoxon e os valores $p$. Em negrito são destacados os valores $p<0,05$.

Em resumo, os resultados apresentados do Experimento 3 mostram que: a) durante a Fase 1 os animais receberam um número de infusões de COC normal dentro do reportado na 
literatura, b) os sujeitos do grupo CO atingiram 90\% ou mais de ID durante a a Fase 2, c) os animais dos três grupos atingiram estabilidade no número de infusões de COC durante a Fase 3, e não foram encontradas diferenças entre grupos nas respostas de busca e administração; d) Durante a Fase 4, os sujeitos do grupo CO mostraram maior número de respostas de busca e respostas totais na presença de $\mathrm{S} 1$ comparado com o grupo $\mathrm{CP}$ e $\mathrm{Ctr}$, e os sujeitos do grupo $\mathrm{CP}$ mostraram maior número de respostas de busca na presença de $\mathrm{S} 1$ comparado com o grupo Ctr ; e) No teste de transferência da Fase 4, o grupo CO mostrou um ID superior a 80\% nas respostas de busca e respostas totais na presença de $\mathrm{S} 1$, sendo diferente dos grupos $\mathrm{CP}$ e Ctr, porém o grupo CP mostrou um ID superior a 80\% nas respotas de administração na presença de S1, sendo diferente dos grupos $\mathrm{CO}$ e Ctr; f) não houve uma clara preferência pela resposta de busca nem de administração na presença de S1 durante a fase 4; e f) no teste de transferência, a latência de resposta de busca na presença de S1 foi menor no grupo CO comparado com o Ctr. Além disto, os resultados imunohistoquímicos mostram que a o grupo $\mathrm{CO}$ expressou maior quantidade de $\Delta \mathrm{FosB}$ comparado com o $\mathrm{CP}$ e Ctr no LO, BLA e CeA. No DG, MeA e 1CPu o grupo CO teve maior expressão que o CP; e no Cg1, IL, Core, Shell, mCPu e CA1, o grupo $\mathrm{CO}$ e $\mathrm{CP}$ tiveram maior expressão que o $\mathrm{Ctr}$ (mas não ouve diferença entre estes). Ainda, foi evidente que houve aumento do número de células imunorreativas a $\Delta$ FosB, por $\mathrm{mm}^{2}$, da Fase2 à Fase 4, na maioria das subáreas.

As tabelas 3 e 4, localizadas na seção de análise de dados dos experimentos 1 e 2 , respectivamente, podem auxiliar o acompanhamento dos resultados e da discussão deste experimento.

\section{Discussão}

O experimento 3 teve como primeiro objetivo utilizar o protocolo de administração de drogas aperfeiçoado durante o experimento 2 para observar o controle de estímulos estabelecido durante os condicionamentos operante e pavloviano. O segundo objetivo foi 
avaliar o efeito dos condicionamentos operante e pavloviano na autoadministração e administração passiva de $\mathrm{COC}$, respectivamente, sobre a expressão de $\Delta \mathrm{FosB}$ em diferentes áreas do cérebro implicadas na dependência às drogas.

Durante a Fase 1, cada vez que um sujeito do grupo CO respondia na roda operante tinha como consequência uma infusão de COC e simultaneamente o sujeito do grupo CP e o do grupo Ctr a ele acoplados receberam sob contingência Pavloviana uma injeção i.v da droga na mesma dose ou de veículo, respectivamente. A média de infusões para esta fase esteve entre o normal segundo o reportado outros estudos de autoadministração de COC (Mierzejewski et al., 2003; Suto et al., 2011). Usualmente, na faixa das doses utilizadas, o limite de infusões é de 20 em um período de 2 h (que é o tempo total de sessão) para evitar grandes diferenças de administração entre sujeitos, sendo comum que os sujeitos se autoadministrem as 20 vezes, como aconteceu neste experimento. Uma vez foi estável o número de infusões, se deu continuidade ao treino discriminativo da Fase 2, no qual os sujeitos do grupo CO atingiram o critério de ID $\geq 90 \%$ nas últimas duas sessões, e se autoadministraram um número de infusões (com dose programada) dentro do normal segundo o reportado outros estudos de autoadministração de COC (Mierzejewski et al., 2003; Suto et al., 2011). Esta fase se desenvolveu também sem imprevistos e de forma similar ao Experimento 2 .

Durante a Fase 3 os sujeitos não estiveram mais acoplados, portanto todos eles aprenderam a se autoadministrar COC, independentemente do grupo ao qual pertenciam. Não foram observadas diferenças entre os grupos, indicando que o treino realizado na Fase 1 não teve efeito sobre a aquisição da pressão de barra. Isto é, a taxa de respostas e média de infusão dos animais dos três grupos foi similar a despeito da experiência prévia com COC e com diferentes contingências de sua administração. Esses dados validam os obtidos na Fase 
4, uma vez que grandes diferenças no número de infusões entre grupos durante esta fase poderiam alterar o responder durante a seguinte.

Durante a Fase 4 foi realizado o teste de transferência em condições de extinção. Os estímulos S1 e S2 foram apresentados em intervalos e as respostas de busca e de autoadministração foram registradas, porém sem terem consequências programadas. Os resultados indicaram que $\mathrm{S} 1$ adquiriu controle sobre a resposta de pressão de barra dos animais do grupo $\mathrm{CO}$ e CP, mas não dos animais do grupo Ctr (ID de respostas totais e de respostas na presença de S1), indicando transferência de controle desses estímulos para um novo operante, no caso do grupo CO, e PIT para o grupo CP. Este resultado replica estudos que utilizaram COC e reportaram a apresentação de PIT (Kruzic, Congelton \& See, 2001; LeBlanc, Ostlund \& Maidment, 2012; Saddoris et al., 2011). Como discutido no Experimento 2, a transferência de controle observada indica que os procedimentos de treino estabeleceram os controles esperados e adequados sobre o comportamento dos animais do grupo $\mathrm{CO}$ (Barnes-Holmes et al., 2000; Catania, 1999) e no grupo CP (Alarcon et al.,2018; Cartoni et al., 2016; Delamater et al., 2007).

O controle de estímulos estabelecido por S1 se viu refletido não só nos dados de ID, mas também na frequência e na latência de respostas na presença deste estímulo, sendo que este estímulo controlou as respostas dos animais do grupo $\mathrm{CO}$ unicamente na barra B e adicionalmente ocasionou um aumento na frequência de resposta nesta barra, assim como uma menor latência de resposta a esta, comparados com os grupos CP e Ctrl. Ainda se observou controle de estímulos estabelecido por S1 no grupo CP, o qual teve um ID e uma frequência de respostas significativamente maior em comparação com o grupo Ctr. Este padrão foi observado no Experimento 2 e a explicação sobre o controle diferencial de S1 sobre as respostas na barra $\mathrm{B}$ e A dos animais dos grupos $\mathrm{CO}$ e CP é exposta na discussão dos dados desse experimento. 
O controle de estímulos durante o teste de transferência que mostrou o grupo CP sobre a resposta de autoadministração na presença de S1 é entendível em termos de eficiência de respostas (Catania, 1999), pois uma vez as duas barras estiveram disponíveis, é mais eficiente responder na barra que levaria a infusão da droga. Durante um teste de transferência, quando disponibilizados simultaneamente dois operandos que formaram parte de um treino encadeado de respostas, existe a tendência de responder no operando que dava acesso direto a um reforçador. Esta tendência tem sido reportada em estudos de PIT com comida (Corbit \& Balleine, 2003b) e com COC (LeBlanc et al., 2012).

Os resultados do Experimento 3 sugerem que se apresentou um padrão observado no Experimento 2, porém de forma menos robusta. No experimento 2 se observou uma tendência do grupo $\mathrm{CO}$ responder na barra $\mathrm{B}$ e o grupo $\mathrm{CP}$ na barra $\mathrm{A}$, tanto na frequência e ID total, como quando S1 estava presente. Os resultados da latência e de frequência de respostas sugerem em conjunto com resultados de ID discutidos previamente, que tenha se originado esta tendência ou padrão, pelo menos para o grupo $\mathrm{CO}$ na barra $\mathrm{B}$, pois a latência na barra B na presença de S1 apresentou diferenças significativas, sendo muito menor no grupo $\mathrm{CO}$, comparado com o grupo $\mathrm{CP}$. O grupo CP não apresentou uma menor latência de resposta na barra A comparado com o grupo $\mathrm{CO}$ quando $\mathrm{S} 1$ foi apresentado pela primeira vez, porém estas diferenças não foram estatisticamente significativas. Ainda, a frequência de respostas na barra $\mathrm{B}$ foi muito mais alta no grupo $\mathrm{CO}$ comparado com o $\mathrm{CP}$. Assim mesmo, a frequência de respostas na barra $\mathrm{B}$ foi maior no grupo $\mathrm{CP}$ comparado com o $\mathrm{Ctr}$, sustentando o padrão observado no Experimento 2, porém de forma parcial, especificamente para o grupo $\mathrm{CO}$, mas não paro o CP. A formação desta tendência no grupo $\mathrm{CO}$ é discutida no Experimento 2, porém a não formação desta no grupo CP neste experimento não será discutida, ao não houverem dados suficientes para isto e ao não ser relevante para os objetivos deste experimento. 
Os resultados do efeito dos condicionamentos operante e pavloviano na autoadministração e administração passiva de COC sobre a expressão de $\Delta \mathrm{FosB}$ em diferentes áreas do cérebro implicadas na dependência às drogas foram de grande interesse para os objetivos deste estudo.

No grupo $C O$ (Anexo 1) a diferença de expressão de $\Delta$ FosB entre Fase 2 e 4 foi mínima para quase todas as subáreas, com exceção de $\mathrm{LO}$, na qual $\Delta \mathrm{FosB}$ continuou se acumulando até a Fase 4. Este resultado era esperado, pois o grupo $\mathrm{CO}$ já devia ter atingido uma estabilidade na expressão de $\Delta$ FosB desde a Fase 2, portanto não é de surpreender que na Fase 4 não se apresentassem aumentos, porém, a subárea LO continuou acumulando $\Delta$ FosB até a Fase 4, o que é de grande interesse ao destacar o envolvimento desta área, a qual já foi reportada por Winstanley et al. (2007) por ter um papel importante na CO.

Em geral, para grupo $\mathrm{CP}$, a diferença de expressão de $\Delta$ FosB entre Fase 2 e 4 (Anexo 2) teve diferenças estatisticamente significativas para LO, Cg1, PrL, mCPu, DG, BLA e CeA. Com exceção de LO, as subáreas restantes não tinham sido previamente reportadas como influenciadas diferencialmente pela contingência operante comparadas à Pavloviana em experimentos que utilizaram COC como droga de estudo, o que também poderia ser explicado por diferenças no modelo e delineamento experimental, pois em outros estudos não terem utilizado o modelo de administração acoplado o qual, como mencionado na sessão introdutória, é um modelo mais adequado para estudar as diferenças nas diferentes contingências de aprendizagem da administração de drogas. Independentemente disto, é de grande interesse e relevância ter indícios destas subáreas estarem implicadas na dependência às drogas e apresentar diferenças de expressão de $\Delta \mathrm{FosB}$ a depender do tipo de contingência em que a COC foi administrada, contingência operante ou Pavloviana. 
Os resultados da comparação da expressão de $\Delta$ FosB entre Fase 2 e 4 para o grupo Ctr (Anexo 3) mostraram que houve diferenças nas medições entre estas duas fases em quase todas as sensíveis a $\Delta$ FosB (Perrotti et al., 2008; Winstanley et al., 2007) avaliadas neste estudo. Isto poderia sugerir que em subáreas que apresentaram diferenças significativas entre grupos $\mathrm{CO}$ e $\mathrm{CP}$, mas que não apresentaram diferença no grupo $\mathrm{Ctr}$ entre as medições feitas nas fases 2 e 4, que S1 ao ser apresentado durante a administração nos grupo CO e CP desde a Fase 1, que também foi treinado discriminativamente e associado à droga na Fase 2, foi um fator que potencializou a associação S-droga, o que teria levado ao aumento na expressão de $\Delta$ FosB nesta subárea. Dado que até a Fase 2 os sujeitos do grupo Ctr só tinham recebido salina e durante a Fase 3 aprenderam se autoadministrar COC, o que era esperado era observar segundo a literatura (Jacobs et al., 2002, 2003, 2005; Lüscher \& Malenka, 2011; Miguéns et al., 2008; Winstanley et al., 2007). Os resultados apresentados neste experimento estão em concordância com esta literatura ao mostrar o aumento de expressão de $\Delta \mathrm{FosB}$ em subáreas sensíveis a esta após a administração de COC.

De forma consistente, nenhuma subárea mostrou diferenças entre grupos na medição da Fase 4. Este resultado era esperado, pois dado que $\Delta \mathrm{FosB}$ se acumula gradativamente com administrações repetidas de uma droga (Nestler, 2012, 2014), para o momento da medição após a Fase 4, todos os grupos já tinham passado por autoadministração de COC durante a Fase 3. Portanto, os dados discutidos se focam principalmente nos resultados que mostram as diferenças entre grupos obtidas nas medições de $\Delta$ FosB após a Fase 2.

A seguir se discute os resultados imunohistoquímico nas diferentes subáreas avaliadas e se menciona a implicação destas na PIT quando reportada previamente. Adicionalmente, se integram estes dados aos dados comportamentais nas possíveis implicações que poderiam ter as subáreas, dependendo das suas funções, porém, se destaca que como apontado por Nestler 
(2012, 2014) e Ruffle (2014), o $\Delta$ FosB funcionaria como uma espécie de "interruptor molecular" que ajuda iniciar e manter o estado de dependência em um organismo, e portanto uma variação da sua expressão entre animais que se autoadministraram uma droga sob uma contingência operante e os que a receberam passivamente sob uma contingência Pavloviana, não necessariamente implicaria uma conexão com diferenças comportamentais entre estes tipos de contingências. Portanto, as análises estão fundamentadas em possibilidades segundo os resultados obtidos e a literatura que sugere esta conexão entre contingencia de aprendizagem e mudanças génicas no SNC (e.g Choi et al., 2011; Jacobs et. al., 2003, 2005; Lüscher \& Malenka, 2011), especialmente a de $\Delta$ FosB (Perrotti et al., 2008; Winstanley et al., 2007).

A primeira subárea avaliada neste experimento foi o LO do OFC, uma área que está implicada em características da procura por drogas na dependência, como impulsividade, associações S-R e comportamentos de meta dirigida (Ostlund \& Balleine, 2007; Shoenbaum, Roesch, Stalnaker \& Takahashi, 2009). Se sabe que no OFC, a COC produz uma grande expressão deste IEG em comparação com outras subáreas, especialmente quando esta é autoadministrada (Perrotti et al. 2008; Winstanley et al., 2007). Ainda se sabe que o OFC tem sido reportado por estar implicado na PIT, já que lesões nesta área perturbam a manifestação desta quando realizada antes dos treinos em contingência operante e Pavloviana (Ostlund \& Balleine, 2007). Segundo isto, é esperada a diferença que se observou entre os grupos CO, $\mathrm{CP}$ e o $\mathrm{Ctr}$, pois mesmo observando um padrão na expressão de $\Delta \mathrm{FosB}(\mathrm{CO}>\mathrm{CP}>\mathrm{Ctr})$, o grupo CP teve uma diferença significativa comparada com o Ctr, sugerindo que o efeito central que produz a COC é suficiente para expressar $\triangle \mathrm{FosB}$ no LO, mas que o tipo de contingência, operante ou Pavloviana, pode modular ou potenciar esta expressão. 
Estes resultados estão em concordância e replicam o dado do estudo de Winstanley et al. (2007), que reporta que foram encontradas diferenças na expressão de $\Delta \mathrm{FosB}$, sendo maior no grupo que autoadministrou COC em comparação com o que recebeu esta de forma passiva. Ainda, tendo em conta a função mencionada desta subárea e a sua sensibilidade a expressar $\Delta$ FosB quando COC é administrada, os dados do LO acompanham o observado comportamentalmente com o resultado que mostra que o grupo $\mathrm{CO}$ teve uma maior frequência de respostas e ID na presença de S1 em comparação com o CP.

Os resultados para as diferentes subáreas avaliadas do PFC no Experimento 3 mostram que não houve diferenças significativas de expressão de $\Delta \mathrm{FosB}$ entre os grupos $\mathrm{CO}$ e CP nas subáreas do PFC avaliadas, porém no CG1 e no IL se pode observar uma aparente tendência a uma expressão maior no grupo CO, comparado com os outros. Os dados do PrL mostraram que o grupo $\mathrm{CO}$ teve uma marcação de $\Delta \mathrm{FosB}$ igual à do grupo $\mathrm{CP}$ nesta subárea, portanto a expressão nesta subárea seria mediada principalmente pelo efeito central da COC.

No $\mathrm{Cg} 1$, os grupos $\mathrm{CO}$ e $\mathrm{CP}$ tiveram diferenças na expressão de $\Delta \mathrm{FosB}$, em comparação com o Ctr, mas não entre estes, porém, os resultados mostraram que poderia existir uma diferença entre os grupos $\mathrm{CO}$ e $\mathrm{CP}$, sendo relevante conferir este dado em futuros estudos, dado que o $\mathrm{Cg} 1$ tem um papel no processamento e aprendizagem das consequências que produz um comportamento (Hayden \& Platt, 2010). Os dados obtidos não são suficientes para concluir que no $\mathrm{Cg} 1$, a COC aumenta a expressão de $\Delta \mathrm{FosB}$ de forma diferenciada em função ao tipo de contingência em que esta foi administrada e não unicamente pela ação farmacológica da droga.

De forma similar, os resultados das medições no IL são interessantes para o presente estudo, e dada a sua função de associação na aprendizagem operante (Tran-Tu-Yen et al., 2009), se esperava que o grupo $C O$ apresentasse uma maior expressão de $\Delta$ FosB que o $C P$, 
porém os resultados mostram diferenças entre o grupo CO comparado com o Ctr, e também do $\mathrm{CP}$ comparado com o controle, mas não entre $\mathrm{CO}$ e CP. De forma similar aos resultados do Cg1, parece existir um padrão de aumento na expressão de $\Delta \mathrm{FosB}$ regulado pela contingência $(\mathrm{CO}>\mathrm{CP}>\mathrm{Ctr})$ o qual seria interessante conferir em futuros estudos.

Como descrito no Experimento 1, o NAc é uma área de integração límbica e cortical (Goto \& Grace, 2008), implicada no processamento de estímulos pavlovianos e o estado motivacional (Everitt, 2001). O NAc tem um papel importante na PIT. O Core e Shell têm sido reportados bibliograficamente pelos seus diferentes papeis nesta. Por um lado, as lesões no Core, mas não no Shell, tem mostrado impedir a PIT generalizada (Cardinal, Parkinson \& Everitt, 2002; Corbit \& Balleine, 2005; 2011; Hal, Parkinson, Conor, Dickson \& Everitt, 2001). Também tem sido previamente reportado que a PIT específica é impedida por lesões no Shell e não no Core (Corbit et al., 2001; Corbit \& Balleine, 2005; 2011).

Segundo o reportado por Perrotti et al. (2008), não se esperava que os resultados em relação ao NAc mostrassem diferença na expressão de $\Delta \mathrm{FosB}$ entre o grupo Ctr e os outros grupos, pois esta área é comumente reportada por expressar este IEG após a administração crónica de $\mathrm{COC}$ em geral, sem estar esta expressão relacionada à contingência em que esta droga foi administrada. Em concordância com este estudo, tanto os resultados no Core como no Shell mostraram que os grupos $\mathrm{CO}$ e CP tiveram uma expressão muito maior comparados com o Ctr, mais não entre estes dois.

Alguns autores têm proposto que o papel do NAc Core é mais relevante para a autoadministração de COC quando associada a um S, pois a inativação reversível do Core, mas não do NAc, alterou a reinstalação de COC induzida por um S (Fuchs, Evans, Parker, \& See, 2004). Porém, dado que é consistente que a expressão de $\Delta \mathrm{FosB}$ não diferencial na administração de COC sob contingências operante e Pavloviana, no NAc Core e Shell, os 
resultados comportamentais e imunohistoquímicos de este estudo para essas subáreas não parecem estar relacionados.

Os resultados para o $1 \mathrm{CPu}$ mostram diferenças na expressão de $\Delta \mathrm{FosB}$ entre os grupos que receberam COC nas contingências operante e Pavloviana, em comparação com o Ctr, o que sugere que foi o efeito central da droga a causante da indução de expressão gênica, e esta não se deu em relação às contingências. De forma similar, os resultados para o $\mathrm{mCPu}$ mostraram que houve diferenças significativas entre os grupos $\mathrm{CO}$ e $\mathrm{Ctr}$, e $\mathrm{CP}$ e $\mathrm{Ctr}$, mas não entre $\mathrm{CO}$ e $\mathrm{CP}$. O conhecimento sobre como o $\mathrm{CPu}$ está envolvida na dependência as drogas é bastante restrito, se limitando, entre outros fatores, às conexões do $1 \mathrm{CPu}$ com o córtex somatossensorial e motor, com que em conjunto regulam diferentes aspectos do movimento (Fricker, et al., 1996), e às conexões que o $\mathrm{mCPu}$ recebe do $\mathrm{mPFC}$, regulam funções como aprendizagem de sequências e seleção de estratégias, (McDonald, \& White, 1999).

Os dados obtidos em conjunto para $1 \mathrm{CPu}$ e mCPu mostram que a administração de $\mathrm{COC}$ induz a expressão de $\Delta \mathrm{FosB}$ no $\mathrm{CPu}$ em geral e que esta expressão não é regulada pelas contingências e sim pelo efeito central da droga. Isto sugere que o papel que o $\mathrm{CPu}$ tem na dependência às drogas está mais relacionado às conexões com áreas corticais com as que em conjunto regulam movimentos e aprendizagem de sequências. Os dados obtidos neste experimento, comportamentais e imunohistoquímico, são insuficientes para interagir com o que se conhece na literatura destas subáreas para sugerir uma interação entre estes.

Em relação aos resultados no hipocampo, as subáreas DG e CA1 mostraram diferenças entre grupos, mas estas não se observaram no CA3. Para o DG houve uma maior marcação no grupo $\mathrm{CO}$ em relação ao $\mathrm{CP}$ e ao Ctr. Tendo em conta que o DG tem um papel importante na codificação conjuntiva de informação e na separação de padrões espaciais e separação de padrões contextuais (Kesner, 2013), este resultado sugere que essas funções 
poderiam ser atingidas diferencialmente na contingência operante e na contingência pavloviana, induzindo portanto diferentes níveis de $\Delta$ FosB nesta subárea entre grupos. Por outro lado, os resultados para CA1 mostram marcações maiores nos grupos $\mathrm{CO}$ e $\mathrm{CP}$ em comparação ao Ctr, mas não entre estes dois últimos, sugerindo que houve principalmente um efeito central da COC sobre esta subárea como causa da expressão de $\Delta \mathrm{FosB}$, sem ser afetada pela contingência de aprendizagem. Dado que o mesmo resultado para CA1 foi obtido no Experimento 1, parece houver consistência que esta subárea seja afetada unicamente pelo efeito central de uma droga e não pela história de administração desta, porém seria possível que uma outra droga diferente de morfina ou COC pudesse induzir um efeito diferencial segundo a contingência, o qual poderia ser conferido em estudos posteriores. Os resultados do DG e CA1 estão em concordância com o reportado por Perrotti et. al. (2008), em relação ao aumento na expressão de $\triangle \mathrm{FosB}$ que a administração de COC causa nestas subáreas.

No CA3, os resultados obtidos não mostram diferenças significativas entre grupos, e não parece existir um padrão de aumento ou diminuição de expressão de $\Delta \mathrm{FosB}$ em relação ao tipo de contingência, pois as medidas de células imunorreativas por $\mathrm{mm}^{2}$ são similares nos três grupos. Como se pode observar na Figura 32, a quantidade de células imunorreativas foi similar às das outras subáreas e se manteve estável nas medições feitas após a Fase 4, em relação às primeiras, para todos os grupos, incluindo o Ctr. Dado que não houve diferenças nesta medição entre os sujeitos que se autoadministraram $\mathrm{COC}$ ou receberam esta de forma passiva com os sujeitos que receveram um veículo (grupo Ctr), e estes último grupo não mostrou um aumento após ter autoadministrado a droga, o resultado indica que o CA3 não é vulnerável à administração crónica de $\mathrm{COC}$ e que o papel que esta subárea poderia ter em relação à dependência de $\mathrm{COC}$, se existir, estaria ligado ao processamento sequencial de informação em cooperação com CA1 e no processamento de geometria do ambiente em cooperação com o DG (Kesner, 2007). 
O hipocampo tem sido reconhecido pelo seu papel em aprendizagem e memória e existe evidência que sugere mudanças na plasticidade e mecanismos moleculares no hipocampo foram associados a memórias contextuais induzidas por um S previamente presente durante a administração da droga, levando a busca e autoadministração da droga (Hou et al., 2009; Taubenfeld, Muravieva, Garcia-Osta, \& Alberini, 2010). Estudos específicos do hipocampo em relação a seu papel na PIT não foram encontrados. Isto provavelmente porque a maioria destes estudos realizam lesões específicas das áreas de estudo antes ou depois do treino para observar como se afeta o desempenho da tarefa durante o teste de transferência. Lesões no hipocampo dificultariam ou impediriam diretamente a PIT, a depender da subárea lesionada, porém, dado que os mecanismos de memória estariam sendo afetados diretamente, não se poderia concluir que se a lesão afetou a PIT ou se simplesmente incapacitou os sujeitos para manter ou recobrar as suas memórias (Knierim, 2004; Mumby, 2002; Palmer, 2002). Os resultados do presente experimento não são conclusivos e estudos posteriores teriam que ser realizados para ampliar o conhecimento além do que pode ser concluído com unicamente os dados apresentados. O papel do hipocampo é realmente importante para compreender a dependência às drogas, dado a conexão que existe entre Ss presentes no ambiente e o uso de uma droga que poderiam ser induzidos por plasticidade nesta área (Dacher \& Nugent, 2011).

Os resultados para os subnúcleos BLA, CeA e MeA da amígdala são interessantes para os objetivos deste experimento. Segundo Blundell et al. (2001) e Corbit et al. (2001), a BLA e o Shell estariam diretamente involucrados na PIT específica, e a CeA e o Core estão implicados na PIT generalizada (Hall et al., 2001; Holland \& Gallagher, 2003). Na BLA se encontraram diferenças significativas entre o grupo $\mathrm{CO}$ comparado com o $\mathrm{CP}$ e Ctr, observando a tendência que tem aparecido em outras subáreas em relação à expressão de $\Delta \mathrm{FosB}(\mathrm{CO}>\mathrm{CP}>\mathrm{Ctr})$. Como mencionado previamente, a BLA possui conexões eferentes 
dirigidas ao NAc que ajudam a mediar a motivação, e se acredita esteja implicada na aprendizagem relacionada a estímulos ambientais/contextuais (Martinez et al, 2011; Setlow, et al., 2002). Este resultado é sem precedentes, pois nos estudos prévios como os de Perrotti et al. (2008) e Wistanley et al. (2007), não foi avaliada esta subárea ou as outras da amígdala para ver as diferenças na expressão de $\Delta$ FosB na autoadministração e administração passiva de COC. Segundo este resultado para a BLA, é possível que esta subárea pudesse estar implicada em resultados comportamentamentais deste experimento, como que o grupo CO teve uma maior frequência de respostas e ID na presença de S1 em comparação com o CP.

$\mathrm{Na} \mathrm{CeA}$ mostraram diferenças no grupo $\mathrm{CO}$ comparado com o $\mathrm{CP}$ e com $\mathrm{Ctr}$, sendo a expressão de $\Delta$ FosB significativamente maior em $\mathrm{CO}$ e praticamente igual entre $\mathrm{CP}$ e $\mathrm{Ctr}$. Isto sugere que o efeito farmacológico da COC não tem um efeito relevante na expressão de $\Delta \mathrm{FosB}$ na $\mathrm{Ce} A$, mas sim na contingência é administrada, sendo induzida apenas pela $\mathrm{CO}$. Estes resultados na BLA e CeA foram similares no Experimento 1, o que poderia sugerir a generalização para outras drogas, pelo menos outros opioides e derivados da COC.

Adicionalmente, como pode ser observado nas medições após da Fase 4 (Fig. 33), os resultados sugerem que a BLA e a CeA se encontram estreitamente ligadas ao processo de aprendizagem ou associação quando a COC é autoadministrada cronicamente por $\mathrm{CO}$, pois os níveis das células imunorreativas por $\mathrm{mm}^{2}$ se estabilizaram na medição após a Fase 4 ao mesmo nível que o as marcações no grupo $\mathrm{CO}$ na medição após a Fase 2.

Finalmente, os resultados obtidos na MeA não mostram diferenças estatisticamente significativas entre grupos, sendo similares as medições para todos estes. Dado que as medições realizadas após a Fase 4 não mostram diferenças com as realizadas após a Fase 2, sendo similar ao observado nesta subárea no Experimento 1, parece ser que CeA não está 
implicada na aprendizagem relacionada à dependência às drogas, nem é afetada diferencialmente em relação à expressão de $\Delta \mathrm{FosB}$ por $\mathrm{CO}$ ou $\mathrm{CP}$.

Winstanley et al. (2007), reportaram que a expressão de $\Delta \mathrm{FosB}$, após de autoadministração, mas não de administração passiva, no OFC. De forma similar, no Experimento 3 se reporta uma diferença significativa entre estes dois grupos, sendo claramente maior em CO, comparado com CP. Porém, contrário ao reportado nesse estudo, neste experimento também se obteve marcação no grupo $\mathrm{CP}$, o qual poderia ser explicado por diferenças delineamento experimental, tendo em conta que no estudo de Winstanley et al. (2007) o grupo CP recebeu injeções intraperitoneais e não foi um esquema acoplado com infusões i.v acompanhadas de um S, como no presente estudo. Segundo esta ordem de ideias, os resultados sugerem que a contingência S1-droga aprendida durante a contingência Pavloviana a que teria induzido a expressão de $\Delta \mathrm{FosB}$ no grupo $\mathrm{CP}$, o que não se conseguiria unicamente com uma administração passiva por meio injeções de COC.

Como mencionado anteriormente, a expressão gênica pode ser maior em algumas subáreas cerebrais quando os sujeitos receberam a droga em contingência operante, comparados com sujeitos que a receberam em contingência Pavloviana (Choi et al., 2011; Jacobs et al., 2002, 2003, 2005; Krawczyk, 2002; Kuzmin \& Johansson, 1999; Lüscher \& Malenka, 2011; Miguéns et al., 2008; Nestler, 2012; Thomas et al., 2003; Winstanley et al., 2007). Esta expressão gênica tem sido reportada em áreas do SNC implicadas na regulação do reforço de drogas, como PFC e OFC, nas que drogas como a COC e morfina aumentam a sensibilidade aos efeitos reforçadores e de ativação locomotora (Colby et al., 2003; Winstanley, 2007; Zachariou et al., 2006). Coerente com esses dados, os resultados de Experimento 3 mostram que existem diferenças na expressão de $\Delta \mathrm{FosB}$, em áreas cerebrais implicadas na dependência às drogas, entre os sujeitos que receberam $\mathrm{COC}$ em contingência 
operante e os que receberam a mesma em contingência Pavloviana, assim como dos sujeitos do grupo Ctr.

Em resumo, os resultados imunohistoquímico obtidos no Experimento 3 estão em concordância com dados reportados previamente na bibliografia em relação diferenças da expressão de $\Delta$ FosB no OFC (Perrotti et al., 2008; Winstanley et al., 2007). Adicionalmente, foram obtidos resultados similares para outras subáreas que não foram reportadas previamente em outros estudos por terem uma expressão de $\Delta \mathrm{FosB}$ afetada de forma diferencial pela contingência operante ou Pavloviana na administração repetida de COC, como o DG do hipocampo, a BLA e a CeA. Adicionalmente, os dados comportamentais mostraram a transferência, replicando estudos prévios (Kruzic, Congelton \& See, 2001; LeBlanc, Ostlund \& Maidment, 2012; Saddoris et al., 2011).

O grupo CP apresentou PIT com o delineamento experimental utilizado, sendo um excelente indicador do procedimento utilizado, replicando estudos que tem mostrado o surgimento de PIT em estudos com COC (Kruzic, Congelton \& See, 2001; LeBlanc, Ostlund \& Maidment, 2012; Saddoris et al., 2011). Ainda, no estudo de LeBlanc et al., 2012, o qual também utilizou duas barras para separar as respostas de busca e de autoadministração, também se reporta uma maior frequência de respostas na resposta de autoadministração quando o S associado ao efeito da COC foi apresentado durante o teste de transferência. Resultados como esse em comum com outros estudos mostram consistência no procedimento.

Ainda, os resultados comportamentais mostraram que os sujeitos do grupo CO apresentaram uma frequência de respostas total e na presença de S1 maior em comparação com o grupo CP. De forma similar, o ID total e durante a apresentação de S1 foi maior no grupo $\mathrm{CO}$ na resposta de busca, comparado com o $\mathrm{CP}$, e a latência de respostas na barra $\mathrm{B}$ foi 
menor no grupo $\mathrm{CO}$, comparado com o $\mathrm{CP}$. Adicionalmente, na presença de S1, o grupo $\mathrm{CP}$ apresentou um ID na barra A maior em comparação com o grupo Ctr.

Alguns dos resultados imunohistoquímico apoiam com os resultados comportamentais e sugerem que a maior expressão de $\Delta \mathrm{FosB}$ no LO e na BLA no grupo $\mathrm{CO}$ em comparação ao $\mathrm{CP}$, estejam relacionados às diferenças entre estes grupos no controle de estímulos estabelecido por S1 para estes dois grupos, em relação ao ID atingido na presença deste, e pela diferença entre estes dois grupos na frequência e latência de resposta na barra B.

Poucos estudos são realizados com os fatores considerados no presente estudo para tentar obter um modelo adequado de estudo de controle de estímulos na autoadministração e administração passiva de drogas, pois existe um grande custo e variáveis a serem consideradas ao trabalhar com PIT (Cartoni et. al 2016), assim como inumeráveis dificuldades que acarretam os procedimentos em si ao estudar controle de estímulos neste paradigma (LeBlanc et al., 2012).

Estudos posteriores devem ser realizados para conferir os dados aqui apresentados e brindar valiosa informação complementar ao papel que estas subáreas têm na dependência às drogas e como estas podem ser afetadas ou não de forma diferencial pela história de administração de uma droga em contingência operante ou Pavloviana. 


\section{Discussão Geral}

Diferentes abordagens da dependência às drogas parecem concordar em atribuir aos estímulos ambientais papel determinante sobre a autoadministração, procura por drogas e recaída observadas em sujeitos dependentes (e.g. Everitt \& Robbins, 2005; Kalivas \& O'Brien, 2008; Kalivas, Peters, \& Knackstedt, 2006; Robinson \& Berrigde 2003; Siegel \& Ramos, 2002). Porém, alguns autores propõem que são as relações pavlovianas estímulodroga (CS-US) estabelecidos durante a procura e consumo da droga que determinariam a dependência a uma droga (Bachteler et al., 2005; Robinson \& Berridge, 1993, 2003, 2008), enquanto outros defendem que são as relações operantes estímulo-resposta-droga (SD-R-S $)$ as que determinariam esses comportamentos (Chen et al., 2008; Melzack, 1990; Stefanski et al., 1999). Os resultados aqui obtidos não parecem apoiar nenhuma das propostas em termos de priorizar um ou outro processo de aprendizagem como determinante da dependência de drogas e oferecem um panorama alternativo a essa dicotomia.

Os resultados apresentados poderiam ajudar a dar uma explicação a perguntas como por que diferentes autores (e corpos teóricos) apontam e mostram resultados contraditórios, indicando que seriam as associações aprendidas durante a contingência Pavloviana ou as associações aprendidas durante a contingência operante as que levariam à dependência às drogas. Como mencionado na introdução desta tese, é possível que a resposta não se ache focando nos argumentos dados por estes estudos para tentar mostrar que é a contingência operante ou a Pavloviana a responsável pela dependência a uma droga. Existem fatores em comum entre estes autores/estudos, que não são contraditórios e que estão em concordância com os resultados de inumeráveis pesquisas nas áreas da análise do comportamento e das neurociências.

A controvérsia entre propostas sobre o desenvolvimento de dependência durante a interação com uma droga em contingência Pavloviana ou operante pode ser consequência de 
diferentes paradigmas, pois com tantas variações possíveis não é de surpreender que se obtenham resultados diferentes e aparentemente opostos, dependendo de fatores como o tipo de PIT reportada, seletiva ou generalizada (Corbit \& Balleine, 2005; 2011), a ordem dos treinos operantes e Pavlovianos, a substância e dose usada como reforçador (ou punidor no caso da devaluação), sujeitos de estudo, entre outros (Holmes, Marchand \& Coutureau, 2010). Os resultados do presente experimento não teriam sido possíveis de obter se o delineamento experimental não incluísse a separação das respostas. No estudo prévio realizado no laboratório (Patarroyo et al., 2014), ao não ter a divisão de respostas, os resultados indicaram a ausência de PIT em um protocolo muito similar ao aqui realizado, porém, sem a divisão das respostas de busca e autoadministração.

Os resultados de expressão de $\Delta$ FosB obtidos nas Fases 1 do Experimento 1 e 3 estão em concordância com estudos que reportam que a administração repetida de uma droga em contingências operantes ou pavlovianas alteram diferencialmente a expressão desta em estruturas cerebrais envolvidas nos processos da dependência às drogas (e.g. Saddoris et al, 2011; West \& Carelli, 2016). Perrotti et al. (2008), reportam que a autoadministração de COC ocasiona uma expressão de $\Delta$ FosB no NAc Core e Shell igual à que ocasiona a administração passiva da mesma, indicando que para estas subáreas a indução deste IEG se dá em função do efeito farmacológico e não da contingência na qual uma droga é administrada, porém, estes mesmos autores reportam que a autoadministração de COC ocasiona uma expressão maior de $\Delta$ FosB no OFC que a que ocasiona a administração passiva da mesma, indicando que para esta subárea não unicamente à exposição à COC a que causou a expressão de $\Delta \mathrm{FosB}$, mas a contingência na qual a droga foi administrada.

De forma similar, Jacobs et al. (2005) reportaram uma maior expressão de $\Delta$ FosB no NAc Core na contingência operante de heroína, que na contingência Pavloviana desta. O 
Experimento 1 registrou este mesmo dado empregando infusões de morfina, outro opioide, sugerindo que talvez este efeito se possa generalizar para outras drogas, pelo menos outros opioides. No Experimento 1 foi encontrado que a contingência operante ocasionou uma maior expressão de $\Delta$ FosB que a contingência Pavloviana em outras subáreas, além do NAc Core, como o PrL, Core, CA3, BLA e CeA, as quais não têm sido reportadas previamente em estudos similares medindo a expressão de $\Delta$ FosB entre a contingência operante e Pavloviana de drogas. Comparativamente, no Experimento 3, foi encontrado que a contingência operante ocasionou uma maior expressão de $\Delta \mathrm{FosB}$ que a contingência Pavloviana no $\mathrm{OFC}$, resultado que replica o reportado em Winstanley et al. (2007). Este mesmo resultado também se observou em áreas não reportadas previamente, o DG do hipocampo, a BLA e a CeA.

Os resultados também mostram algumas subáreas em comum (a BLA e a CeA) em que a contingência operante de morfina e COC ocasionaram uma forte marcação de $\Delta$ FosB que a contingência Pavloviana destas mesmas, e alguma subáreas que só foram afetadas diferencialmente pela contingência operante ou Pavloviana de morfina (NAc Shell, CA3) ou COC (OFC, IL e DG). Esses dados podem indicar efeito específicos da droga, corroborando e ampliando dados da literatura de que diferentes drogas podem causar a expressão de $\Delta$ FosB em diferentes subáreas Perrotti et al. (2008).

Em conjunto, os resultados dos experimentos 1 e 3 mostraram que a contingência na qual uma droga é administrada, operante ou Pavloviana, pode induzir de forma diferencial a expressão de $\Delta$ FosB em diferentes áreas cerebrais. A literatura reporta o NAc (Goto \& Grace, 2008), a Amígdala (Corbit and Balleine, 2005) e o PFC (Ostlund \& Balleine, 2007), como estruturas envolvidas dos processos de PIT, e os dados comportamentais dos experimentos 2 e 3 apontam uma conexão entre estas áreas envolvidas na PIT e a expressão de $\Delta$ FosB induzida por diferentes contingências de administração de drogas, pois coincidem com áreas 
em que se acharam diferenças entre os grupos $\mathrm{CO}$ e $\mathrm{CP}$ nos experimentos 1 e 3 . Ainda, em estruturas como o NAc, a literatura reporta que existe uma conexão direta entre aumento na autoadministração de uma droga e o aumento na expressão de $\Delta$ FosB (Olsen, 2011; Robinson \& Nestler, 2011; Ruffle, 2014).

Saddoris et al. (2011), mostraram que durante o teste de transferência de PIT a atividade de neurônios no NAc aumentou em animais que se autoadministraram COC e que receberam esta passivamente em comparação com o grupo controle. Os autores reportam que no grupo que pasou pelo treino da contingência operante, os neurônios do Core, em comparação com os do Shell, foram principalmente ativados na presença do CS, na presença de um reforçador e durante a tarefa operante, sendo esta codificação no Core correlacionada com o nível de transferência mostrado no teste de transferência da PIT. Por outro lado, em ratos experimentalmente ingênuos, apenas os neurônios do Shell responderam ante US. De acordo com o autor, seus dados indicariam que a atividade do Core está envolvida na aquisição de informação sobre o S no ambiente e a contingência ao responder, enquanto que o Shell seria importante para usar essas informações para modular o comportamento, sendo especialmente afetado pela contingência de administração de uma droga, indicando que em termos de atividade neuronal, ainda que ambos os subnúcleos do NAc se ativem na presença de um CS ou US, o Core estaria mais envolvido na contingência operante e o Shell mais envolvido na Pavloviana

Destaca-se a semelhança entre os grupos $\mathrm{CO}$ e $\mathrm{CP}$ em relação à expressão de $\Delta \mathrm{FosB}$ para ambas as subáreas do NAc, Core e Shell, no Experimento 3, pois, a diferença dos resultados tão característicos do Experimento 1, a administração de morfina sob as contingências operantes e pavlovianas ocasionaram diferenças marcantes na expressão de $\Delta$ FosB no Shell. Uma possível explicação para a diferença encontrada entre os resultados dos experimentos e as propriedades de droga e os efeitos que produz no organismo, pois segundo 
o segundo experimento de Perrotti et al. (2008), ao comparar expressão de $\Delta$ FosB induzida por diferentes drogas em diferentes subáreas cerebrais, cada droga pode pode induzir $\Delta \mathrm{FosB}$ em diferentes subáreas. Ainda, o segundo experimento do estudo destes autores e o estudo de Winstanley et al. (2007) mostram que as contingências sob as quais uma droga é administrada tem um efeito diferencial na indução de $\Delta$ FosB em algumas subáreas cerebrais. Portanto, segundo esta lógica, é apenas razoável que os resultados de comparação entre contingências de administração de duas drogas se tenham apresentado em diferentes subáreas.

Mesmo que este estudo não pretendeu comparar as diferenças em expressão de $\Delta$ FosB causadas pela contingência operante ou Pavloviana entre morfina e COC, é interessante destacar, que como reportado por Perrotti et al. (2008), diferentes drogas produzem expressão de $\Delta$ FosB em diferentes subáreas. Pois os resultados do Experimento 3, utilizando COC, que mostraram diferenças de expressão deste IEG produzidas pelas contingências estudadas, operante e Pavloviana, são em subáreas diferentes às reportadas no Experimento 1, no qual foi utilizada morfina. Adicionalmente, como apontado por Holmes et al. (2010) as variações importantes no delineamento (droga utilizada, dosagem, procedimento, modelo, ordem dos treinos, etc), são fatores que influiriam importantemente nos estudos que avaliam o controle de estímulos usando um procedimento com tantas variações como a PIT.

$\mathrm{Na}$ literatura se considera $\Delta \mathrm{FosB}$ como o mais importante mecanismo biomolecular nos estudos de dependência às drogas pois tem sido reportado que aumentos na autoadministração de uma droga são dependentes da expressão deste IEG no NAc (Olsen, 2011; Robinson \& Nestler, 2011; Ruffle, 2014), porém, estes estudos têm focado no efeito central que produz uma droga durante a autoadministração e portanto os resultados são em relação a um protocolo simples de autoadministração e não em comparação de contingências 
de administração. De fato, Nestler $(2012,2014)$ e Ruffle (2014) sugerem que o $\Delta$ FosB seria uma espécie de "interruptor molecular", que ajuda iniciar e manter o estado de dependência em um organismo. Isto indica que ainda que a expressão de $\Delta$ FosB induzida por uma droga possa estar diretamente relacionada com o aumento da autoadministração da mesma, não necessariamente esta expressão indica o desenvolvimento de dependência ou de controle de estímulos, pois se fosse desse jeito, não existiriam as diferenças de expressão deste IEG em diferentes subáreas e dadas por diferentes drogas, como apontado por Perrotti et al. (2008) e Winstanley et al. (2007). Ainda, segundo este raciocínio, durante um procedimento como o utilizado neste estudo, a expressão de $\Delta$ FosB durante a Fase 2 poderia predizer unicamente de forma parcial os resultados comportamentais da Fase 4.

No experimento 3, as medições imunohistoquímicas após da Fase 4 foram maiores para a maioria das subáreas em comparação com as medições realizadas na Fase 2. Ainda, estas medições na Fase 4 não revelaram diferença entre grupos, o que parece indicar que a autoadministração da droga na Fase 3 induziu a expressão de $\Delta$ FosB entre os grupos ao ponto de "igualar" o nível de expressão, apoiando a proposta de Nestler, (2012) sobre estabilidade de acumulação gradativa deste IEG produzida pela administração repetidas de uma droga. Por outro lado, na Fase 4 houve diferenças importantes de comportamento entre os animais dos diferentes grupos no Experimentos 2 e 3, que sugerem que o a expressão de $\Delta$ FosB está relacionado não unicamente ao aumento nas respostas de autoadministração de uma droga, mas também depende da contingência em que esta droga foi administrada inicialmente, podendo influenciar vaiáveis como ID e latência de resposta.

Tanto no Experimento 2, como no 3, o grupo CP apresentou PIT durante o teste de transferência, replicando estudos que mostram esta transferência em estudos com drogas (Kruzic, Congelton \& See, 2001; LeBlanc, Ostlund \& Maidment, 2012; Saddoris et al., 
2011). Ainda, os resultados de estes experimentos apontam ao surgimento de um padrão de respostas, de forma diferencial entre os grupos $\mathrm{CO}$ e $\mathrm{CP}$ durante o teste de transferência. Esta tendência se sustenta nos dados de IDs e de frequência de respostas e de latência de respostas quando S1 foi apresentado, sugerindo que a contingência operante ocasionou uma tendência a responder na barra $\mathrm{B}$.

Como exposto na introdução, se considera que o esquema acoplado (Catania, 1999; Sanchis-Segura\& Spanagel, 2006) é o mais adequando para um estudo como o presente, porém, deve ir acompanhado de métodos como a implantação de cateter para infusões i.v. para garantir a administração da droga sem a interrupção do procedimento, de uma forma rápida, asséptica e sem dor, assim como da implementação de uma separação de respostas (busca e autoadministração) do processo que levam a administração de uma droga (SanchisSegura \& Spanagel, 2006), que como visto nos resultados apresentados, pode brindar dados relevantes para a compreensão do controle de estímulos na dependência às drogas, tendo em conta que não todas as respostas no processo de consumo de uma droga são afetadas da mesma forma por estímulos que foram associados a estas em diferentes histórias de associação.

Os resultados dos três experimentos apresentados nesta tese aportam valiosos dados desde a perspectivas comportámemtal e bioquímica para o entendimento sobre o controle de estímulos e a dependência às drogas. Eles estão em concordância com a bibliografia que suporta que a contingência operante e Pavloviana são processos diferentes de aprendizagem, como discutido por Pear e Eldridge (1984), Rescorla e Solomon (1967), Rehfeldt e Hayes, 1998, e Skinner (1937), entre outros; e portanto, ainda tendo propriedades em comum, poderiam influenciar diferencialmente um organismo, especialmente no caso da dependência às drogas. 


\section{Conclusões}

Desde os estudos de Estes e Skinner (1941) reportando que um S associado com comida podia aumentar a frequência de uma resposta operante que tinha também comida como consequência, e a proposta dos dois processos por Rescorla e Solomon (1967), muito se tem descoberto sobre o controle de estímulos e a sua relevância na dependência às drogas, e muitas mais incógnitas têm surgido também em relação a estes novos conhecimentos. Se considera que os objetivos de todos os experimentos foram atingidos durante o desenvolvimento deste projeto de doutorado. Os resultados dos três experimentos apresentados nesta tese aportam valiosos dados desde a perspectivas comportamental e bioquímica para o entendimento sobre o controle de estímulos e a dependência às drogas. Eles estão em concordância com a bibliografia que suporta que a contingência operante e Pavloviana são processos diferentes de aprendizagem e, portanto, podem influenciar diferencialmente um organismo, especialmente em casos como a dependência às drogas. Os resultados apresentados não só replicam dados de estudos prévios na área, mas aportam dados novos, não reportados previamente, que se complementam entre si. Ainda foi desenvolvido um procedimento melhorado para o estudo da contingência operante e Pavloviana de drogas, mostrando a sua eficácia e consistência.

Os dados em relação à expressão de $\Delta$ FosB podem brindar informações valiosas em relação a processos como aquisição, manutenção e recaída, na dependência às drogas. Mesmo que não se conhece totalmente seu funcionamento, vale a pena destacar a proposta de Nestler (2012, 2014) e Ruffle (2014), a qual sugere que o $\Delta$ FosB pode ser uma espécie de “interruptor molecular", que ajuda iniciar e manter o estado de dependência em um organismo.

Que além de todas as subáreas em que a autoadministração em contingência operante causou uma maior expressão de $\Delta$ FosB do que a administração passiva em contingência 
Pavloviana, no Experimento 1, se tenha achado que a contingência Pavloviana causou uma maior expressão no NAc Shell e no DG, do que a operante, é um resultado que sugere que as diferenças produzidas em um organismo na aprendizagem que se adquire durante diferentes histórias de administração de drogas em contingência operante ou Pavloviana, não são questão de "tudo ou nada", nem tampouco apresentadas unicamente por uma das contingências, mas diferentes em relação ao que implica a aprendizagem em cada tipo de contingência. Isto é apoiado pelos resultados imunohistoquímico do Experimento 3, que mostraram de forma similar maior expressão no LO, BLA e CeA, e ainda, em conjunto, replicam e ampliam dados do estudo de Perrotti et al. (2008) que mostram que diferentes drogas podem induzir a expressão de $\Delta \mathrm{FosB}$ em diferentes subáreas do $\mathrm{SNC}$ relacionadas à administração de drogas.

De forma indubitável, a inclusão de medidas como IEGs brinda um complemento ideal ao estudo da dependência às drogas se articulando aos dados comportamentais. Como mostrado nos resultados apresentados, os dados comportamentais e bioquímicas estão em concordância entre si, mostrando a compatibilidade e o complemento entre medidas ao estudar a dependência às drogas.

Por outro lado, se tem proposto neste estudo que a PIT é relevante para a compreensão dos comportamentos controlados por estímulos ambientais, como comer, beber e consumir drogas. Dado que o procedimento e o delineamento experimentais utilizados permitiram a aparição de PIT, se propõem como indicados e adequados para estudar a PIT como processo básico do comportamento.

Ainda, dentro do limite da bibliografia conhecida, esta é o primeiro estudo experimental que reporta que a contingência operante e a Pavloviana de uma droga tenha ocasionado diferentes padrões de respostas, preferência na resposta de busca no grupo CO, e 
preferência na resposta de autoadministração no grupo CP. Adicionalmente, também é a primeira vez que se reporta a apresentação de PIT com autoadministração i.v de morfina.

Futuros experimentos poderão utilizar o procedimento aqui desenvolvido indagando questões que vão além das exploradas neste estudo, aperfeiçoando o procedimento e adaptando este. Muito pode ser modificado ou adaptado no procedimento em pró de atingir formas mais adequadas para diferentes questões sobre a dependência às drogas, por exemplo, a possibilidade de dividir o comportamento de consumo de drogas em mais do que dois respostas, uso de outras drogas além das clássicas nos estudos de dependência (incluindo drogas modernas que afetam a saúde da população e a combinação de drogas), uso de aparelhos que permitam o registro de resposta 24/7 (como as caixas de alojamento com sistema de infusão), uso de machos e fêmeas, acesso a um ambiente enriquecido, entre outras. Como cientistas devemos estar cientes das limitações dos nossos estudos, modelos e procedimentos, que tentam replicar condições naturais isolando variáveis de forma artificial para ter controle experimental, portanto é imprescindível aumentar as variáveis observadas simultaneamente para tentar ter uma visão mais molar e natural dos mesmos fenômenos que estudamos. 


\section{Referências}

Alarcón, D. E., Bonardi, C., \& Delamater, A. R. (2018). Associative mechanisms involved in specific Pavlovian-to-instrumental transfer in human learning tasks. Quarterly Journal of Experimental Psychology, 71(7), 1607-1625. doi:

10.1080/17470218.2017.1342671.

Alexander, B. K., Coambs R. B., \& Hadaway, P. F. (1978). The effects of housing and gender on morphine self-administration in rats. Psychopharmacology, 58(2), 175179. doi: 10.1007/BF00426903.

Ambroggi, F., Ghazizadeh, A., Nicola, S. M., \& Fields, H. L. (2011). Roles of Nucleus Accumbens Core and Shell in Incentive-Cue Responding and Behavioral Inhibition. Journal of Neuroscience,31(18), 6820-6830. doi: 10.1523/jneurosci.6491-10.2011.

Arroyo, M., Markou, A., Robbins, T. W., \& Everitt, B. J. (1998). Acquisition, maintenance and reinstatement of intravenous cocaine self-administration under a second-order schedule of reinforcement in rats: Effects of conditioned cues and continuous access to cocaine. Psychopharmacology, 140(3), 331-344. doi: 10.1007/s002130050774.

Bachá-Méndez, G., Reid, A. K., \& Mendoza-Soylovna, A. (2007). Resurgence of Integrated Behavioral Units. Journal of the Experimental Analysis of Behavior, 87(1), 5-24. doi: 10.1901/jeab.2007.55-05.

Badiani, A., Oates, M. M., \& Robinson, T. E. (2000). Modulation of morphine sensitization in the rat by contextual stimuli. Psychopharmacology, 151(2-3), 273-282. doi: $10.1007 / \mathrm{s} 002130000447$.

Balleine, B., 1994. Asymmetrical interactions between thirst and hunger in pavlovianinstrumental transfer. Q. J. Exp. Psychol. B, Comp. Physiol. Psychol. 47 (2), 211-231. 
Balleine, B. W., \& Ostlund, S. B. (2007). Still at the choice-point: action selection and initiation in instrumental conditioning. Ann. N. Y. Acad. Sci. 1104, 147-171.

Barbey, A. K., Krueger, F., \& Grafman, J. (2009). Structured event complexes in the medial prefrontal cortex support counterfactual representations for future planning. Philosophical Transactions of the Royal Society B: Biological Sciences,364(1521), 1291-1300. doi: 10.1098/rstb.2008.0315.

Barnes-Holmes, D., \& Barnes-Holmes, Y. (2000). Explaining Complex Behavior: Two Perspectives on the Concept of Generalized Operant Classes. The Psychological Record, 50(2), 251-265. doi: 10.1007/bf03395355.

Barrientos, S. A., \& Tiznado, V. (2016). Hippocampal CA1 Subregion as a Context Decoder. The Journal of Neuroscience, 36(25), 6602-6604. doi: 10.1523/jneurosci.110716.2016.

Bachteler, D., Economidou, D., Danysz, W., Ciccocioppo, R., \& Spanagel, R. (2005). The Effects of Acamprosate and Neramexane on Cue-Induced Reinstatement of EthanolSeeking Behavior in Rat. Neuropsychopharmacology, 30(6), 1104-1110. doi:10.1038/sj.npp.1300657.

Baxter, D. J., \& Zamble, E., (1982). Reinforcer and response specificity in appetitive transfer of control. Anim. Learn. Behav. 10 (2), 201-210.

Berridge, K. C., Robinson, T. E., \& Aldridge, J. W. (2009). Dissecting components of reward: 'liking', 'wanting', and learning. Current Opinion in Pharmacology, 9(1), 65-73. doi: 10.1016/j.coph.2008.12.014. 
Berridge, K. C., \& Robinson, T. E. (2016). Liking, wanting, and the incentive-sensitization theory of addiction. American Psychologist, 71(8), 670-679. doi: 10.1037/amp0000059.

Bindra, D. (1972). A unified acount of classical conditioning and operant Training. In: A. H. Black \& W. F. Prokasy (Eds.), Classical conditioning II. New York: Appleton-Century-Crofts.

Blundell, P., Hall, G., \& Killcross, S. (2001). Lesions of the basolateral amygdala disrupt selective aspects of reinforcer representation in rats. J. Neurosci. 21 (22), 9018-9026.

Burgos, J. E. (2018). Selection by reinforcement: A critical reappraisal. Behavioural Processes. http://doi.org/10.1016/j.beproc.2018.01.019.

Canteras, N. S., \& Goto, M. (1999). Connections of the precommissural nucleus. J. Comp. Neurol. 408(1), 23-45. doi: 10.1002/(SICI)1096-9861(19990524)408:1<23::AIDCNE3>3.0.CO;2-J.

Catania, A. (1999). Aprendizagem: Comportamento, Linguagem e Cognição (Deisy das Graças de Souza, Trad.). Porto Alegre: Artmed Editora.

Cardinal, R. N., \& Cheung, T. H. (2005). Nucleus accumbens core lesions retard instrumental learning and performance with delayed reinforcement in the rat. BMC Neurosci;6:9.

Cardinal, R. N., Parkinson, J. A., Hall, J., \& Everitt, B. J. (2002). Emotion and motivation: The role of the amygdala, ventral striatum, and prefrontal cortex. Neuroscience \& Biobehavioral Reviews, 26(3), 321-352. doi: 10.1016/s0149-7634(02)00007-6.

Carlson, N. (2012). Physiology of behavior. Pearson. p. 336. ISBN 978-0205239399.

Cartoni, E., Balleine, B., \& Baldassarre, G. (2016). Appetitive Pavlovian-instrumental Transfer: A review. Neuroscience and Biobehavioral Reviews, 71, 829-848. 
Chen, B. T., Bowers, M. S., Martin, M., Hopf, F. W., Guillory, A. M., Carelli, R. M., Chou, J. K., \& Bonci, A. (2008). Cocaine but not natural reward self-administration nor passive cocaine infusion produces persistent LTP in the VTA. Neuron, 59, 288-297. doi: 10.1016/j.neuron.2008.05.024.

Childress, A. R., McLellan, A. T., Ehrman, R., \& O'Brien, C. P. (1988). Classically conditioned responses in opioid and cocaine dependence: A role in relapse? In B. A. Ray, Learning factors in substance abuse. NIDA Research Monograph No. 84, pp. 44-61. Washington, DC: U.S. Government Printing Office. PMID: 3147384.

Choi, K. H., Edwards, S., Graham, D. L., Larson, E. B., Whisler, K. N., Simmons, D., Friedman, A. K., Walsh, J. J., \& Rahman, Z. (2011). Reinforcement-Related Regulation of AMPA Glutamate Receptor Subunits in the Ventral Tegmental Area Enhances Motivation for Cocaine. Journal of Neuroscience, 31(21), 7927-7937. doi: 10.1523/JNEUROSCI.6014-10.2011.

Christie, M. J. (2008). Cellular neuroadaptations to chronic opioids: tolerance, withdrawal and addiction. British Journal of Pharmacology, 154(2), 384-396. doi: 10.1038/bjp.2008.100.

Cicero, T. J., Aylward, S. C., \& Meyer, E. R. (2003). Gender differences in the intravenous self-administration of mu opiate agonists. Pharmacology, Biochemistry, and Behavior, 74(3), 541-549. doi: 10.1016/S0091-3057(02)01039-0.

Colby, C. R., Whisler, K., Steffen, C., Nestler, E. J, \& Self, D. W. (2003). Striatal cell typespecific overexpression of $\Delta \mathrm{FosB}$ enhances incentive for cocaine. J Neurosci 23:2488-2493. 
Colwill, R. M., \& Rescorla, R. A. (1985). Instrumental responding remains sensitive to reinforcer devaluation after extensive training. Journal of Experimental Psychology: Animal Behavior Processes, 11(4), 520.

Colwill, R.M., \& Rescorla, R.A. (1988). Animal Learning \& Behavior. 16: 105. https://doi.org/10.3758/BF03209051.

Comer, S. D., Zacny, J. P., Dworkin, R. H., Turk, D. C., Bigelow G. E., Foltin R. W., et al. (2012). Core outcome measures for opioid abuse liability laboratory assessment studies in humans: IMMPACT recommendations. Pain, 153(12), 2315-2324. doi: 10.1016/j.pain.2012.07.035.

Corbit, L. H., Muir, J. L., \& Balleine, B.W. (2001). The role of the nucleus accumbens in instrumental conditioning: evidence of a functional dissociation between accumbens core and shell. J. Neurosci. 21, 3251-3260.

Corbit, L. H., \& Balleine, B. W. (2003a). The role of prelimbic cortex in instrumental conditioning. Behavioural Brain Research, 146(1-2), 145-157. doi: 10.1016/j.bbr.2003.09.023

Corbit, L. H., \& Balleine, B. W. (2003b). Instrumental and Pavlovian incentive processes have dissociable effects on components of a heterogeneous instrumental chain. Journal of Experimental Psychology: Animal Behavior Processes, 29(2), 99-106. doi: 10.1037/0097-7403.29.2.99.

Corbit, L. H., \& Balleine, B.W. (2005). Double dissociation of basolateral and central amygdala lesions on the general and outcome-specific forms of pavlovianinstrumental transfer. J. Neurosci. 25 (4), 962-970. 
Corbit, L. H., \& Janak, P. H. (2007). Inactivation of the lateral but not medial dorsal striatum eliminates the excitatory impact of Pavlovian stimuli on instrumental responding. J. Neurosci. 27, 13977-13981.

Corbit, L. H., Janak, P. H., \& Balleine, B.W. (2007). General and outcome-specific forms of pavlovian-instrumental transfer: the effect of shifts in motivational state and inactivation of the ventral tegmental area. Eur. J. Neurosci. 26 (11), 3141-3149.

Corbit, L. H., \& Janak, P. H., (2010). Posterior dorsomedial striatum is critical for both selective instrumental and pavlovian reward learning. Eur. J. Neurosci. 31 (7), 13121321.

Corbit, L. H., \& Balleine, B. W. (2011). The general and outcome-specific forms of pavlovian-instrumental transfer are differentially mediated by the nucleus accumbens core and shell. J. Neurosci. 31 (33), 11786-11794.

Criswell, H. E., \& Ridings, A. (1983). Intravenous self-administration of morphine by naive mice. Pharmacology Biochemistry and Behavior, 18(3), 467-470. doi: 10.1016/00913057(83)90471-9.

Crombag, H. S., Galarce, E. M., \& Holland, P. C. (2008). Pavlovian influences on goaldirected behavior in mice: the role of cue-reinforcer relations. Learn. Memory (Cold Spring Harbor, N. Y.) 15 (5), 299-303.

Dacher, M., \& Nugent, F. S. (2011). Opiates and plasticity. Neuropharmacology, 61(7), 1088-1096. doi: 10.1016/j.neuropharm.2011.01.028.

Delamater, A. R., \& Oakeshott, S. (2007). Learning about Multiple Attributes of Reward in Pavlovian Conditioning. Annals of the New York Academy of Sciences, 1104(1), 120. doi: 10.1196/annals.1390.008. 
Delgado, D., \& Hayes, L. J. (2014). An Integrative Approach to Learning Processes: Revisiting Substitution of Functions. The Psychological Record, 64(3), 625-637. http://doi.org/10.1007/s40732-014-0071-6.

Devan, B. D., McDonald, R. J., \& White, N. M. (1999). Effects of medial and lateral caudateputamen lesions on place- and cue-guided behaviors in the water maze: Relation to thigmotaxis. Behavioural Brain Research, 100, 5-14.

Deroche-Gamonet, V. (2004). Evidence for Addiction-like Behavior in the Rat. Science,305(5686), 1014-1017. doi: 10.1126/science.1099020.

De Vries, T. J., \& Shippenberg, T. S. (2002). Neural systems underlying opiate addiction. Journal of Neuroscience, 22(9), 3321-3325. PMID: 11978806.

Dickinson, A., \& Dawson, G. R. (1987). Pavlovian processes in the motivational control of instrumental performance. Q. J. Exp. Psychol. B, Comp. Physiol. Psychol. 39 (3), 201-213.

Dickinson, A., Smith, J., \& Mirenowicz, J. (2000). Dissociation of Pavlovian and instrumental incentive learning under dopamine antagonists. Behav. Neurosci. 114, 468-483.

Domjan, M. (2015). The Principles of Learning Behavior (7thed). Wadsworth Cengage learning: Belmon.

Donahoe, J. W., Burgos, J. E., \& Palmer, D. C. (1993). A Selectionist Approach to Reinforcement. Journal of the Experimental Analysis of Behavior, 60(1), 17-40.

Donahoe, J. W., \& Palmer, D. C. (1994). Learning and complex behavior. Allyn \& Bacon. 
Dwyer, C., Sowerby, L., \& Rotenberg, B. W. (2016). Is cocaine a safe topical agent for use during endoscopic sinus surgery? The Laryngoscope, 126(8), 1721-1723. doi: 10.1002/lary.25836.

El-Amamy, H., \& Holland, P. C. (2007). Dissociable effects of disconnecting amygdala central nucleus from the ventral tegmental area or substantia nigra on learned orienting and incentive motivation. Eur. J. Neurosci. 25, 1557-1567.

Epstein, D. H., Preston, K. L., Stewart, J., \& Shaham, Y. (2006). Toward a model of drug relapse: an assessment of the validity of the reinstatement procedure. Psychopharmacology (Berl), 189(1), 1-16. doi: 10.1007/s00213-006-0529-6

Goto, Y., \& Grace, A. A. (2008). Limbic and cortical information processing in the nucleus accumbens. Trends in Neurosciences, 31(11), 552-558. doi: 10.1016/j.tins.2008.08.002.

Ehrman, R. N., Robbins, S. J., Childress, A. R., \& Obrien, C. P. (1992). Conditioned responses to cocaine-related stimuli in cocaine abuse patients. Psychopharmacology, 107(4), 523-529. doi: 10.1007/bf02245266.

Everitt, B. J., Dickinson, A., \& Robbins, T. W. (2001). The neuropsychological basis of addictive behaviour. Brain Research Reviews, 36(2-3), 129-138. doi: 10.1016/s01650173(01)00088-1.

Everitt, B. J., \& Robbins, T. W. (2005). Neural systems of reinforcement for drug addiction: from actions to habits to compulsion. Nature Neuroscience, 8(11), 1481-1489. doi: $10.1038 / \mathrm{nn} 1579$.

Everitt, B. J., Belin, D., Economidou, D., Pelloux, Y., Dalley, J. W., \& Robbins, T. W. (2008). Neural mechanisms underlying the vulnerability to develop compulsive drug- 
seeking habits and addiction. Philosophical Transactions of the Royal Society B:

Biological Sciences, 363(1507), 3125-3135. doi: 10.1098/rstb.2008.0089.

Estes, W. K., \& Skinner, B.F. (1941). Some quantitative properties of anxiety. J. Exp. Psychol. 29 (5), 390-400.doi: 10.1037/11324-028.

Estes, W. K. (1943). Discriminative conditioning. I. A discriminative property of conditioned anticipation. Journal of Experimental Psychology, 32(2), 150-155. doi: $10.1037 / \mathrm{h} 0058316$.

Estes, W. K. (1948). Discriminative conditioning; effects of a Pavlovian conditioned stimulus upon a subsequently established operant response. Journal of Experimental Psychology, 38(2), 173-177. doi: 10.1037/h0057525.

Fricker, R. A., Annett, L. E., Torres E. M., \& Dunnett, S. B. (1996). The placement of a striatal ibotenic acid lesion affects skilled forelimb use and the direction of druginduced rotation. Brain Research Bulletin, 41, 409-416.

Fuchs, R. A., Evans, K. A., Parker, M. C., \& See, R. E. (2004). Differential involvement of the core and shell subregions of the nucleus accumbens in conditioned cue-induced reinstatement of cocaine seeking in rats. Psychopharmacology, 176(3-4), 459-465. doi: 10.1007/s00213-004-1895-6.

Gajewski, P. A., Eagle, L. A., \& Robison, A. J. (2017). Neuroscience of cocaine: Mechanisms and treatment. Chapter 26 - The Role of the Hippocampus in Cocaine. Responses London: Academic Press. p259 -268.

Goldberg, S. R., \& Gardner, M. L. (1981). Second-order schedules: extended sequences of behavior controlled by brief environmental stimuli associated with drug self- 
administration. ehavioral Pharmacology of Human Drug Dependence, (37), 241 -70. PMID: 6798462.

Goldberg, S. R., Spealman, R. D. \&, Kelleher, R. T. (1979). Enhancement of drug-seeking by environmental stimuli associated with cocaine or morphine injections. Neuropharmacology, 18(12), 1015-1017. doi: 10.1016/0028-3908(79)90169-2.

Goldberg, S. R., \& Schuster, C. R. (1967). Conditioned suppression by a stimulus associated with nalorphine in morphine-dependent monkeys. Journal of the Experimental Analysis of Behavior, 10(3), 235-242. doi: 10.1901/jeab.1967.10-235.

Goldberg, S. R., \& Tang, A. H. (1977). Behavior maintained under second-order schedules of intravenous morphine injection in squirrel and rhesus monkeys. Psychopharmacology (Berl), 51(3), 235-242. doi: 10.1007/BF00431630.

Goto, Y., \& Grace, A. A., (2005). Dopaminergic modulation of limbic and cortical drive of nucleus accumbens in goal-directed behavior. Nat. Neurosci. 8, 805-812.

Hall, J., Parkinson, J. A., Connor, T. M., Dickinson, A., \& Everitt, B. J. (2001). Involvement of the central nucleus of the amygdala and nucleus accumbens core in mediating Pavlovian influences on instrumental behaviour. European Journal of Neuroscience, 13(10), 1984-1992. doi: 10.1046/j.0953-816x.2001.01577.x.

Haney, R.Z., Calu, D,J., Takahashi, Y.K., Hughes, B.W., \& Schoenbaum G. (2010). Inactivation of the central but not the basolateral nucleus of the amygdala disrupts learning in response to overexpectation of reward. J Neurosci. 30:2911-2917. [PubMed: 20181588]. 
Harper, S. J., \& Jones, N. S. (2006). Cocaine: What role does it have in current ENT practice? A review of the current literature. The Journal of Laryngology \& Otology, 120(10). doi: $10.1017 / \mathrm{s} 0022215106001459$.

Hayden, B. Y., \& Platt, M. L. (2010). "Neurons in Anterior Cingulate Cortex Multiplex Information about Reward and Action". Journal of Neuroscience. 30 (9): 3339-3346.

Heyman, G. M. (2010). Addiction: A disorder of choice. Cambridge, MA: Harvard University Press.

Herrnstein, R. J., \& Prelec, D. (1992). A theory of addiction. In G. Loewenstein \& J. Elster (Eds.), Choice over time (pp. 331-360). New York, NY, US: Russell Sage Foundation

Hinson, R. E., Poulos, C. X., Thomas, W., \& Cappell, H. (1986). Pavlovian conditioning and addictive behavior: Relapse to oral self-administration of morphine. Behavioral Neuroscience, 1 100(3), 368-375. doi: 10.1037/0735-7044.100.3.368.

Holland, P.C., \& Gallagher, M. (2003). Double dissociation of the effects of lesions of basolateral and central amygdala on conditioned stimulus-potentiated feeding and Pavlovian-instrumental transfer. European Journal of Neuroscience. 17:1680-1694. [PubMed: 12752386].

Holland, P. (2004). Relations Between Pavlovian-Instrumental Transfer and Reinforcer Devaluation. Journal of Experimental Psychology. Animal Behavior Processes, 30(2), 104-117. doi: 10.1037/0097-7403.30.2.104.

Holmes, N. M., Marchand, A. R., \& Coutureau, E. (2010). Pavlovian to instrumental transfer: a neurobehavioural perspective. Neurosci. Biobehav. Rev. 34 (8), 1277-1295.

Hickey, C., \& Peelen, M. V. (2015). Neural mechanisms of incentivesalience in naturalistic human vision.Neuron, 85,512-518.http://dx.doi.org/10.1016/j.neuron.2014.12.049. 
Hyman, S. E., \& Malenka, R. C. (2001). Addiction and the brain: The neurobiology of compulsion and its persistence. Nature Reviews Neuroscience. 2, 695-703. doi: $10.1038 / 35094560$.

Hyman, S. E., Malenka, R. C., \& Nestler, E. J. (2006). Neural mechanisms of addiction: the role of reward-related learning and memory. Annual Review of Neuroscience, 29, 565-598. doi: 10.1146/annurev.neuro.29.051605.113009.

Hsu, S. M. \& Raine, L. (1981). Protein A, avidin, and biotin in immunohistochemistry. $J$ Histochem Cytochem, 29(11), 1349-53. doi: 10.1177/29.11.6172466.

Itoh, K., Konishi A., Nomura S., Mizuno N., Nakamura Y. \& Suguimoto T. (1979). Aplication of coupled oxidation reaction to electron microscopic demonstration of the horseradish peroxidase: cobalt-glucose oxidase method. Brain Res. 175, 341-346. doi: 10.1016/0006-8993(79)91013-8.

Jacobs, E. H., Smit, A. B., De Vries, T., J., \& Schoffelmeer, A. N. (2003). Neuroadaptive effects of active versus passive drug administration in addiction research. Trends Pharmacological Sciences, 24(11), 566-573. doi: 10.1016/j.tips.2003.09.006.

Jacobs, E. H., Smit, A. B., De Vries, T., J., \& Schoffelmeer, A. N. (2005). Long-Term Gene Expression in the Nucleus Accumbens Following Heroin administration is subregionspecific and depends on the nature of drug administration. Adiction Biology, (10), 91100. doi: $10.1080 / 13556210412331284748$.

Jacobs, E. H., Spijker, S., Verhoog, C. W., Kamprath, K., De Vries, T. J., Smit, A. B. et al. (2002). Active heroin administration induces specific genomic responses in the nucleus accumbens shell. Federation of American Societies for Experimental Biology Journal, 16(14), 1961-1963. doi: 10.1096/fj.02-0272fje. 
Jacobs, E. H., Spijker, S., Verhoog, C. W., Kamprath, K., de Vries, T. J., Smit, A. B. et al. (2002). Active heroin administration induces specific genomic responses in the nucleus accumbens shell. Federation of American Societies for Experimental Biology Journal, 16(14), 1961-1963. doi: 10.1096/fj.02-0272fje.

Katz, J. L. (1979). A comparison of responding maintained under second-order schedules of intramuscular cocaine injection or food presentation in squirrel monkeys. Journal of the Experimental Analysis of Behavior, 32(3), 419-431. doi: 10.1901/jeab.1979.32419.

Kalivas, P. W., \& Obrien, C. (2008). Drug Addiction as a Pathology of Staged Neuroplasticity. Neuropsychopharmacology, 33(1), 166-180. doi: 10.1038/sj.npp.1301564.

Kalivas, P. W., Peters, J., \& Knackstedt, L. (2006). Animal Models and Brain Circuits in Drug Addiction. Molecular Interventions, 6(6), 339-344. doi: 10.1124/mi.6.6.7.

Kesner, R. P. (2007). Behavioral functions of the CA3 subregion of the hippocampus. Learning \& Memory,14(11), 771-781. doi: 10.1101/lm.688207.

Kesner, R. P. (2013). An analysis of the dentate gyrus function. Behavioural Brain Research, 254, 1-7. doi: 10.1016/j.bbr.2013.01.012.

Keistler, C., Barker, J. M., \& Taylor, J. R. (2015). Infralimbic prefrontal cortex interacts with nucleus accumbens shell to unmask expression of outcome-selective Pavlovian-toinstrumental transfer. Learning \& Memory, 22(10), 509-514. doi:

$10.1101 / \operatorname{lm} .038810 .115$

Koob, G. F. (1992). Dopamine, addiction and reward. Seminaris in Neuroscience, 4, 139148. doi: 10.1016/1044-5765(92)90012-Q. 
Knierim, J. (2004). Faculty of 1000 evaluation for Recollection-like memory retrieval in rats is dependent on the hippocampus. F1000 - Post-publication Peer Review of the Biomedical Literature. doi: 10.3410/f.1020949.247667.

Kreek, M. J., Levran, O., Reed, B., Schlussman, S. D., Zhou, Y., \& Butelman, E. R. (2012). Opiate addiction and cocaine addiction: Underlying molecular neurobiology and genetics. Journal of Clinical Investigation,122(10), 3387-3393. doi: 10.1172/jci60390.

Kruzich, P. J., Congelton, K. M., \& See, R. E. (2001). Conditioned reinstatement of drugseeking behavior with a discrete compound stimulus classically conditioned with intravenous cocaine. Behavioral Neuroscience,115(5), 1086-1092. doi: 10.1037//0735-7044.115.5.1086.

Kuzmin, A., \& Johansson, B. (1999). Expression of c-Fos, NGFI-A and secretogranin II mRNA in brain regions during initiation of cocaine self-administration in mice. European Journal of Neuroscience, 11(10), 3694-3700. doi: 10.1046/j.14609568.1999.00795.x.

Lansade, L., Coutureau, E., Marchand, A., Baranger, G., Valenchon, M., \& Calandreau, L. (2013). Dimensions of Temperament Modulate Cue-Controlled Behavior: A Study on Pavlovian to Instrumental Transfer in Horses (Equus Caballus). PLoS ONE, 8(6). doi: 10.1371/journal.pone.0064853.

Lattal, K. Matthew, and Kennon A. Lattal. "Facets of Pavlovian and Operant Extinction." Behavioural Processes, vol. 90, no. 1, 2012, pp. 1-8., doi: 10.1016/j.beproc.2012.03.009.

LeBlanc, K. H., Ostlund, S. B., \& Maidment, N. T. (2012). Pavlovian-to-instrumental transfer in cocaine seeking rats. Behavioral Neuroscience, 126(5), 681-689. doi: $10.1037 / \mathrm{a} 0029534$. 
Leung, B.K., \& Balleine, B. W. (2015). Ventral pallidal projections to mediodorsal thalamus and ventral tegmental area play distinct roles in outcome-specific pavlovianinstrumental transfer. J. Neurosci. 35 (12), 4953-4964.

Lüscher, C., \& Malenka, R. (2011). Drug-evoked synaptic plasticity in addiction: from molecular changes to circuit remodeling. Neuron, 69(4), 650-663. doi: 10.1016/j.neuron.2011.01.017.

Martinez, R., Carvalho-Netto, E., Ribeiro-Barbosa, É, Baldo, M., \& Canteras, N. (2011). Amygdalar roles during exposure to a live predator and to a predator-associated context. Neuroscience, 172, 314-328. doi: 10.1016/j.neuroscience.2010.10.033.

McDonald, R. V., \& Siegel, S. (2004). The potential role of drug onset cues in drug dependence and withdrawal. Experimental and Clinical Psychopharmacology, 12(1), 23-26. doi: 10.1037/1064-1297.12.1.23.

Melzack, R. (1990). The tragedy of needless pain. Scientific American, 262(2), 27-33. doi: 10.1038/scientificamerican0290-27.

Mierzejewski, P., Koroś, E., Goldberg, S. R., Kostowski, W., \& Stefański, R. (2003). Intravenous self-administration of morphine and cocaine: a comparative study. Pol J Pharmacol. 55(5):713-26. ISSN 1230-6002.

Miguéns, M., Crespo, J. A., Del Olmo, N., Higuera-Matas, A., Montoya, G. L., GarciaLecumberri, C., \& Ambrósio, E. (2008). Differential cocaine-induced modulation of glutamate and dopamine transporters after contingent and non-contingent administration. Neuropharmacology, 55(5), 771-779. doi: 10.1016/j.neuropharm.2008.06.042. 
Morse, W. H., \& Skinner, B. F. (1958). Some Factors Involved in the Stimulus Control of Operant Behavior. Journal of the Experimental Analysis of Behavior, 1(1), 103-107. doi: 10.1901/jeab.1958.1-103.

Mumby, D. G. (2002). Hippocampal Damage and Exploratory Preferences in Rats: Memory for Objects, Places, and Contexts. Learning \& Memory, 9(2), 49-57. doi: 10.1101/lm.41302.

Negus, S. S., \& Mello, N. K. (2003). Effects of chronic d-amphetamine treatment on cocaineand food-maintained responding under a progressive-ratio schedule in rhesus monkeys. Psychopharmacology, 167(3), 324-332. doi: 10.1007/s00213-003-1409-y.

Nestler, E. J. (2012). Transcriptional Mechanisms of Drug Addiction. Clinical Psychopharmacology and Neuroscience, 10(3), 136-143. doi: http://dx.doi.org/10.9758/cpn.2012.10.3.136.

Nestler, E. J. (2014). Epigenetic mechanisms of drug addiction. Neuropharmacology, 76, 259-268. doi: http://dx.doi.org/10.1016/j.neuropharm.2013.04.004.

Nevin, J. A., \& Grace, R. C. (2000). Behavioral momentum and the Law of Effect. Behavioral and Brain Sciences, 23(1), 73-90. doi: 10.1017/s0140525x00002405.

Nevin, J. A., \& Grace, R. C. (2005). Resistance to Extinction in the Steady State and in Transition. Journal of Experimental Psychology: Animal Behavior Processes, 31(2), 199-212. doi: 10.1037/0097-7403.31.2.199.

O’Brien, C. P., Childress, A. R., Ehrman, R., \& Robbins, S. J. (1998). Conditioning factors in drug abuse: can they explain compulsion? Journal of Psychopharmacology, 12(1), 1522. doi: $10.1177 / 026988119801200103$ 
O'Brien, C. P., Ehrman, R. N., \& Ternes, J. W. (1986). Classical conditioning in human opioid dependence. In S. R. Goldberg, \& I. P. Stolerman (Eds.), Behavioral analysis of drug dependence (pp. 329-356). New York: Academic Press.

Olsen, C. M. (2011). Natural rewards, neuroplasticity, and non-drug addictions. Neuropharmacology, 61(7), 1109-1122. doi: 10.1016/j.neuropharm.2011.03.010.

Ostlund, S. B., \& Balleine, B. W. (2007). Orbitofrontal Cortex Mediates Outcome Encoding in Pavlovian But Not Instrumental Conditioning. Journal of Neuroscience, 27(18), 48194825. doi: 10.1523/jneurosci.5443-06.2007.

Palmer, T. (2002). Faculty of 1000 evaluation for Critical role of the hippocampus in memory for sequences of events. F1000 - Post-publication Peer Review of the Biomedical Literature. doi: 10.3410/f.1006559.110758.

Parkinson, J. A., Willoughby, P. J., Robbins, T. W., \& Everitt, B. J. (2000). Disconnection of the anterior cingulate cortex and nucleus accumbens core impairs Pavlovian approach behavior: further evidence for limbic cortical-ventral striatopallidal systems. Behav Neurosci 114:42-63.

Patarroyo, W. E. P., Felício, L. F., \& García-Mijares, M. (2014). Avaliação do treino com estímulos discriminativos e condicionados sobre a autoadministração endovenosa de morfina em ratos. Dissertação de Mestrado, Instituto de Psicologia, Universidade de São Paulo, São Paulo.

Pavlov, Ivan (1927). Conditioned Reflexes: An Investigation of the Physiological Activity of the Cerebral Cortex. Classics in the History of Psychology. 
Pavuluri, M., Volpe, K., \& Yuen, A. (2017). Nucleus Accumbens and Its Role in Reward and Emotional Circuitry: A Potential Hot Mess in Substance Use and Emotional Disorders. AIMS Neuroscience, 4(1), 52-70. doi: 10.3934/neuroscience.2017.1.52.

Pecina, S., Schulkin, J., \& Berridge, K.C. (2006). Nucleus accumbens corticotropinreleasing factor increases cue-triggered motivation for sucrose reward: paradoxical positive incentive effects in stress? BMC Biol. 4, 8.

Pear, J. J., \& Eldridge, G. D. (1984). The operant-respondent distinction: Future directions. Journal of the Experimental Analysis of Behavior, 42(3), 453-467. doi: 10.1901/jeab. 1984.42-453.

Perrotti, L. I., Weaver, R. R., Robison, B., Renthal, W., Maze, I., Yazdani, S., ... \& Nestler, E. J. (2008). Distinct patterns of DFosB induction in brain by drugs of abuse. Synapse, 62, 358-369. doi: 10. 1002/syn.20500.

Pomara, C., Cassano, T., Derrico, S., Bello, S., Romano, A., Riezzo, I., \& Serviddio, G. (2012). Data Available on the Extent of Cocaine Use and Dependence: Biochemistry, Pharmacologic Effects and Global Burden of Disease of Cocaine Abusers. Current Medicinal Chemistry, 19(33), 5647-5657. doi: 10.2174/092986712803988811.

Pulvirenti, L. (n.d.). Glutamate Neurotransmission in the Course of Cocaine Addiction. Glutamate and Addiction, 171-182. doi: 10.1385/1-59259-306-2:171.

Rehfeldt, R. A., \& Hayes, L. J. (1998). The operant-respondent distinction revisited: Toward an understanding of stimulus equivalence. Psychological Record, 48(2), 187-210. http://doi.org/10.1007/BF03395266. 
Reid, L. D., Marglin S. H., Mattie M. E., \& Hubbell C. L. (1989). Measuring morphine's capacity to establish a place preference. Pharmacology Biochemistry and Behavior, 33(4), 765-775. doi: 10.1016/0091-3057(89)90468-1.

Rescorla, R. A. (1985). Associationism in animal learning. In L. G. Nilsson \& T. Archer (Eds.), Perspectives in learning and memory (pp.39-61). New Jersey: Erlbaum.

Rescorla, R. A. (1994). Transfer of instrumental control mediated by a devalued outcome. Animal Learning \& Behavior, 22(1), 27-33. doi: 10.3758/BF03199953.

Rescorla, R. A., \& Lolordo, V. M. (1965). Inhibition of avoidance behavior. Journal of Comparative and Physiological Psychology, 59(3), 406-412. doi: 10.1037/h0022060.

Rescorla, R. A., \& Solomon, R. L. (1967). Two process learning theory: Relationships between Pavlovian conditioning and instrumental learning. Psychological Review, 74(3), 151182. doi: $10.1037 / \mathrm{h} 0024475$.

Ritz, M. C., Lamb, R. J., Goldberg, S. R., \& J., K. M. (1988). Cocaine self-administration appears to be mediated by dopamine uptake inhibition. Progress in NeuroPsychopharmacology and Biological Psychiatry, 12(2-3), 233-239. doi: 10.1016/0278$5846(88) 90040-1$.

Roberts, D. C., Morgan, D., \& Liu, Y. (2007). How to make a rat addicted to cocaine. Progress in Neuro-Psychopharmacology and Biological Psychiatry,31(8), 1614-1624. doi: 10.1016/j.pnpbp.2007.08.028.

Robinson, T. E., \& Berridge, K. C. (1993). The neural basis of drug craving: an incentivesensitization theory of addiction. Brain Research. Brain Research Reviews, 18(3), 247-291. doi: 10.1016/0165-0173(93)90013-P. 
Robinson, T. E., \& Berridge, K. C. (2003). Addiction. Annual Review of Psychology, 54, $25-$ 53. doi: 10.1146/annurev.psych.54.101601.145237.

Robinson, T. E., \& Berridge, K. C. (2008). Review. The incentive sensitization theory of addiction: some current issues. Philosophical Transactions of the Royal Society of London. Series B, Biological Sciences, 363(1507), 3137-3146. doi: 10.1098/rstb.2008.0093.

Robison, A. J., \& Nestler, E. J. (2011). Transcriptional and epigenetic mechanisms of addiction. Nature Reviews Neuroscience, 12(11), 623-637. doi: 10.1038/nrn3111.

Rocha, B., Fumagalli, F., Gainetdinov, R., Jones, S., Ator, R., Giros, B., Miller, G. W., \& Caron, M. (1998). Erratum: Cocaine self-administration in dopamine-transporter knockout mice. Nature Neuroscience, 1(4), 330-330. doi: 10.1038/1152.

Ruffle, J. K. (Nov 2014). "Molecular neurobiology of addiction: what's all the $(\Delta)$ FosB about?". The American Journal of Drug and Alcohol Abuse. 40 (6): 428-37. doi: $10.3109 / 00952990.2014 .933840$.

Saddoris, M. P., Stamatakis, A., \& Carelli, R. M. (2011). Neural correlates of Pavlovian-toinstrumental transfer in the nucleus accumbens shell are selectively potentiated following cocaine self-administration. European Journal of Neuroscience,33(12), 2274-2287. doi: 10.1111/j.1460-9568.2011.07683.x.

Sánchez-Cardoso, P., Higuera-Matas, A., Martín, S., Miguéns, M., Del Olmo, N., GarcíaLecumberri, C., Ambrósio, E. (2009). Strain differences between Lewis and Fischer 344 rats in the modulation of dopaminergic receptors after morphine selfadministration and during extinction. Neuropharmacology, 57, 8-17. 
Sanchez-Ramos. J. R., \& Schuster. C. R. (1977). Second-order schedules of intravenous drug self-administration in rhesus monkeys. Pharmacology Biochemistry and Behavior, 7(5), 443-450. doi: 10.1016/0091-3057(77)90212-X.

Sanchis-Segura, C., \& Spanagel, R. (2006). Behavioural assessment of drug reinforcement and addictive features in rodents: an overview. Addiction Biology, 11(1), 2-38. doi: 10.1111/j.1355-6215.2006.00012.x.

Setlow, B., Holland, P.C., \& Gallagher, M. (2002). Disconnection of the basolateral amygdala complex and nucleus accumbens impairs appetitive pavlovian second-order conditioned responses. Beh Neurosci. 116:267-275.

Siegel, S. (1976). Morphine analgesic tolerance: its situation specificity supports a Pavlovian conditioning model. Science, 193, 323-325. doi: 10.1126/science.935870.

Siegel, S. (1988). State dependent learning and morphine tolerance. Behavioral Neuroscience, 102(2), 228-232. doi: 10.1037//0735-7044.102.2.228.

Siegel, S. (2001). Pavlovian conditioning and drug overdose: when tolerance fails. Addiction Research and Theory, 9(5), 503-513. doi: 10.3109/16066350109141767.

Siegel, S. (2005). Drug tolerance, drug addiction, and drug anticipation. Current Directions in Psychological Science, 14, 296-300. doi: 10.1111/j.0963-7214.2005.00384.x.

Siegel, S., Hinson, R. E., \& Krank, M. D. (1978). The role of predrug signals in morphine analgesic tolerance: Support for a Pavlovian conditioning model of tolerance. Journal of Experimental Psychology: Animal Behavior Processes, 4(2), 188-196. doi: 10.1037/0097-7403.4.2.188. 
Siegel, S., \& Ramos, B. M. (2002). Applying laboratory research: Drug anticipation and the treatment of drug addiction. Experimental and Clinical Psychopharmacology, 10(3), 162-183. doi:10.1037//1064-1297.10.3.162.

Skinner, B. F. (1937). Two Types of Conditioned Reflex: A Reply to Konorski and Miller. Journal of General Psychology, 16(1), 272-279. http://doi.org/10.1080/00221309.1937.9917951.

Skinner, B. F. (1938). The Behavior of Organisms: an Experimental Analysis. Oxford, England: Appleton-Century.

Smith, K. S., \& Berridge, K. C. (2007). Opioid Limbic Circuit for Reward: Interaction between Hedonic Hotspots of Nucleus Accumbens and Ventral Pallidum. Journal of Neuroscience,27(7), 1594-1605. doi: 10.1523/jneurosci.4205-06.2007.

Stefanski, R., Ladenheim, B., Lee, S.H., Cadet, J.L., \& Goldberg, S.R. (1999). Neuroadaptations in the dopaminergic system after active self-administration but not after passive administration of methamphetamine. European journal of pharmacology, 371(2-3), 123-135. doi: 10.1016/S0014-2999(99)00094-1.

Suppes, Patrick, et al. "A Model for Response Latency in Paired-Associate Learning.” Journal of Mathematical Psychology, vol. 3, no. 1, 1966, pp. 99-128., doi: 10.1016/0022-2496(66)90006-X.

Suto, N., \& Wise, R. A. (2011). Satiating Effects of Cocaine Are Controlled by Dopamine Actions in the Nucleus Accumbens Core. Journal of Neuroscience, 31(49), 1791717922. doi: 10.1523/jneurosci.1903-11.2011. 
Suto, N., Wise, R. A., \& Vezina, P. (2011). Dorsal as well as ventral striatal lesions affect levels of intravenous cocaine and morphine self-administration in rats. Neuroscience Letters, 493(1-2), 29-32. doi: 10.1016/j.neulet.2011.02.011.

Taubenfeld, S. M., Muravieva, E. V., Garcia-Osta, A., \& Alberini, C. M. (2010). Disrupting the memory of places induced by drugs of abuse weakens motivational withdrawal in a context-dependent manner. Proceedings of the National Academy of Sciences, 107(27), 12345-12350. doi: 10.1073/pnas.1003152107.

Thrailkill, E. A., \& Bouton, M. E. (2015). Extinction of chained instrumental behaviors: Effects of procurement extinction on consumption responding. Animal Learning and Cognition, 41(1), 232-246. doi: 10.1037/xan0000064.

Thrailkill, E. A., \& Bouton, M. E. (2016). Extinction of chained instrumental behaviors: Effects of consumption extinction on procurement responding. Learning \& Behavior, 44(1), 85-96. doi: 10.3758/s13420-015-0193-y.

Tran-Tu-Yen, D. A., Marchand, A. R., Pape, J., Scala, G. D., \& Coutureau, E. (2009). Transient role of the rat prelimbic cortex in goal-directed behaviour. European Journal of Neuroscience,30(3), 464-471. doi: 10.1111/j.1460-9568.2009.06834.x.

Troisi, J. R., \& Mauro, B. C. (2017). Do Pavlovian Processes Really Mediate Behavioral Momentum? Some Conflicting Issues. The Psychological Record, 67(4), 597-604. doi: $10.1007 / \mathrm{s} 40732-017-0259-7$.

Uhl, G. R., Hall, F. S., \& Sora, I. (2002). Cocaine, reward, movement and monoamine transporters. Molecular Psychiatry, 7(1), 21-26. doi: 10.1038/sj/mp/4000964.

van den Bos, R., van der Harst, J., Vijftigschild, N., Spruijt, B., van Luijtelaar, G., \& Maes, R. (2004). On the relationship between anticipatory behaviour in a pavlovian paradigm 
and pavlovian-to-instrumental transfer in rats (rattus norvegicus). Behav. Brain Res. $153(2), 397-408$.

Volkow, N. D., Wang, G. J., Fowler, J. S., \& Telang, F. (2008). Overlapping neuronal circuits in addiction and obesity: evidence of systems pathology. Philosophical Transactions of the Royal Society of London, 363(1507), 3191-3200. doi: 10.1098/rstb.2008.0107.

Weiss, S. J., Kearns, D. N., Cohn, S. I., Schindler, C. W, \& Panlilio, L. V. (2003). Stimulus control of cocaine self-administration. Journal of the Experimental Analysis of Behavior, 79(1), 111-135. doi: 10.1901/jeab.2003.79-111.

Weissenborn, R., Robbins, T. W., \& Everitt, B. J. (1997). Effects of medial prefrontal or anterior cingulate cortex lesions on responding for cocaine under fixed-ratio and second-order schedules of reinforcement in rats. Psychopharmacology, 134(3), 242257. doi: $10.1007 / \mathrm{s} 002130050447$.

West, E. A., \& Carelli, R. M. (2016). Nucleus Accumbens Core and Shell Differentially Encode Reward-Associated Cues after Reinforcer Devaluation. Journal of Neuroscience,36(4), 1128-1139. doi: 10.1523/jneurosci.2976-15.2016.

Winstanley, C.A., LaPlant, Q., Theobald, D. E. H., Green, T. A., Bachtell, R. K., Perrotti, L. I., ... \& Nestler, E. J. (2007). $\Delta$ FosB induction in orbitofrontal cortex mediates tolerance to cocaine-induced cognitive dysfunction. Journal of Neuroscience, 2, 10497-10507. doi: 10.1523/JNEUROSCI.2566-07.2007.

Wise, R. A. 1(996). Neurobiology of addiction. Curr. Opin. Neurobiol. 6, 243-251. doi: 10.1016/b978-0-12-419239-3.x5036-x. 
Woods, J. H., \& Schuster, C. R. (1968). Reinforcement Properties of Morphine, Cocaine, and SPA as a Function of Unit Dose. International Journal of the Addictions, 3(1), 231-237. doi:10.3109/10826086809042898.

Wyvell, C. L., \& Berridge, K. C. (2001). Incentive sensitization by previous amphetamine exposure: Increased cue-triggered "wanting" for sucrose reward. Journal of Neuroscience, 21(19), 7831-7840. PMID: 11567074.

Zachariou, V., Bolanos, C. A., Selley, D. E., Theobald, D., Cassidy, M. P., Kelz, M. B., ShawLutchman, T., Berton, O., Sim-Selley, L. J, Dileone, R. J, Kumar, A. \& Nestler, E. J. (2006). An essential role for $\Delta \mathrm{FosB}$ in the nucleus accumbens in morphine action. Nature Neuroscience, 9(2), 205-211. doi: 10.1038/nn1636.

Zeaman, David. "Response Latency as a Function of the Amount of Reinforcement." Journal of Experimental Psychology, vol. 39, no. 4, 1949, pp. 466-483., doi: $10.1037 / \mathrm{h} 0060477$.

Zimmerman, J. L. (2012). Cocaine Intoxication. Critical Care Clinics,28(4), 517-526. doi: 10.1016/j.ccc.2012.07.003. 
Anexo 1. Valores de Medianas, estatístico $Z$ de Wilcoxon e valores $p$ - Grupo CO

\begin{tabular}{lcccc}
\hline & \multicolumn{4}{c}{ Grupo CO } \\
Subárea & Mdn F2 & Mdn F4 & $\boldsymbol{Z}$ & $\boldsymbol{p}$ \\
\hline PFC LO & 23,875 & 31 & $-2,201$ & $\mathbf{, 0 2 8}$ \\
mPFC Cg1 & 20,000 & 21,750 & $-0,943$ &, 345 \\
mPFC PrL & 19,250 & 20,500 & $-1,051$ &, 293 \\
mPFC IL & 26,000 & 23,625 & $-1,367$ &, 173 \\
NAc Core & 28,625 & 31,375 & $-1,363$ &, 172 \\
NAc Shell & 34,000 & 28,500 & $-1,153$ &, 249 \\
CPu Lateral & 30,500 & 32,370 & $-0,736$ &, 462 \\
CPu Medial & 47,250 & 49,875 & $-1,153$ &, 249 \\
Hipp. DG & 23,625 & 25,000 & $-0,734$ &, 463 \\
Hipp. CA1 & 26,500 & 23,500 & $-1,472$ &, 141 \\
Hipp. CA3 & 21,000 & 23,875 & $-9,43$ &, 345 \\
Amig. Bas & 72,875 & 77,875 & $-1,682$ &, 093 \\
Amig. Cen & 29,625 & 34,500 & $-1,153$ &, 249 \\
Amig. Med & 18,250 & 16,000 & $-2,201$ & $\mathbf{0 , 0 2 8}$ \\
\hline
\end{tabular}

Anexo 2. Valores de Medianas, estatístico $Z$ de Wilcoxon e valores $p$ - Grupo CP

\begin{tabular}{lcccc}
\hline & \multicolumn{3}{c}{ Grupo CP } & \\
Sub-área & Mdn F2 & Mdn F4 & $\boldsymbol{Z}$ & $\boldsymbol{p}$ \\
\hline PFC LO & 82,284 & 135,527 & $-2,201$ & $\mathbf{, 0 2 8}$ \\
mPFC Cg1 & 77,444 & 108,301 & $-2,201$ & $\mathbf{, 0 2 8}$ \\
mPFC PrL & 94,990 & 104,670 & $-2,201$ & $\mathbf{, 0 2 8}$ \\
mPFC IL & 108,301 & 118,586 & $-1,472$ &, 141 \\
NAc Core & 132,502 & 136,132 & $-0,105$ &, 917 \\
NAc Shell & 142,182 & 147,628 & $-0,105$ &, 917 \\
CPu Lateral & 137,947 & 148,838 & $-1,214$ &, 225 \\
CPu Medial & 219,627 & 247,458 & $-2,201$ & $\mathbf{, 0 2 8}$ \\
Hipp. DG & 94,385 & 113,746 & $-1,992$ &, $\mathbf{0 4 6}$ \\
Hipp. CA1 & 11,931 & 113,141 & $-0,105$ &, 917 \\
Hipp. CA3 & 118,586 & 115,561 & 0 & 1 \\
Amig. Bas & 270,450 & 356,364 & $-1,992$ & $\mathbf{, 0 4 6}$ \\
Amig. Cen & 87,124 & 164,569 & $-2,201$ & $\mathbf{, 0 2 8}$ \\
Amig. Med & 78,049 & 77,444 & $-0,405$ & 0,686 \\
\hline
\end{tabular}


Anexo 3. Valores de Medianas, estatístico $Z$ de Wilcoxon e valores $p$ - Grupo Ctr

\begin{tabular}{lcccc}
\hline \multicolumn{4}{c}{ Grupo Ctr } \\
Sub-área & Mdn F2 & Mdn F4 & $\boldsymbol{Z}$ & $\boldsymbol{p}$ \\
\hline PFC LO & 38,722 & 129,477 & $-2,023$ &, $\mathbf{0 4 3}$ \\
mPFC Cg1 & 38,722 & 100,435 & $-2,023$ &, $\mathbf{0 4 3}$ \\
mPFC PrL & 60,503 & 110,116 & $-2,023$ &, $\mathbf{0 4 3}$ \\
mPFC IL & 83,494 & 118,586 & $-1,214$ &, 225 \\
NAc Core & 68,973 & 134,317 & $-0,944$ &, 345 \\
NAc Shell & 76,234 & 140,367 & $-0,405$ &, 686 \\
CPu Lateral & 118,586 & 151,258 & $-0,73$ &, 465 \\
CPu Medial & 175,459 & 249,273 & $-2,023$ &, $\mathbf{0 4 3}$ \\
Hipp. DG & 95,595 & 110,116 & $-1,753$ &, 080 \\
Hipp. CA1 & 87,124 & 112,536 & $-0,135$ & 0,893 \\
Hipp. CA3 & 105,275 & 116,166 & $-0,271$ & 0,786 \\
Amig. Bas & 226,286 & 342,449 & $-1,753$ &, 080 \\
Amig. Cen & 77,444 & 163,359 & $-2,023$ &, $\mathbf{0 4 3}$ \\
Amig. Med & 72,604 & 81,074 & 0 & 1 \\
\hline
\end{tabular}

